FEDERAL RESERVE BANK OF SAN FRANCISCO

WORKING PAPER SERIES

\title{
Seawalls and Stilts: A Quantitative Macro Study of Climate Adaptation
}

\author{
Stephie Fried \\ Arizona State University \\ Federal Reserve Bank of San Francisco \\ January 2021 \\ Working Paper 2021-07 \\ https://www.frbsf.org/economic-research/publications/working-papers/2021/07/
}

\section{Suggested citation:}

Fried, Stephie. "Seawalls and Stilts: A Quantitative Macro Study of Climate Adaptation," Federal Reserve Bank of San Francisco Working Paper 2021-07. https://doi.org/10.24148/wp2021-07

The views in this paper are solely the responsibility of the authors and should not be interpreted as reflecting the views of the Federal Reserve Bank of San Francisco or the Board of Governors of the Federal Reserve System. 


\title{
Seawalls and Stilts: A Quantitative Macro Study of Climate Adaptation
}

\author{
Stephie Fried \\ (ASU and SF Fed)
}

January 22, 2021

\begin{abstract}
Can we reduce the damage from climate change by investing in seawalls, stilts, or other forms of adaptation? Focusing on the case of severe storms in the US, I develop a macro heterogeneous-agent model to quantify the interactions between adaptation, federal disaster policy, and climate change. The model departs from the standard climate damage function and incorporates the damage from storms as the realization of idiosyncratic shocks. I find that while the moral hazard effects from disaster aid reduce adaptation in the US economy, federal subsidies for investment in adaptation more than correct for the moral hazard. I introduce climate change into the model as a permanent increase in either or both the severity or probability of storms. Adaptation reduces the damage from this climate change by approximately one third. Finally, I show that modeling the idiosyncratic risk component of climate damage has quantitatively important implications for adaptation and for the welfare cost of climate change.
\end{abstract}

Email: sdfried@asu.edu. The views in this paper are those of the author and do not reflect the views of the Federal Reserve system or its staff. I thank seminar and conference participants at Arizona State University, UC Berkeley, CBO, the ECB, Iowa State, Colorado School of Mines, The Occasional Workshop on Environmental and Resource Economics, CESifo Conference on Energy and Environmental Economics, CESifo conference on Heterogeneous Agents and the Macroeconomics of Climate Change, SURED, and the VSCE for their helpful insights. I thank Alex Bick, Greg Casey, Betty Daniel, Matt Goldman, Garth Heutel, Bart Hobijn, Nick Kuminoff, Will Peterman, Dan Silverman, Tamra Sheldon, Tony Smith, Gustavo Ventura, and four anonymous referees for their many helpful comments. All potential errors are my own. 


\section{Introduction}

Climate change creates damage for the global economy by causing severe storms, drought, disease, crop loss, and other damages. Scientists predict that these damages will intensify as carbon emissions continue to accumulate in the atmosphere (IPCC 2000; IPCC 2014). Countries can address the progression of climate change through two main channels. First, countries can introduce policies, such as a carbon tax, to slow or reverse climate change itself. Second, countries can invest in adaptation and provide aid for disaster relief to reduce the damage that individuals experience as a result of climate change.

Recent macro models of climate change focus on the first channel, and analyze policies to reduce carbon emissions, see e.g. Acemoglu, Aghion, Bursztyn, and Hémous (2012), Golosov, Hassler, Krusell, and Tsyvinski (2014), and Barrage (2019). However, the second channel is becoming increasingly important, as carbon emissions continue to rise in the absence of global climate policy (USGCRP, 2018). This paper focuses on the second channel and develops a dynamic, general equilibrium model to quantify the effects of adaptation in response to climate change and the impact of disaster aid. I focus on severe storms and federal disaster policy in the US as a prominent example of these effects.

The model modifies the macro heterogeneous-agent framework (e.g, Aiyagari, 1994) to incorporate storms and adaptation. The economy is divided into different regions which are distinguished by their weather distributions. Each region is populated by heterogeneous households that experience idiosyncratic storm shocks in addition to the standard labor productivity shocks. Households derive utility from the consumption of a non-durable good and from housing services (either rental or owner-occupied). Each household endogenously chooses whether to be a homeowner or a renter, based on their preferences and on a minimum size for owneroccupied housing. A "bad" storm shock destroys a portion of the household's housing capital, generating a utility loss from the reduction in housing services, and, in the case of homeowners, a wealth loss from the reduction in housing capital. Like households, firms in the model also experience idiosyncratic storm shocks, which destroy a portion of their productive capital. Both households and firms can invest in adaptation capital to reduce storm damage. Examples of such adaptation capital include seawalls, storm drains, and wind-proof garage doors.

Additionally, households can partially smooth consumption following a storm by purchasing insurance and saving in a risk-free asset.

A federal government taxes households and uses the revenue to provide aid for disaster relief and subsidies for adaptation investment, analogous to the functions of the Federal Emergency Management Agency (FEMA) in the US. There is an inherent tension between disaster aid and adaptation; since disaster aid compensates the affected households and firms, it disincentivizes investment in adaptation. To offset these moral hazard effects, US federal disaster 
policy includes subsidies for adaptation investment in addition to disaster aid. Note that the only role for the government in the model is to implement disaster policy; it does not directly invest in public capital, either adaptive or productive. Consistent with much of the macroeconomic literature, I abstract from the market or coordination failures that would necessitate the public provision of capital, assuming instead that all capital is privately determined by households' and firms' investment decisions.

An important feature of the heterogeneous agent framework is that it allows me to model the damage from climate change (in this case storms) as the realization of idiosyncratic shocks. This approach differs from the climate damage functions often used in the literature (e.g., Nordhaus, 1992, 2017; Acemoglu et al., 2012; Golosov et al., 2014; Barrage, 2019), which typically assign all households and firms within a region the average value of the region's damage in each period. However, some types of climate damage, such as the damage from storms, are the realization of idiosyncratic shocks. In any given period, some households experience damage and suffer utility and wealth losses (e.g., they are hit by a storm), while other households don't experience any damage and thus don't suffer any losses (e.g., they are not hit by a storm). Since utility is concave, the welfare cost of receiving the expected value of the shock in every period (i.e., a climate damage function) is less than the welfare cost of receiving a large negative shock realization in some periods and a neutral shock realization in other periods (i.e., idiosyncratic storm shocks). As a result, idiosyncratic storm risk can have important implications for adaptation incentives.

A challenge for calibrating the model is to determine the effectiveness of adaptation capital at reducing the damage from a storm. We do not observe this relationship directly because we do not have comprehensive data on adaptation capital (USGCRP, 2018). Such data would require cost estimates of all adaptation investments, ranging from seawalls and city drainage systems to the extra capital required to flood-proof a home or business. ${ }^{1}$ To calibrate the main structural parameters in the model, I borrow insights from an empirical literature which treats adaptation as a latent variable. This literature looks for evidence of adaptation from the frequency with which an area experiences an extreme weather event, such as a hurricane or a very hot day, and a measure of the associated damage per event, such as mortality or crop loss. ${ }^{2}$

\footnotetext{
${ }^{1}$ The Fourth National Climate Assessment Report stresses that "it remains difficult...to tally the extent of adaptation implementation in the United States because there are no common reporting systems and many actions that reduce climate risk are not labeled as climate adaptation" (USGCRP 2018, Chapter 28).

${ }^{2} \mathrm{~A}$ negative relationship between frequency and damage per event suggests that adaptation has occurred. Barreca, Clay, Deschenes, Greenstone, and Shapiro (2016), Gourio and Fries (2020), Heutel, Miller, and Molitor (2017), Hsiang and Narita (2012), Keefer, Neumayer, and Plumper (2011), and Sadowski and Sutter (2008) find evidence of a negative relationship, and thus suggest there is potential for adaptation. Dell, Jones, and Olken (2012), Schlenker and Roberts (2009) and Burke and Emerick (2016) do not find strong evidence of this negative relationship. Hsiang (2016) provides an overview of this literature.
} 
Many of these papers find a negative relationship between frequency and damage, generating the important empirical inference that adaptation has occurred. I calibrate the parameters in the structural model so that it is consistent with this same type of reduced-form evidence.

One advantage of the structural model is that I can use it to quantify the level of adaptation in the US economy, the latent variable in the empirical literature, and its effect on storm damage. I find that adaptation capital is a little over one percent of the total US capital stock. The model predicts that storms destroy approximately 0.1 percent of the capital stock on average each year. Thus, adaptation capital is over 10 times the amount of capital destroyed by storms.

I use the model to understand the moral-hazard effects of disaster aid and the ability of the adaptation subsidy to correct those effects. I compute a set of counterfactual stationary equilibria with different components of federal disaster policy. Comparing the different equilibria, I find that the provision of disaster aid without a counteracting subsidy reduces adaptation capital by five percent. ${ }^{3}$ This reduction in adaptation capital increases the damage from storms by an average of $\$ 3.2$ billion per year in 2018 dollars. To put this value in perspective, stormrelated disaster aid from FEMA averages $\$ 7.7$ billion per year. Hence, the increase in damage from moral hazard is approximately 40 percent of the disaster aid provided by FEMA each year. The federal subsidy for adaptation more than offsets the moral hazard effects from the disaster aid. On net, I find that federal disaster policy increases adaptation in the US economy.

One of the paper's key results is that adaptation reduces the damage and welfare cost of climate change. I focus on one specific aspect of climate change, the shift in the distribution of idiosyncratic storm shocks. I analyze a set of climate-change scenarios in which I increase either or both the probability or severity of storms, in line with scientific projections for the effects of climate change on storms. For each climate change scenario, I calculate two stationary equilibria, one in which adaptation can respond to the climate change, and one in which it cannot. Climate change generates a substantial increase in adaptation capital. Averaging across the different scenarios, this adaptation response reduces the damage from climate change by approximately 33 percent and the welfare cost of climate change by approximately 11 percent.

Adaptation also has important implications for the distribution of destroyed housing capital following a storm. I find that rental-housing firms have substantially lower adaptive capacity, loosely defined as their level of protection from storms, than homeowners. Consequently, renters experience the largest percentage decreases in housing services from a storm. Among

\footnotetext{
${ }^{3}$ Consistent with these results, Cohen and Werker (2008) find that expectations of international aid following a disaster reduce countries' investments in disaster preparedness. Similarly, Lewis and Nickerson (1989) show theoretically that federal aid for disaster relief reduces individuals' expenditures to protect their property from harm. Federal aid can also create adaptation-related moral hazard in other contexts. For example, Annan and Schlenker (2015) demonstrate that federally subsidized yield guarantees reduce farmers' incentives to adapt to extreme heat.
} 
homeowners, adaptive capacity is relatively constant across the wealth distribution. However, meaningful differences in adaptive capacity arise for the subgroup of homeowners who are just barely able to afford to own their home. To satisfy the minimum house size constraint, these homeowners shift resources away from adaptation towards productive housing capital, leaving them more exposed to damage from storms.

Finally, the paper highlights the importance of modeling the damage from storms as the realization of idiosyncratic shocks instead of using a standard climate-damage function. To quantify the role of idiosyncratic storm risk, I specify a damage-function version of the model in which I eliminate the idiosyncratic storm risk. Instead, I assume that households and firms experience the expected value of the storm shock in every period, analogous to the climatedamage functions used in the environmental literature. Comparing the baseline equilibrium under the idiosyncratic-storm-risk and damage-function specifications reveals that the damagefunction specification reduces average adaptive capacity among homeowners by approximately 80 percent. Homeowners are risk averse, and thus they value adaptive capacity both because it reduces the realized damage from a storm and because it reduces the variance in the realized levels of housing services and wealth. The damage-function specification eliminates the latter motive, reducing homeowners' incentives to invest in adaptation. Comparing the climate change equilibria under the idiosyncratic-storm-risk and damage-function specifications reveals that idiosyncratic storm risk meaningfully affects the welfare costs of climate change.

The paper is designed to quantify adaptation incentives in response to storm risk and existing federal disaster policy. The quantitative model allows us to predict the intersecting roles of adaptation and federal disaster policy going forward as climate change progresses. The paper does not study optimal disaster policy because such an analysis requires taking a stand on the many different market failures that disaster policy could be designed to correct. Modeling existing disaster policy allows for realistic predictions about the current and future effects of adaptation and its associated welfare implications.

This paper contributes to the growing literature which uses macro models to study climate policy. ${ }^{4}$ The existing literature focuses on aspects of climate change other than adaptation. Related to the present paper, Bakkensen and Barrage (2018) also study the macro effects of storms. They examine the effects of cyclones on economic growth by introducing country-level cyclone shocks, which destroy physical and human capital, into a stochastic growth model. Like the present paper, Krusell and Smith (2017) extend the heterogeneous agent macro framework to study climate change. Focusing on how the effects of climate change vary around the world, they develop a global model in which agents in many tiny heterogeneous regions experience

\footnotetext{
${ }^{4}$ Hassler et al. (2016), Heutel and Fischer (2013), and Hassler and Krusell (2018) provide overviews of this literature.
} 
deterministic damage along a transition path to a zero carbon equilibrium.

This paper also relates to an environmental literature that analyzes the role of adaptation as a component of climate policy. ${ }^{5}$ These papers typically model adaptation as a mechanism through which a country can use economic resources to reduce all types of damage from climate change, including everything from extreme weather, to species loss, to disease. However, the estimates used to determine the costs and benefits of adaptation in these models are highly uncertain (Bosello et al., 2011). One goal of the present paper is to calibrate the parameters governing the costs and benefits of adaptation from US data on severe storms and disaster aid. To do this, I make an important simplification relative to earlier work and model only one type of adaptation, capital investment, and one type of climate damage, the destruction caused by storms. Additionally, the present paper focuses on idiosyncratic storm risk and the effects of federal disaster policy on household and firm incentives for adaptation, neither of which are modeled in earlier work.

The paper proceeds as follows: Section 2 describes the macro heterogeneous agent model with storm shocks and adaptation. Section 3 discusses the calibration, with a particular emphasis on the parameters determining the effectiveness of adaptation. Section 4 uses several different approaches to validate the calibration. Section 5 reports quantitative results on the current level and distribution of adaptation capital in the US economy, the interaction of adaptation capital with federal disaster policy and climate change, and the impact modeling of idiosyncratic storm risk. Section 6 concludes.

\section{Model}

Time is discrete and infinite. The economy is composed of $N$ regions, which are differentiated by their storm risk and the severity of the storm if it occurs. I use the term storm to refer to severe storm-related weather, including hurricanes, tornadoes, and other heavy rain or high wind events. Each region contains a unit mass of infinitely-lived heterogeneous households, a unit mass of firms that produce the final good, and a unit mass of firms that produce rental housing services.

Households derive utility from the consumption of a non-durable good and housing services. Households can self-produce housing services by investing in housing capital (homeowners) or they can purchase housing services from the rental-housing firms in their region (renters). In addition to housing, households can own financial assets held in mutual funds, which earn a risk-free rate of return. The mutual funds own equity shares of the final-good

\footnotetext{
${ }^{5}$ See for example Agrawala, Bosello, Carraro, Bruin, Cian, Dellink, and Lanzi (2011), Barrage (2015), Bosello, Carraro, and Cian (2010), Brechet, Hritonenko, and Yarsenko (2013), DeBruin, Dellink, and Tol (2009), Felgenhauer and Bruin (2009), Felgenhauer and Webster (2014), Kane and Shogren (2000), and Tol (2007). Bosello, Carraro, and Cian (2011) provides an overview.
} 
and rental-housing firms. The mutual funds can also purchase international bonds, which earn an exogenous rate of return determined by world financial markets. Households supply labor in a competitive regional labor market, and their labor productivity is subject to persistent, idiosyncratic shocks, as in Aiyagari (1994).

At the start of each period, a fraction of households and firms in each region experiences a storm. Storms damage the households' productive housing capital, used to produce housing services, as well as the firms' productive capital, used to produce the final good and rental housing services. Households and firms can invest in adaptation capital to reduce the damage they experience if they are hit by a storm. All storm risk is idiosyncratic; there is no aggregate uncertainty in a region. ${ }^{6}$

A federal government taxes households and uses the revenue to provide households and firms with aid for disaster relief from storms and subsidies for investment in adaptation. The only connections between regions are through the federal tax system and through the mutual funds, which hold equity shares in firms across regions. There is no migration between regions. ${ }^{7}$

All capital in the model is privately provided by households and firms; all disaster aid and adaptation subsidies are distributed directly to households and firms. In practice, market and coordination failures often necessitate the public provision both adaptive capital (like a seawall) and productive capital (like a road). Consequently, local governments receive federal disaster aid to repair damaged public productive capital and they receive subsidies for investment in public adaptation capital. As is standard in the macro literature, I abstract from any market or coordination failures that would require the public provision of capital. Instead, I assume that all capital is privately determined by households' and firms' investment decisions. Every unit that the household or firm invests in adaptation in the model could correspond in practice to a unit of tax payments for public adaptation capital (such as a seawall), or a unit of private adaptation capital (such as stilts), whichever is the most cost-effective investment on the margin.

\footnotetext{
${ }^{6}$ The regions are large in the calibrated model, equal to half of the US economy. I abstract from aggregate uncertainty because storms do not typically generate substantial risk at this large regional scale. For example, the average hurricane to make landfall in the US from 2004-2018 caused damage equal to less than 0.1 percent of US GDP.

${ }^{7}$ In practice, households can also adapt by moving away from storm-prone areas. While migration could become an important response to climate change in the future (Desmet et al., forthcoming), the US Fourth National Climate Assessment reports that "communities are currently focused more on capacity building and on making buildings and other assets less sensitive to climate impacts. Communities have been less focused on reducing exposure through actions such as land-use change (preventing building in high-risk locations) and retreat." (USGCRP 2018, Chapter 28). To simplify the model, I focus only on adaptation capital; I do not allow migration.
} 


\subsection{Households}

Preferences. Households have heterogeneous preferences over non-durable consumption and owner-occupied and rental housing services. The utility function is given by:

$$
U\left(c_{i t}, \tilde{h}_{i t}^{s o}, \tilde{h}_{i t}^{s r}\right)=\frac{\left[c_{i t}^{\zeta}\left(\tilde{h}_{i t}^{s}\right)^{1-\zeta}\right]^{1-\sigma}}{1-\sigma}, \quad \text { where } \tilde{h}_{i t}^{s} \equiv \phi_{i}^{o} \tilde{h}_{i t}^{s o}+\phi_{i}^{r} \tilde{h}_{i t}^{s r} .
$$

Variable $c_{i t}$ denotes non-durable consumption for household $i$ in period $t$. Variables $\tilde{h}_{i t}^{s o}$ and $\tilde{h}_{i t}^{s r}$ denote household $i$ 's values of owner-occupied and rental housing services after the realization of the period $t$ storm shock. I use 'tildes' throughout the paper to denote the value of a variable after the realization of the storm shock. Parameter $\sigma$ is the coefficient of relative risk aversion. Households discount the future with discount factor $\beta$ and maximize expected lifetime utility.

Households can self-produce housing services from housing capital that they own and they can rent housing services from rental-housing firms at price $p_{n}^{r}$, where subscript $n$ denotes the household's region. Preference parameters $\phi_{i}^{o} \leq 1$ and $\phi_{i}^{r} \leq 1$ reflect whether household $i$ has an inherent preference for owner-occupied or rental housing. I assume that fraction $\chi$ of households prefer owner-occupied housing, and therefore have parameter values $\phi_{i}^{r}=\bar{\phi}^{r}<1$ and $\phi_{i}^{o}=1$, as posited by much of the macro-housing literature (e.g., Fisher and Gervais, 2011; Kiyotaki, Michaelides, and Nikolov, 2011). The intuition is that, compared to a homeowner, a renter has limited ability to modify the house according to her tastes, implying that rental housing services generate a smaller utility flow than owner-occupied housing services. The remaining fraction $1-\chi$ of households prefer rental housing and therefore have parameter values, $\phi_{i}^{r}=1$ and $\phi_{i}^{o}=\bar{\phi}^{o}<1$. Intuitively, these households place a high value on the ease, flexibility, and mobility that rental housing provides as compared to owner-occupied housing.

Owner-occupied housing. Households can invest in two types of housing capital, productive and adaptive. Productive housing capital, $h_{i t}^{p}$, is used to produce owner-occupied housing services and is susceptible to storm damage. Adaptive housing capital, $h_{i t}^{a}$, reduces the damage to productive capital from a storm. Households produce owner-occupied housing services from productive housing capital that is not damaged by a storm, $\tilde{h}_{i t}^{p}$, (defined formally below) using a linear production technology, $\tilde{h}_{i t}^{s o}=A^{h} \tilde{h}_{i t}^{p}$. Variable $A^{h}$ denotes total factor productivity in the production of housing services.

I assume that owner-occupied housing is not perfectly divisible, which I model using a minimum house size, $h_{i t}^{p}>\underline{h}^{p}$, as in Gervais (2002). In contrast, rental housing services are perfectly divisible, with no minimum size. For the fraction $\chi$ of households with an inherent preference for homeownership, the minimum size for owner-occupied housing implies that the household will choose to rent only if it desires a house smaller than the minimum house size. 
Hence, in equilibrium, low-income households choose to rent and high-income households choose to own. Empirically, while renters have lower incomes than homeowners on average, there exists a substantial fraction of higher income renters. ${ }^{8}$ The assumption that only fraction $\chi$ of households prefer owner-occupied housing allows the model to generate higher-income renters. In particular, the fraction $1-\chi$ of households that prefer rental housing will always choose to rent, regardless of their income.

Labor endowment and productivity. Each household is endowed with one unit of labor, which it supplies exogenously to firms in its region. The household earns labor income $w_{n t} z_{i t}$, where $w_{n t}$ denotes the market wage in region $n$ and $z_{i t}$ is the household's idiosyncratic labor productivity draw. The log of the household's idiosyncratic labor productivity is the sum of two components:

$$
\log \left(z_{i t}\right)=v_{i t}+\xi_{i}
$$

Component $v_{i t}$ is an idiosyncratic persistent productivity shock which follows a finite-state Markov chain with transition probabilities $\pi\left(v_{i, t+1} \mid v_{i t}\right)$, and unique invariant distribution $\Pi\left(v_{i t}\right) .^{9}$ Component $\xi_{i} \sim N\left(0, \sigma_{\xi}^{2}\right)$ is a household-specific fixed effect (i.e., ability) that is constant over time. The household's ability is uncorrelated with its other time-invariant characteristics, namely its housing preference parameters, $\phi_{i}^{r}$ and $\phi_{i}^{o}$, and its region, $n$.

Storm shocks and adaptation. At the start of period $t$, each household experiences an idiosyncratic storm shock, $e_{i t}^{h} \in\{0,1\}$. Value $e_{i t}^{h}=1$ indicates that the household is hit by a storm and value $e_{i t}^{h}=0$ indicates that the household is not hit by a storm. The storm shocks are i.i.d. across households within a region. Parameter $\gamma_{n}$ is the region-specific probability that a household is hit by a storm. Let $\Gamma_{n}\left(e_{i t}^{h}\right)$ denote the vector of storm-shock probabilities in region $n$, where $\Gamma_{n}(0)=1-\gamma_{n}$ and $\Gamma_{n}(1)=\gamma_{n}$. By the law of large numbers, $\gamma_{n}$ corresponds to the fraction of households in region $n$ that are hit by storms in any period $t$.

Among households that are homeowners, the realization of a storm $\left(e_{i t}^{h}=1\right)$ destroys a fraction of the homeowner's productive housing capital. For example, consider a cyclone or tornado destroying the houses, buildings and other infrastructure in its path. The amount of

\footnotetext{
${ }^{8}$ For example, 21 percent of the renters surveyed in the 2018 Current Population Survey had income greater than the mean income (see CPS 2018 Table PINC-01).

${ }^{9}$ The household's realizations of the labor-productivity and storm shocks are uncorrelated. Empirically, I find no statistically significant effect of storms on wages. I regress county-level wages (from the Census's Quarterly Workforce Indicators) on an indicator variable for storms (defined using Presidential Disaster Declarations as described in Section 3) and county and year fixed effects. The estimated coefficient on the storm indicator variable is not statistically different from zero. Similarly, Deryugina (2017) estimates at the effects of hurricane strikes on average wages in US counties between 1979 and 2002 and finds no systematic effect.
} 
homeowner $i$ in region $n$ 's productive housing capital destroyed by a storm in period $t$ equals:

$$
h_{i t}^{d}=e_{i t}^{h} F\left(a_{i t}^{h}\right) \Omega_{n}^{h} h_{i t}^{p} .
$$

Parameter $\Omega_{n}^{h}$ determines the severity of the storm in region $n$; all else constant, increases in $\Omega_{n}^{h}$ imply that the storm destroys a larger fraction of the house. Variable $a_{i t}^{h}$ denotes the homeowner's adaptive capacity, equal to the ratio of her adaptive housing capital relative to her productive housing capital: $a_{i t}^{h} \equiv h_{i t}^{a} / h_{i t}^{p}$. The intuition for the ratio is that homeowners with larger amounts of productive housing capital require more adaptive housing capital to achieve a given level of protection.

Function $F\left(a_{i t}^{h}\right)$ governs the process through which adaptive capacity reduces damage. I assume that $F\left(a_{i t}^{h}\right)$ satisfies the standard Inada conditions. It is decreasing and convex in adaptive capacity, implying that there are diminishing returns to adaptation. The marginal product of the first unit of adaptive capacity is infinite, and hence all homeowners find it beneficial to invest in at least a small amount of adaptation. For example, rain gutters and levees are common throughout the US, even in areas where severe rain storms are relatively rare. I use a simple functional form for $F\left(a_{i t}^{h}\right)$ that satisfies these properties:

$$
F\left(a_{i t}^{h}\right)=\exp \left(-\theta\left(a_{i t}^{h}\right)^{\frac{1}{\theta}}\right) .
$$

Parameter $\theta>1$ determines the effectiveness of adaptive capacity at reducing the damage from a storm. In particular, the magnitude of the marginal product of adaptive capacity, $\partial F / \partial a_{i t}^{h}$, is increasing in $\theta$, implying that higher values of $\theta$ increase the effectiveness of adaptive capacity. After the realization of the storm shock, the homeowner produces owner-occupied housing services from her non-damaged productive housing capital, $\tilde{h}_{i t}^{p} \equiv h_{i t}^{p}-h_{i t}^{d}$.

In addition to owner-occupied housing capital, storms also destroy rental housing capital. If a renter is hit by a storm, then implicitly the rental-housing firm or firms from which she rents are hit by a storm. The renter only receives the rental housing services that the rental-housing firm can produce from its non-damaged capital, $\tilde{h}_{i t}^{s r}$. This value is less than the rental housing services the renter intended to purchase, $h_{i t}^{s r}$. Importantly, the renter only pays for the housing services she actually receives, $\tilde{h}_{i t}^{s r}$, implying that the rental-housing firms absorb the financial loss from the destroyed rental housing capital.

In sum, being hit by a storm leads to a direct utility loss for both homeowners and renters from the decrease in housing services. ${ }^{10}$ Homeowners also lose a portion of their wealth when

\footnotetext{
${ }^{10}$ While the model includes the main sources of utility loss from storms, it abstracts from other sources such as damage to belongings or personal injury. In most cases, preventing injury and death from storms is accomplished through behavioral changes at the time of the storm, such as heeding evacuation warnings, instead of through
} 
part of their house is destroyed by the storm. The law of motion for productive housing capital depends on the non-depreciated and non-damaged productive housing capital:

$$
h_{i, t+1}^{p}=\left(1-\delta^{h}\right) \tilde{h}_{i t}^{p}+i_{i t}^{h p}
$$

Parameter $\delta^{h}$ is the depreciation rate of productive housing capital and variable $i_{i t}^{h p}$ denotes the homeowner's investment in productive housing capital.

Financial assets. Households can save by investing in housing capital and by making deposits, $f_{i, t+1}$, in a mutual fund. Mutual-fund deposits earn risk-free rate of return $1+r_{t+1}$. Asset markets are integrated across regions, implying that the rate of return does not depend on the household's region.

Insurance. Homeowners can purchase insurance, $x_{i, t+1}$, against next period's storm damage. If a homeowner experiences a storm in period $t+1$, then she receives the value of her insurance, subject to the constraint that her insurance payout cannot exceed her damage, $h_{i, t+1}^{d}$. If the homeowner does not experience a storm, then she receives zero. Homeowners purchase insurance from perfectly-competitive insurance intermediaries. It costs the intermediary $\lambda$ to disburse each unit of an insurance claim. This cost captures the transaction and assessment costs associated with the distribution of insurance claims. The insurance premium per unit of insurance in region $n, p_{n}^{x}$, equals the expected payout, $\gamma_{n}$, plus the expected cost of disbursing the insurance claim, $\gamma_{n} \lambda: p_{n}^{x} \equiv \gamma_{n}+\gamma_{n} \lambda$. Summing across homeowners within a region in any period, the law of large numbers implies that the insurance premiums equal insurance claims plus the cost of providing the insurance.

The insurance premium does not depend on the homeowner's adaptive capacity, $a_{i t}^{h}$. The homeowner (and the insurance intermediary) know the amount of damage she will experience if she is hit by a storm, and the homeowner optimally chooses a level of insurance that is less than the damage. Thus, regardless of her level of adaptive capacity, the homeowner's expected claim equals the probability of a storm multiplied by her amount of insurance, $\gamma_{n} x_{i, t+1} \cdot{ }^{11}$

Federal policy. The US federal government provides aid to assist both homeowners and renters

adaptation capital. Furthermore, consumer durables are only one quarter of the value of residential fixed assets (NIPA Table 1.1). Many consumer durables are stored inside a house or garage and thus are somewhat protected from storms. Hence, the damage to belongings is likely small compared to the damage to housing capital.

${ }^{11}$ This model of insurance abstracts from many of the complexities of insurance markets. For example, homeowners' insurance policies have widely varying deductibles, flood insurance premiums are below the actuarially fair rates in some areas and above them in others (NRC, 2015), and agents might not internalize the true probability of a disaster when they make their insurance decisions (Gallagher 2014; Bakkensen and Barrage 2017). The model is not sufficiently detailed to incorporate these many nuances. However, the model does capture the household's realized level of consumption smoothing in response to a storm, which is most important for quantifying adaptation incentives. 
with disaster recovery. This aid is primarily provided through FEMA's Individuals and Households Program, though other federal agencies also participate. In the model, the federal government provides disaster aid to homeowners in proportion to their damaged owner-occupied housing capital, $h_{i t}^{d}$, subject to the constraint that the aid cannot exceed the damage net of insurance claims. This constraint ensures that disaster aid does not duplicate insurance claims, as required by federal law. Specifically, federal disaster aid for homeowner $i$ equals, $\min \left[\psi^{h o} h_{i t}^{d}, h_{i t}^{d}-x_{i t}\right]$, where parameter $\psi^{h o} \in[0,1]$ denotes the fraction of damaged owneroccupied housing capital covered by federal disaster aid. ${ }^{12}$

Parallel to the specification for homeowners, I assume that renters receive disaster aid in proportion to the damaged rental housing capital. The production function for rental housing services, defined formally below, is identical to the one for owner-occupied housing services. Hence, damaged rental housing capital equals the difference between the housing services the renter planned to purchase, $h_{i t}^{s r}$, and the housing services she actually purchased, $\tilde{h}_{i t}^{s r}$, divided by the total factor productivity in the production of housing services, $A^{h}$. Disaster aid for renter $i$ equals, $\psi^{h r}\left(h_{i t}^{s r}-\tilde{h}_{i t}^{s r}\right) / A^{h}$, where parameter $\psi^{h r} \in[0,1]$ denotes the fraction of damaged rental housing capital covered by federal disaster aid to renters.

In addition to the disaster aid, the US federal government also subsidizes investment in adaptation. Federal grants for adaptation capital often require cost sharing between the federal government and the grant recipient, effectively reducing the relative price of adaptation capital funded through the grant. For example, FEMA Hazard Mitigation grants require that 25 percent of the project be financed with non-federal dollars (FEMA, 2019a). Similarly, US Army Corps financed flood control and hurricane damage projects require the grant recipient to finance 35-50 percent of the overall cost (USACE, 2020).

In line with US policy, the adaptation subsidy in the model, $\eta$, reduces the relative price of adaptation investment. The law of motion for a homeowner's adaptation capital equals:

$$
h_{i, t+1}^{a}=\left(1-\delta^{a}\right) h_{i t}^{a}+(1+\eta) i_{i t}^{h a},
$$

where parameter $\delta^{a}$ denotes the depreciation rate of adaptation capital and variable $i_{i t}^{h a}$ denotes the homeowner's investment in adaptation capital. One additional unit of adaptation capital only costs the homeowner $1 /(1+\eta)<1$ units of final good.

12 This specification implies that homeowners can receive payments from both FEMA and insurance providers, as long as the sum of the payments is less than the total damage. In practice, homeowners often receive payments from both FEMA and insurance providers, if they experience multiple types of damage from a storm, and not all types of damage are covered by their insurance policies. For example, the majority of US homeowners have homeowners' insurance but do not have flood insurance, implying that if they experience wind and flood damage from a storm, then they would receive compensation from FEMA for the flood damage and compensation from their insurance providers for the wind damage. 
The government finances the disaster aid and the adaptation subsidy with a flat tax on labor income, $\tau$, for all households. Consistent with US policy, the labor-income tax does not vary with the household's expected receipts of disaster aid or adaptation subsidies. In equilibrium, the level of the labor-income tax, $\tau$, is such that the government budget constraint clears in each period.

Recursive formulation of the household's problem. I describe the optimization problem for a generic household $i$ that could endogenously choose to be a homeowner, a renter, or both a homeowner and a renter (though this latter choice is never optimal in equilibrium). Let $\tilde{m}_{i t}$ denote household $i$ 's cash at hand:

$$
\begin{aligned}
& \tilde{m}_{i t}\left(h_{i t}^{p}, h_{i t}^{a}, h_{i t}^{s r}, f_{i t}, x_{i t}, e_{i t}^{h}, v_{i t} ; \Upsilon_{i}\right)=(1-\tau) w_{n t} z_{i t}+\left(1+r_{t}\right) f_{i t}+\left(1-\delta^{h}\right) \tilde{h}_{i t}^{p} \\
& \quad+\left(1-\delta^{a}\right)\left(\frac{h_{i t}^{a}}{1+\eta}\right)+e_{i t}^{h} \min \left[x_{i t}, h_{i t}^{d}\right]+\min \left[\psi^{h o} h_{i t}^{d}, h_{i t}^{d}-x_{i t}\right]+\psi^{h r}\left(h_{i t}^{s r}-\tilde{h}_{i t}^{s r}\right) / A^{h} \\
& \quad-p_{n}^{x} x_{i t}-p_{n}^{r} \tilde{h}_{i t}^{s r},
\end{aligned}
$$

which I define as the value, after the period $t$ storm and labor-productivity shocks have materialized, of all income plus all assets brought into the period, plus insurance claims, plus disaster aid receipts, minus insurance premiums, and minus payments for rental housing services. Vector $\Upsilon_{i}$ in equation (3) denotes the vector of time-invariant household characteristics, containing the household's region, ability, and preference parameters: $\Upsilon_{i} \equiv\left\{n, \xi_{i}, \phi_{i}^{r}, \phi_{i}^{o}\right\}$. The household's individual state variables are its cash at hand, $\tilde{m}_{i t}$, its persistent labor productivity shock, $v_{i t}$, and its preference-weighted level of housing services after the realization of the storm shock, $\tilde{h}_{i t}^{s}$.

Following the realization of the storm and labor productivity shocks, each household chooses period $t$ consumption and period $t+1$ levels of productive and adaptive housing capital, rental housing services, insurance, and financial assets to maximize expected lifetime welfare. The dynamic programing problem for household $i$ equals:

$$
\begin{aligned}
V^{h}\left(\tilde{h}_{i t}^{s}, \tilde{m}_{i t}, v_{i t} ; \Upsilon_{i}\right)= & \max _{c_{i t}, h_{i, t+1}^{a}, h_{i, t+1}^{p}, h_{i, t+1}^{s r}, f_{i, t+1}, x_{i, t+1}} \\
+\beta \sum_{v_{i, t+1}} \pi\left(v_{i, t+1} \mid v_{i t}\right) \sum_{e_{i, t+1}^{h}} \Gamma_{n}\left(e_{i, t+1}^{h}\right) V^{h}\left(\tilde{h}_{i, t+1}^{s}, \tilde{h}_{i t}^{s}\right) & \left.\left.\tilde{m}_{i, t+1}, v_{i, t+1} ; \Upsilon_{i}\right)\right]
\end{aligned}
$$

subject to the constraints: the evolution of cash at hand (equation (3)), the household budget 
constraint:

$$
c_{i t}=\tilde{m}_{i t}-\frac{h_{i, t+1}^{a}}{1+\eta}-h_{i, t+1}^{p}-f_{i, t+1} \text {, }
$$

the evolution of the preference-weighted, post-storm-damage housing services:

$$
\tilde{h}_{i, t+1}^{s}\left(h_{i, t+1}^{p}, h_{i, t+1}^{a}, h_{i, t+1}^{s r}, e_{i, t+1} ; \Upsilon_{i}\right)=\phi_{i}^{o} A^{h} \tilde{h}_{i, t+1}^{p}+\phi_{i}^{r} \tilde{h}_{i, t+1}^{s r}
$$

the minimum owner-occupied house size:

$$
h_{i, t+1}^{p} \in\left\{0,\left[\underline{h}^{p}, \infty\right)\right\}
$$

and the non-negativity constraints on next period's wealth (in the absence of a storm), productive housing capital, adaptive housing capital, rental housing services, and insurance:

$$
h_{i, t+1}^{a}+h_{i, t+1}^{p}+f_{i, t+1} \geq 0, \quad h_{i, t+1}^{p} \geq 0, \quad h_{i, t+1}^{a} \geq 0, \quad h_{i, t+1}^{s r} \geq 0, \quad \text { and } \quad x_{i, t+1} \geq 0 .
$$

\subsection{Firms}

Each region contains a continuum of measure one of perfectly competitive final-good firms, denoted with superscript $y$, and a continuum of measure one of perfectly competitive rentalhousing firms, denoted with superscript $r$. The final-good firms hire effective labor from households and both types of firms invest in capital, which they own, to maximize the expected value of their firm. Firms are subject to idiosyncratic storm shocks with the same region-specific probabilities as households. The storm shocks realize at the start of each period, before production takes place, and before the firms decide how much labor to hire for use in the current period and how much to invest in capital for use in the next period. Implicitly, if a rental-housing firm is hit by a storm, then the renter or renters who purchase its rental housing services are hit by a storm.

If a firm is hit by a storm, it destroys some of its productive capital stock. As with homeowners, firms can invest in adaptation capital to reduce the amount of productive capital destroyed by a storm. The damaged productive capital in each period for a final-good firm $i, k_{i t}^{y d}$, and a rental-housing firm $i, k_{i t}^{r d}$, in region $n$ equal:

$$
k_{i t}^{y d}=e_{i t}^{y} F\left(a_{i t}^{y}\right) \Omega_{n}^{y} k_{i t}^{y p} \quad \text { and } \quad k_{i t}^{r d}=e_{i t}^{r} F\left(a_{i t}^{r}\right) \Omega_{n}^{h} k_{i t}^{r p} \text {, }
$$

paralleling the specification for damaged owner-occupied housing capital in equation (1). Variable $e_{i t}^{j}$ denotes the realization of the storm shock for firm $i$ of type $j \in\{y, r\}$. Variable $a_{i t}^{j}$ de- 
notes the adaptive capacity for firm $i$ of type $j$, equal to the ratio of the firm's adaptive capital relative to its productive capital: $a_{i t}^{j} \equiv k_{i t}^{j a} / k_{i t}^{j p}$. Storm severity parameters $\Omega_{n}^{y}$ and $\Omega_{n}^{h}$ denote the respective region-specific fractions of final-good and rental-housing productive capital destroyed by storms. The storm severities for housing and final-good capital differ to reflect the fact that residential and industrial centers often have different locations (e.g., on the coast versus inland) and therefore could have different susceptibilities to storm damage.

As with households, each firm $i$ of type $j$ collects disaster aid in proportion to the amount of its productive capital damaged by the storm, $\psi^{k j} k_{i t}^{j d}$. Additionally, firms also receive the federal subsidy, $\eta$, for investment in adaptation capital. The law of motion for adaptation capital for firm $i$ of type $j$ equals:

$$
k_{i, t+1}^{j a}=\left(1-\delta^{a}\right) k_{i t}^{j a}+(1+\eta) i_{i t}^{j a},
$$

where variable $i_{i t}^{j a}$ denotes the firm's adaptation investment. I assume that the adaptation subsidy, $\eta$, is the same for households and firms because the two main funding sources for adaptation subsidies, FEMA's Hazard Mitigation Grant Program and the US Army Corps of Engineers, subsidize adaptation investment designed to protect both households and firms.

The final-good firm produces output, $\tilde{y}_{i t}$, from its non-damaged productive capital stock, $\tilde{k}_{i t}^{y p} \equiv k_{i t}^{y p}-k_{i t}^{y d}$, according to the Cobb-Douglas production function:

$$
\tilde{y}_{i t}=\left(\tilde{k}_{i t}^{y p}\right)^{\alpha}\left(A^{y} l_{i t}\right)^{1-\alpha} \text {. }
$$

Parameter $\alpha$ denotes capital's share, parameter $A^{y}$ is total factor productivity in the production of the final good, and variable $l_{i t}$ denotes the firm's demand for effective labor. Similarly, the rental-housing firm produces rental housing services, $\tilde{h}_{i t}^{s r}$, from its non-damaged productive capital, $\tilde{k}_{i t}^{r p} \equiv k_{i t}^{r p}-k_{i t}^{r d}$, using the same linear production technology as households use to produce owner-occupied housing services: $\tilde{h}_{i t}^{s r}=A^{h} \tilde{k}_{i t}^{r p}$.

Firms make all decisions to maximize the expected present discounted value of their future cash flows. The dynamic programming problem for final-good firm $i$ in region $n$ is:

$$
\begin{aligned}
V^{y}\left(k_{i t}^{y p}, k_{i t}^{y a}, e_{i t}^{y} ; n\right)= & \max _{i_{i t}^{y p}, i_{i t}^{y y}, l_{i t}}\left[\left(\tilde{k}_{i t}^{y p}\right)^{\alpha}\left(A^{y} l_{i t}\right)^{1-\alpha}-w_{n t} l_{i t}+\psi^{k y} k_{i t}^{y d}-i_{i t}^{y p}-i_{i t}^{y a}\right. \\
& \left.+\left(\frac{1}{1+r_{t+1}}\right) \sum_{e_{i, t+1}^{y}} \Gamma_{n}\left(e_{i, t+1}^{y}\right) V^{y}\left(k_{i, t+1}^{y p}, k_{i, t+1}^{y a}, e_{i, t+1} ; n\right)\right],
\end{aligned}
$$

subject to the law of motion for adaptive capital (equation (5)) and the law of motion for 
productive capital:

$$
k_{i, t+1}^{y p}=\left(1-\delta^{y}\right) \tilde{k}_{i t}^{y p}+i_{i t}^{y p},
$$

where parameter $\delta^{y}$ denotes the depreciation rate of final-good capital and variable $i_{i t}^{y p}$ denotes the final-good firm's productive capital investment. ${ }^{13}$

The dynamic programming problem for rental-housing firm $i$ in region $n$ is:

$$
\begin{aligned}
V^{r}\left(k_{i t}^{r p}, k_{i t}^{r a}, e_{i t}^{r} ; n\right)= & \max _{i_{i t}^{r}, i_{i t}^{r a}}\left[p_{n t}^{r} A^{h} \tilde{k}_{i t}^{r p}+\psi^{k r} k_{i t}^{r d}-i_{i t}^{r p}-i_{i t}^{r a}\right. \\
& \left.+\left(\frac{1}{1+r_{t+1}}\right) \sum_{e_{i, t+1}^{r}} \Gamma_{n}\left(e_{i, t+1}^{r}\right) V^{r}\left(k_{i, t+1}^{r p}, k_{i, t+1}^{r a}, e_{i, t+1}^{r} ; n\right)\right]
\end{aligned}
$$

subject to the law of motion for adaptive capital (equation (5)) and the law of motion for productive capital:

$$
k_{i, t+1}^{r p}=\left(1-\delta^{h}\right) k_{i t}^{r p}+i_{i t}^{r p}
$$

where variable $i_{i t}^{r p}$ denotes the rental-housing firm's productive capital investment.

Following Favilukis (2013), firms finance investment entirely through earnings; they do not issue new shares or debt. I normalize the number of shares of each firm to unity. The dividends to the shareholders of a final-good firm $i, d_{i t}^{y}$, and a rental-housing firm $i, d_{i t}^{r}$, equal:

$$
\begin{aligned}
& d_{i t}^{y}=\left(\tilde{k}_{i t}^{y p}\right)^{\alpha}\left(A^{y} l_{i t}\right)^{1-\alpha}-w_{n t} l_{i t}-i_{i t}^{y p}-i_{i t}^{y a}+\psi^{k y} k_{i t}^{y d}, \quad \text { and } \\
& d_{i t}^{r}=p_{n t}^{r} A^{h} \tilde{k}_{i t}^{r p}-i_{i t}^{r p}-i_{i t}^{r a}+\psi^{k r} k_{i t}^{r d} .
\end{aligned}
$$

The value of firm $i$ of type $j, V^{j}\left(k_{i t}^{j p}, k_{i t}^{j a}, e_{i t}^{j} ; n\right)$, is the cum-dividend value, meaning that it is measured before the dividend is paid out. To calculate the expected rate of return from purchasing a share in the firm, it is useful to define the ex-dividend value of the firm as $V^{j e}\left(k_{i t}^{j p}, k_{i t}^{j a}, e_{i t}^{j} ; n\right)=V^{j}\left(k_{i t}^{j p}, k_{i t}^{j a}, e_{i t}^{j} ; n\right)-d_{i t}^{j}$. Using this definition, the expected return to purchasing a share of firm $i$ of type $j$ equals:

$$
E_{t}\left(R_{i, t+1}^{j}\right)=E_{t}\left[\frac{V^{j e}\left(k_{i, t+1}^{j p}, k_{i, t+1}^{j a}, e_{i, t+1}^{j} ; n\right)+d_{i, t+1}^{j}}{V^{j e}\left(k_{i t}^{j p}, k_{i t}^{j a}, e_{i t}^{j} ; n\right)}\right] .
$$

\footnotetext{
${ }^{13}$ Alternatively, one could specify the firm's optimization problem so that it discounts future profits using the household's stochastic discount factor instead of $1 /\left(1+r_{t+1}\right)$. Such a specification is equivalent to equation (6) because the idiosyncratic risk implies that the covariance between the stochastic discount factor and the firm's realized marginal product of capital is zero.
} 
Observe from the firm's value function (equations (6) or (7)) and the expression for dividends (equations (8) or (9)), that the ex-dividend value of firm $i$ of type $j$ equals:

$$
V^{j e}\left(k_{i t}^{j p}, k_{i t}^{j a}, e_{i t}^{j} ; n\right)=\left(\frac{1}{1+r_{t+1}}\right) \sum_{e_{i, t+1}^{j}} \Gamma_{n}\left(e_{i, t+1}^{j}\right) V^{j}\left(k_{i, t+1}^{j p}, k_{i, t+1}^{j a}, e_{i, t+1}^{j} ; n\right) .
$$

Rearranging equation (11) to solve for the expected return yields:

$$
1+r_{t+1}=\frac{\sum_{e_{i, t+1}^{j}} \Gamma_{n}\left(e_{i, t+1}^{j}\right) V^{j}\left(k_{i, t+1}^{j p}, k_{i, t+1}^{j a}, e_{i, t+1}^{j} ; n\right)}{V^{j e}\left(k_{i t}^{j p}, k_{i t}^{j a}, e_{i t}^{j} ; n\right)}=E_{t}\left(R_{i, t+1}^{j}\right),
$$

implying that the expected return from purchasing a share of any final-good or rental-housing firm equals $1+r_{t+1}$.

The final good is the numeraire. I assume that the final good can be costlessly transformed into the non-durable consumption good, or into any type of capital for use by any firm or homeowner. Consequently, the prices of consumption and each type of capital all equal unity.

\subsection{Mutual funds}

There is a measure one of perfectly-competitive and risk-averse mutual funds. The representative mutual fund uses household deposits to purchase equity shares in the final-good and rental-housing firms in any region and to purchase international bonds, $b_{t+1}$. International bonds earn exogenous rate of return $1+r^{\star}$. Let $Q_{t+1}$ (defined formally in Appendix A) be a function that describes the mutual fund's allocation of household deposits across equity shares in the measure $2 N$ of firms in the economy. All firm equities are held domestically.

At the end of period $t$, the mutual fund chooses next period's bonds, $b_{t+1}$, and equity shares, described by function $Q_{t+1}$, to maximize the expectation of any strictly increasing and concave function of the value of its portfolio at the end of period $t+1$. Appendix A solves the optimization problem for the representative mutual fund and shows that even though the return on any particular equity is stochastic, the mutual fund's optimal portfolio earns rate of return $1+r_{t+1}$ with certainty. The intuition is that since the mutual fund is risk averse, it allocates an infinitesimally small share of household deposits to each of the infinitely many equities in its portfolio. The variance in the return on the resulting equity portfolio is zero because all equities have the same expected return, the return realizations are independent, and there is no aggregate risk. A simple no-arbitrage argument implies that the return on the mutual fund's optimal equity portfolio, $1+r_{t+1}$, equals the return on international bonds, $1+r^{\star}$.

When $r_{t+1}=r^{\star}$, the mutual fund is indifferent between equities and bonds. In equilibrium, 
the mutual fund's allocation between equities and bonds is determined so that the asset market clears. Asset market clearing requires that the total value of all equity held by mutual funds equals the total value of the $2 N$ firms in the economy:

$$
s_{t+1}-b_{t+1}=\int_{0}^{2 N} V_{i, t}^{e} d i .
$$

Variable $s_{t+1}$ denotes the mutual fund's level of household deposits, hence $s_{t+1}-b_{t+1}$ is the total value of all equity held by the mutual fund. Variable $V_{i, t}^{e}$ refers to the ex-dividend value of firm $i$ in period $t$, equal to $V^{y e}\left(k_{i t}^{y p}, k_{i t}^{y a}, e_{i t}^{y} ; n\right)$ if firm $i$ is a final-good firm in region $n$ or $V^{r e}\left(k_{i t}^{r p}, k_{i t}^{r a}, e_{i t}^{r} ; n\right)$ if firm $i$ is a rental-housing firm in region $n$.

\subsection{Definition of a stationary equilibrium}

I define a stationary recursive competitive equilibrium. Throughout the definition of an equilibrium, I use primes to denote the next period's value of a variable and I suppress the individual firm and household subscripts. Let $g^{h}=\left(\tilde{h}^{s}, m, v, \Upsilon\right)$ denote the vector of household state variables and household characteristics. Let $\mu^{h}$ be the invariant cross-sectional distribution over the household states and characteristics. Similarly, let $g^{j}=\left(k^{j p}, k^{j a}, e^{j}\right)$ denote the vector of firm state variables for firms of type $j \in\{y, r\}$ and let $\mu^{j}$ be the invariant crosssectional distribution over the firm states.

Given an adaptation subsidy, $\eta$, disaster aid parameters, $\psi^{h o}, \psi^{h r}, \psi^{k y}$, and $\psi^{k r}$, and an international interest rate, $r^{\star}$, a stationary recursive competitive equilibrium consists of the timeinvariant value and policy functions for the households, $\left\{V^{h}, h^{p^{\prime}}, h^{a^{\prime}}, h^{s r^{\prime}}, x^{\prime}, f^{\prime}\right\}$, value and policy functions for firms, $\left\{V^{j}, k^{j p^{\prime}}, k^{j a^{\prime}}, l,\right\}$ for $j \in\{y, r\}$, policies for the mutual fund, $\left\{b^{\prime}, Q^{\prime}\right\}$, prices, $\left\{r, w_{n}, p_{n}^{r}, p_{n}^{x}\right\}$ for each $n \in\{1, \ldots, N\}$, labor-income tax, $\tau$, and stationary distributions $\left\{\mu^{h}, \mu^{y}, \mu^{r}\right\}$ such that:

1. Given prices, the labor-income tax, and government policies, the household value function, $V^{h}$, solves the optimization problem in equation (4) and $h^{p^{\prime}}, h^{a^{\prime}}, h^{s r^{\prime}}, f^{\prime}, x^{\prime}$ are the associated policy functions.

2. Given prices and government policies, the final-good firm value function, $V^{y}$, solves the optimization problem in equation (6) and $k^{y p^{\prime}}, k^{y a^{\prime}}$ and $l$ are the associated policy functions.

3. Given prices and government policies, the rental-housing firm value function, $V^{r}$, solves the optimization problem in equation (7) and $k^{r p^{\prime}}$ and $k^{r a^{\prime}}$ are the associated policy functions. 
4. Given prices and government policies, the mutual fund policies, $b^{\prime}, Q^{\prime}$ solve the mutual fund's optimization problem (defined formally in Appendix A).

5. The market for rental housing services clears in each region $n$ :

$$
\int h^{s r^{\prime}}\left(g^{h}\right) d \mu_{g^{h} \mid n}^{h}=A^{h} \int h^{r p^{\prime}}\left(g^{r}\right) d \mu_{g^{r} \mid n}^{r}
$$

6. The federal government budget constraint clears:

$$
\int \tau w z d \mu^{h}=\sum_{n=1}^{N}\left[\Lambda_{n}+\left(\psi^{h r}+\psi^{k r}\right) K_{n}^{r d}+\psi^{k y} K_{n}^{y d}+\eta\left(I_{n}^{a h}+I_{n}^{a y}+I_{n}^{a r}\right)\right]
$$

where $\Lambda_{n}$ denotes disaster aid for homeowners in region $n$ :

$\Lambda_{n} \equiv \gamma_{n} \int \min \left\{\psi^{h o} \Omega_{n}^{h} F\left[a^{h^{\prime}}\left(g^{h} \mid n\right)\right] h^{p^{\prime}}\left(g^{h} \mid n\right), \Omega_{n}^{h} F\left[a^{h^{\prime}}\left(g^{h} \mid n\right)\right] h^{p^{\prime}}\left(g^{h} \mid n\right)-x^{\prime}\left(g^{h} \mid n\right)\right\} d \mu_{g^{h} \mid n}^{h}$,

$a^{h^{\prime}}$ is the implied policy function for homeowner adaptive capacity,

$$
a^{h^{\prime}}\left(g^{h} \mid n\right)=\frac{h^{a^{\prime}}\left(g^{h} \mid n\right)}{h^{p^{\prime}}\left(g^{h} \mid n\right)}
$$

$K_{n}^{y d}$ and $K_{n}^{r d}$ denote the aggregate amounts of final-good and rental-housing capital damaged by storms in region $n$ :

$$
\begin{aligned}
& K^{y d}=\gamma_{n} \Omega_{n}^{y} \int F\left[a^{y^{\prime}}\left(g^{y} \mid n\right)\right] k^{y p^{\prime}}\left(g^{y} \mid n\right) d \mu_{g^{y} \mid n}^{y} \\
& K^{r d}=\gamma_{n} \Omega_{n}^{h} \int F\left[a^{r^{\prime}}\left(g^{r} \mid n\right)\right] k^{r p^{\prime}}\left(g^{r} \mid n\right) d \mu_{g^{r} \mid n}^{r},
\end{aligned}
$$

$a^{j^{\prime}}$ is the implied policy function for adaptive capacity for a firm of type $j \in\{y, r\}$,

$$
a^{j^{\prime}}\left(g^{j} \mid n\right)=\frac{k^{j a^{\prime}}\left(g^{j} \mid n\right)}{k^{j p^{\prime}}\left(g^{j} \mid n\right)}
$$

and $I_{n}^{h a}, I_{n}^{y a}$ and $I_{n}^{r a}$ denote aggregate adaptation investment in region $n$ :

$I_{n}^{h a}=\delta^{a} \int h^{a^{\prime}}\left(g^{h} \mid n\right) d \mu_{g^{h} \mid n}^{h} \quad I^{y a}=\delta^{a} \int k^{y a^{\prime}}\left(g^{y} \mid n\right) d \mu_{g^{y} \mid n}^{y} \quad$ and $\quad I_{n}^{r a}=\delta^{a} \int k^{r a^{\prime}}\left(g^{r} \mid n\right) d \mu_{g^{r} \mid n^{r}}^{r}$ 
7. The asset market clears:

$$
\int V^{y e} d \mu^{y}+\int V^{r e} d \mu^{r}=s^{\prime}-b^{\prime} \quad \text { where } \quad s^{\prime}=\int f^{\prime}\left(g^{h}\right) d \mu^{h} .
$$

8. The labor market clears in each region $n$ :

$$
\int z d \mu_{g^{h} \mid n}^{h}=\int l\left(g^{y} \mid n\right) d \mu_{g^{y} \mid n}^{y} .
$$

\subsection{Incentives for adaptation}

To build intuition for how climate change and federal disaster policy affect adaptation incentives, I analyze the returns to adaptation capital implied by the households' and firms' first order conditions. I take the first order conditions (reported in Appendix A) conditional on the households and firms choosing strictly positive levels of productive capital (otherwise adaptive capacity is undefined). Adaptation capital increases realized household utility in the event of a storm by increasing cash at hand, $\tilde{m}$, and by increasing housing services, $\tilde{h}^{s}$. The realized returns to adaptation capital from its effects on cash at hand, $R_{i, t+1}^{m}$, and housing services, $R_{i, t+1}^{h}$, for a household $i$ in region $n$ equal:

$$
\begin{aligned}
& R_{i, t+1}^{m}\left(e_{i, t+1}^{h}\right)= \begin{cases}1-\delta^{a} & : e_{i, t+1}^{h}=0 \\
1-\delta^{a}+(1+\eta)\left(1-\delta^{h}-\psi^{h o}\right) \Omega_{n}^{h}\left(\frac{-\partial F}{\partial a_{i, t+1}^{h}}\right) & : e_{i, t+1}^{h}=1\end{cases} \\
& R_{i, t+1}^{h}\left(e_{i, t+1}^{h}\right)= \begin{cases}0 & : e_{i, t+1}^{h}=0 \\
(1+\eta) \phi_{i}^{o} A^{h} \Omega_{n}^{h}\left(\frac{-\partial F}{\partial a_{i, t+1}^{h}}\right) & : e_{i, t+1}^{h}=1 .\end{cases}
\end{aligned}
$$

If the household is not hit by a storm, $e_{i, t+1}^{h}=0$, then the realized return to adaptation capital from increased cash at hand, $R_{i, t+1}^{m}(0)$, is just the non-depreciated value of the capital, $1-\delta^{a}$, and the realized return from increased housing services, $R_{i, t+1}^{h}(0)$, is zero. For example, if it does not rain, then elevating a house on stilts generates no benefit beyond the resale value of the stilts. The return to adaptation capital from both channels is larger when the household is hit by a storm, $e_{i, t+1}^{h}=1$. In the event of a storm, adaptation capital increases the household's non-damaged productive housing capital, which in turn increases its consumption of housing services, implying that $R_{i, t+1}^{h}(1)>0$, and increases its wealth, implying that $R_{i, t+1}^{m}(1)>1-\delta^{a}$ (in the empirically relevant region of parameter space in which $\delta^{h}+\psi^{\text {ho }}<1$ ).

In addition to investing in adaptation capital, households can also increase their cash at hand in the event of a storm by purchasing financial assets. I show in Appendix A that the ex- 
pected return to adaptation capital from increased cash at hand, $\gamma_{n} R_{i, t+1}^{m}(1)+\left(1-\gamma_{n}\right) R_{i, t+1}^{m}(0)$, is less than the expected return on financial assets, $1+r_{t+1}$. The intuition is that since adaptation capital pays out in the states of the world with higher marginal utilities of consumption and households are risk averse, it has a negative risk premium. In contrast, financial assets pay out equally in all states of the world, and thus garner the risk-free rate. Furthermore, unlike financial assets, adaptation capital creates direct utility benefits through increased housing services in the event of a storm, implying a lower return from increased cash at hand, all else constant.

The firm's first order conditions imply that the expected return to adaptation capital equals the risk-free rate, $1+r_{t+1}$. Unlike households, firms are risk neutral, and thus adaptation capital for firms does not have a negative risk premium. The returns to adaptation capital for a final-good firm $i, R_{i, t+1}^{y}$, and a rental-housing firm $i, R_{i, t+1}^{r}$, in region $n$ equal:

$$
\begin{aligned}
& R_{i, t+1}^{y}\left(e_{i, t+1}^{y}\right)= \begin{cases}1-\delta^{a} & : e_{i, t+1}^{y}=0 \\
1-\delta^{a}+(1+\eta)\left(\alpha\left(\frac{A^{y}(1-\alpha)}{w_{n, t+1}}\right)^{\frac{1-\alpha}{\alpha}}+1-\delta^{y}-\psi^{k y}\right) \Omega_{n}^{y}\left(\frac{-\partial F}{\partial a_{i, t+1}^{y}}\right) & : e_{i, t+1}^{y}=1,\end{cases} \\
& R_{i, t+1}^{r}\left(e_{i, t+1}^{r}\right)= \begin{cases}1-\delta^{a} & : e_{i, t+1}^{r}=0 \\
1-\delta^{a}+(1+\eta)\left(p_{n, t+1}^{r} A^{h}+1-\delta^{h}-\psi^{k r}\right) \Omega_{n}^{h}\left(\frac{-\partial F}{\partial a_{i, t+1}^{r}}\right) & : e_{i, t+1}^{r}=1 .\end{cases}
\end{aligned}
$$

As with households, the return to adaptation capital beyond its non-depreciated value is zero if the firm does not experience a storm. If the firm does experience a storm, adaptation capital reduces the firm's loss of productive capital (captured by the $1-\delta^{y}$ term in equation (15) and the $1-\delta^{h}$ term in equation (16)). Adaptation capital also reduces the loss in output in the period of the storm, raising current period profits (captured by the term $\alpha\left(\frac{A^{y}(1-\alpha)}{w_{n t+1}}\right)^{\frac{1-\alpha}{\alpha}}$ in equation (15) and the term $p_{n, t+1}^{r} A^{h}$ in equation (16)).

The returns to adaptation capital in equations (13)-(16) highlight the moral hazard effects of disaster aid and the potential for the adaptation subsidy to offset those moral hazard effects. By partially compensating households and firms for the damaged capital, disaster aid reduces the return to adaptation; the $\psi$ parameters enter negatively in equations (13)-(16). Offsetting this moral hazard, the adaptation subsidy in equations (13)-(16) magnifies the return to adaptation beyond its non-depreciated value by factor $1+\eta$.

Climate change is predicted to increase the severity or probability of storms (or both). The expected return to adaptation capital in equations (13)-(16) is increasing in storm severity, $\Omega$, and in the storm probability, $\gamma$. Thus, the progression of climate change creates stronger incentives for agents to make investments in adaptation to reduce the accompanying damage. 


\section{Calibration}

Table 1: Parameter Values: External Calibration

\begin{tabular}{|c|c|}
\hline Parameter & Value \\
\hline \multicolumn{2}{|l|}{ Storms and adaptation } \\
\hline Low-risk region storm probability: $\gamma_{1}$ & 0.002 \\
\hline High-risk region storm probability: $\gamma_{2}$ & 0.022 \\
\hline \multicolumn{2}{|l|}{ Preferences and housing } \\
\hline Coefficient of relative risk aversion: $\sigma$ & 2 \\
\hline \multicolumn{2}{|l|}{ Production } \\
\hline Depreciation rate of final-good capital: $\delta^{y}$ & 0.07 \\
\hline Depreciation rate of housing capital: $\delta^{h}$ & 0.02 \\
\hline Depreciation rate of adaptation capital: $\delta^{a}$ & 0.03 \\
\hline TFP in final-good production: $A^{y}$ & 1 \\
\hline TFP in housing services: $A^{h}$ & 0.14 \\
\hline Capital share in final-good production: $\alpha$ & 0.26 \\
\hline \multicolumn{2}{|l|}{ Mutual fund } \\
\hline 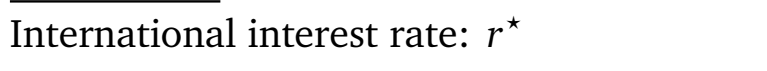 & 0.04 \\
\hline \multicolumn{2}{|l|}{ Labor productivity } \\
\hline Persistent shock persistence: $\rho$ & 0.97 \\
\hline Persistent shock innovation variance: $\sigma_{\varepsilon}^{2}$ & 0.02 \\
\hline Fixed-effect variance: $\sigma_{\xi}^{2}$ & 0.66 \\
\hline
\end{tabular}

Note: This table reports the parameter values that I take from existing estimates.

The time period in the model is one year. I divide the US economy into two risk regions, low and high, denoted with subscripts 1 and 2, respectively. ${ }^{14}$ I calibrate some of the parameters directly from the data or the existing literature. Given these parameters, I jointly calibrate the remaining parameters internally so that a set of moments in the model match their corresponding empirical targets. Tables 1 and 2 report the values of the externally and internally calibrated parameters, respectively.

\footnotetext{
${ }^{14}$ One could include a finer level of geographic detail by breaking the US into more than two regions. How this would impact the amount that adaptation reduces storm damage depends on the magnitudes of two opposing effects. First, introducing more regions results in a more unequal distribution of adaptive capacity, which, all else constant, reduces the magnitude of $\mathrm{dF} / \mathrm{da}$ and hence decreases the reduction in storm damage from adaptation. Offsetting this effect, introducing more regions concentrates adaptive capacity in the regions with the most frequent and severe storms, increasing the reduction in storm damage from adaptation.
} 
Table 2: Parameter Values: Internal Calibration

\begin{tabular}{ll}
\hline \hline Parameter & Value \\
\hline Storms and Adaptation & \\
\hline Low-risk region, housing, storm severity: $\Omega_{1}^{h}$ & 0.15 \\
High-risk region, housing, storm severity: $\Omega_{2}^{h}$ & 0.30 \\
Low-risk region, final-good, storm severity: $\Omega_{1}^{y}$ & 0.11 \\
High-risk region, final-good, storm severity: $\Omega_{2}^{y}$ & 0.21 \\
Effectiveness of adaptation: $\theta$ & 3.78 \\
Federal policy & \\
\hline Subsidy for adaptation investment: $\eta$ & 0.09 \\
Disaster aid fraction for homeowners: $\psi^{h o}$ & 0.10 \\
Disaster aid fraction for renters: $\psi^{h r}$ & 0.03 \\
Disaster aid fraction for rental-housing firms: $\psi^{k r}$ & 0.01 \\
Disaster aid fraction for final-good firms: $\psi^{k y}$ & 0.23 \\
Preferences, housing, and insurance & \\
\hline Discount factor: $\beta$ & 0.94 \\
Non-durable consumption exponent: $\zeta$ & 0.85 \\
Preference discount from renting: $\bar{\phi}^{r}$ & 0.79 \\
Preference discount from owning: $\bar{\phi}^{o}$ & $<1$ \\
Fraction of HHs that prefer homeownership: $\chi$ & 0.79 \\
Disbursement cost of insurance: $\lambda$ & 0.005 \\
\hline
\end{tabular}

Note: This table reports the parameter values that I choose internally so that a set of moments in the model match their corresponding empirical targets.

Much of the calibration approach is standard in the macro literature. The important novelty is determining the set of moments that pin down the structural parameter governing the effectiveness of adaptation capital, $\theta$. Section 3.1 details the calibration of this key parameter. Sections 3.2 - 3.7 calibrate the remaining model parameters. Appendix B describes the data sources and reports additional details including all regression estimates. Complete data on FEMA aid and the other relevant variables is available from 2004-2018. Unless otherwise specified, all targets are computed as annual averages over the 2004-2018 time period. All monetary values are reported in 2018 dollars.

The ideal data to calibrate the model would include a comprehensive measure of adaptation capital, a meteorological measure of the occurrence and damage potential of storms, and direct, county-level damage estimates from the storms themselves. Unfortunately, such ideal data are not available. My goal instead is to exploit the data that is available to the best degree possible. When interpreting the results, the limitation imposed by the data availability should be kept 
in mind.

\subsection{Calibration of the effectiveness of adaptation, $\theta$}

The empirical literature cited in the introduction treats adaptation as a latent variable. It looks for evidence of adaptation from the relationship between the frequency of an extreme weather event and the associated damage per event. The intuition is that when agents more frequently experience extreme weather events, they face stronger incentives to invest in adaptation to reduce the damage. Hence, all else constant, the ability to adapt should result in a negative relationship between frequency and damage per event.

To calibrate the effectiveness of adaptation, $\theta$, I apply the intuition from the empirical literature to the probability that a household experiences a storm, $\gamma_{n}$, and the total disaster aid per household that experiences a storm. I use disaster aid instead of damage because there is no reliable county-level data on damage from severe storms in the US. ${ }^{15}$ Substituting disaster aid for damage is justifiable under two conditions. First, disaster aid must be positively correlated with damage, and second, the fraction of damage covered by disaster aid must be uncorrelated with damage. This second condition is important because if storms with higher damage systematically have a lower fraction of damage covered by disaster aid, then the data on disaster aid would understate the damage from the most damaging storms. The reverse argument holds if the storms with higher damage systematically have a higher fraction of damage covered by disaster aid.

While the absence of county-level damage data implies that I cannot empirically verify these conditions at the county level, I can instead verify them at the storm level. NOAA reports total damage estimates for almost all cyclones and for other large storms. The federal government reports county-storm-level data on disaster aid provided through FEMA, the main source of federal disaster aid following a storm (CBO, 2019). Regressing total FEMA aid from a storm on the storm damage reveals that FEMA aid is positively correlated with storm damage. Similarly, regressing the fraction of storm damage covered by FEMA aid on the total storm damage implies that the fraction of damage covered by FEMA aid is uncorrelated with storm damage. Hence, the empirical literature's insight to infer adaptation from the relationship between probability and damage should also apply to the relationship between probability and FEMA aid.

Importantly, the empirical literature estimates the relationship between damage per event and event frequency holding the severity of the event constant. However in the model, storm severity varies across the different regions. With zero adaptation, disaster aid per affected

\footnotetext{
${ }^{15}$ The Spatial Hazards and Losses Database for the United States (SHELDUS) reports county-level damage information for extreme weather events in the US. However, these data are not suitable for the calibration because they are severely incomplete. The primary source of the data are self-reports by individual weather stations and as a result, many observations are missing. Gallagher (2014) reports that only 8.6 percent of flood-related PDD events from 1960-2007 are included in SHELDUS and many of those events have no reported damage.
} 
household will be larger in the region with more severe storms because the storms in that region destroy a larger fraction of the capital stock. Hence, I can only infer adaption from the difference in disaster aid per affected household across regions, after accounting for the difference in storm severity.

To implement this calibration strategy, I first divide US counties into a low- and high-risk region based on the probability that a household experiences a storm. Second, I calculate relative aid, defined as the ratio of disaster aid per affected household in the high-risk region relative to the low-risk region. Third, I calculate relative severity, defined as the ratio of storm severity in the high-risk region relative to the low-risk region. Finally, given the storm probabilities in each region and the relative severity between regions, I choose $\theta$ (jointly with the other model parameters) so that the value of relative aid in the model matches that in the data.

Low- and high-risk regions. I divide US counties into the low- and high-risk region based on the annual probability that a household in the county experiences a storm (parameter $\gamma_{n}$ in the model). Following Gallagher (2014) and Wilson (2017), I use Presidential Disaster Declarations (PDDs) as a source for severe storms. A storm receives a PDD when the damage is so large that it is beyond state and local capabilities to address (FEMA, 2003). I define a county to have experienced a storm anytime it has a storm-related weather incident that receives a PDD. Storm-related weather includes all storms that involve high winds and heavy rain or flooding, such as tropical cyclones and tornadoes.

When a storm hits a county, not all households in the county necessarily experience damage from the storm. I measure the probability that a household experiences a storm in each county as the average annual fraction of households in the county that experience a storm. Federal aid programs provide one measure of the number of households affected by a storm. Households can apply for federal assistance to cover any uninsured damages through FEMA's Individuals and Households (IH) program. I measure the fraction of households affected by the storm as the fraction of eligible (e.g. uninsured) households that registered for IH aid. ${ }^{16}$ For example, if 100 households in a particular county apply for IH aid after a storm and 200 households in the county do not have insurance, then I assume that the storm affected half of all households in the county. Using the probability that a household in each county experiences a storm, I assign the counties to the low- and high-risk regions. The cutoff probability for the high-risk region is such that the US population is approximately equal across the two regions.

Figure 1 shows a map of US counties shaded according to their risk region. The highrisk counties are predominately located in coastal areas that are susceptible to hurricanes and tropical storms, and in the Midwest where severe storms are also common. GDP per capita is

\footnotetext{
${ }^{16}$ If data on $\mathrm{IH}$ program registrations are not available for a particular storm, I use the average fraction of households affected, where the average is taken over similar storms.
} 
similar across the low- and high-risk regions, equal to 63,274 in the low-risk region and 61,822 in the high-risk region in 2018. Approximately 50.0 percent of the 2018 US population lives in each region.

Figure 1: Map of US Counties By Risk Level

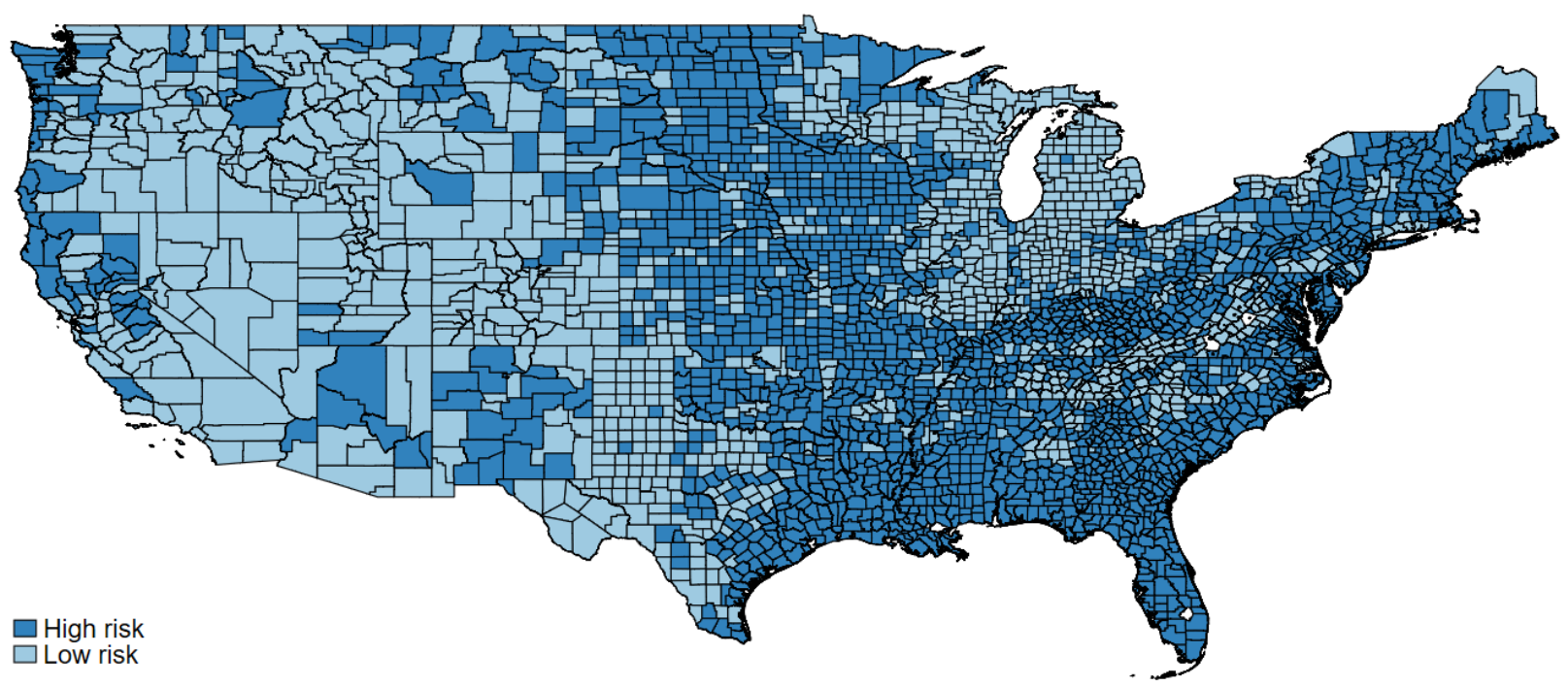

Note: This figure shades US counties according to their risk region. Low-risk counties are in light blue and high-risk counties are in dark blue.

One potential concern with using PDDs to indicate severe storms is that politics could affect the declaration of a presidential disaster (Davlasheridze et al. 2014; Garrett and Sobel 2007; Reeves 2011). However, for politics to affect the calibration, there would need to be systematic differences in the political power across the low- and high-risk region over the 2004-2018 time period. The location of the low- and high-risk counties in Figure 1 suggests that this is not the case. The high-risk counties are primarily in areas with a high meteorological risk of severe storms (e.g. the Gulf Coast) and in states that span the political spectrum from Texas on the right to New York on the left. Additionally, there was considerable political instability over the 2004-2018 time period with presidents and house and senate majority leaders from both parties, and substantial turnover on the congressional FEMA oversight committees (Davlasheridze et al., 2014). Such instability makes it difficult for any particular county to consistently receive political favors in the form of PDDs over this period. Furthermore, while large storms, such as hurricanes Katrina and Sandy, receive PDDs, many smaller storms that are less likely to be political targets also receive PDDs. On average, the federal government issues over 50 storm-related PDDs each year, which combined, cover more than one quarter of all US counties. Thus, from the perspective of the US as a whole, the typical PDD is simply part of the regular country weather patterns, and not an extremely rare, politically-motivated event. 
A second potential concern is that using PDDs to indicate severe storms could understate the true probability of a storm. In particular, a county with high adaptive capacity could be struck by a severe storm but experience relatively little damage, and thus not receive a PDD. The NOAA data on storm tracks provide a meteorological measure of which counties experience cyclones, allowing me to evaluate the magnitude of this downward bias for the case of cyclones. I find that 94 percent of counties that experienced a category one or higher cyclone over the 2004-2018 time period received a PDD. Thus, while using PDDs does slightly underestimate the true probability of a cyclone, it provides a close approximation to the true probability.

Relative aid. I first define relative aid in the stationary equilibrium of the model. Following the empirical cyclone literature's approach to damage (e.g., Nordhaus, 2010; Hsiang and Narita, 2012), I normalize aid in each region by the amount there is to destroy, in this case, the region's stock of productive capital (including both housing and non-housing capital). The intuition is that, all else equal, a storm will cause more damage, and thus result in more aid, if there is more to destroy. Average normalized aid per household hit by a storm in region $n$ equals:

$$
(A I D)_{n}=\frac{\frac{1}{\gamma_{n}}\left[\Lambda_{n}+\psi^{k y} \gamma_{n} \Omega_{n}^{y} \int F\left(a^{y^{\prime}}\right) k^{y p^{\prime}} d \mu_{g^{y} \mid n}^{y}+\psi^{k r} \gamma_{n} \Omega_{n}^{h} \int F\left(a^{r^{\prime}}\right) k^{r p^{\prime}} d \mu_{g^{r} \mid n}^{r}\right]}{\int h^{p^{\prime}} d \mu_{g^{h} \mid n}^{h}+\int k^{y p^{\prime}} d \mu_{g^{y} \mid n}^{y}+\int k^{r p^{\prime}} d \mu_{g^{r} \mid n}^{r}} .
$$

The numerator equals total aid per household hit by a storm, where by the law of large numbers, $\gamma_{n}$ is the number of households hit by a storm in region $n$. The denominator equals the total productive capital stock in region $n$. Relative aid in the model equals normalized aid per household hit by a storm in the high-risk region divided by the corresponding value in the low-risk region, $(A I D)_{2} /(A I D)_{1}$.

To measure relative aid in the data, I calculate disaster aid from FEMA per household affected by a storm for each county-storm pair. I compute relative aid from the data on FEMA aid, as opposed to all federal disaster aid, because it is the only data on federal aid reliably available at the county-storm level. FEMA primarily provides disaster aid through two programs: (1) the Individuals and Households $(\mathrm{IH})$ program provides aid to homeowners and renters and (2) the Public Assistance (PA) program provides aid to local governments, communities and non-profit organizations. Many PA grants are used to repair damaged public infrastructure, such as roads and utilities. In the model, I assume that final-good firms are responsible for all non-residential productive capital investment, including roads and utilities. Consistent with the model assumption, I allocate all non-housing related PA aid to the final-good firms. I allocate all housing-related PA aid to the rental-housing firms. The empirical value of FEMA aid per affected household for each county-storm pair equals the sum of all PA and IH aid for the county-storm pair divided by the number of affected households. 
I normalize FEMA aid per affected household by the county's GDP per capita, a proxy for the amount there is to destroy. Relative aid equals the average of normalized FEMA aid per affected household across all counties and storms in the high-risk region divided by the corresponding average in the low-risk region. The resulting ratio equals 1.16, implying that normalized aid per affected household is 16 percent larger in the high-risk region than in the low-risk region.

Relative severity. Unobserved adaptation makes it challenging to measure the empirical value of the relative severity of a storm between the high- and low-risk regions. Storm severity affects adaptation incentives, which in turn, impact the storm outcomes from which it would be most natural to measure relative severity, such as damage, disaster aid, etc. For example, a storm of a given severity could cause less damage in the high-risk region than in the low-risk region if the high-risk region has more adaptation capital, implying that one cannot infer the difference in the severity of a storm across regions from the difference in damage.

To ensure that unobserved adaptation does not confound the empirical value of relative severity, I measure the severity of a cyclone in each affected county using the cube of the cyclone's maximum sustained wind speed at the point that the storm strikes the county (Emanuel 2005, Strobl 2011). By construction, this meteorological severity measure depends only on the weather characteristics of the storm, and thus I can use it to compare the severity of cyclones across the low- and high-risk regions where quantities of adaptation capital could differ. Note that counties that experience a cyclone do not necessarily experience the storm at its maximum strength; rather they could be at any point along the storm's path. What differentiates cyclone storms from non-cyclone storms is that I have a meteorological measure of the severity of the cyclone at the point that it hits the county. I have no corresponding measure for non-cyclone storms.

To incorporate the severity of non-cyclone storms, I exploit within-county variation in the damage from cyclones compared to non-cyclones. This within-county comparison measures the severity of a non-cyclone compared to a cyclone, as long as the county's adaptation capital is the same for cyclones as it is for non-cyclones. For example, a drainage system reduces flood damage regardless of whether the flooding is caused by a cyclone or a non-cyclone storm. I use the data on disaster aid for homeowners from FEMA's IH program to measure the damage from cyclones relative to non-cyclones within each county. Consistent with the model assumptions, I view IH aid per homeowner that received aid as proportional to the damage that the homeowner experienced from the storm. ${ }^{17}$

\footnotetext{
${ }^{17}$ In principle, statutory limits on the minimum and maximum aid a homeowner can receive from FEMA could invalidate the proportionality assumption. However, in practice these limits rarely bind. The minimum aid requirement is very low, equal to 50 dollars (FEMA, 2019b); zero homeowners in the sample received aid less than 100 dollars. The maximum aid limit equals 34,900 (FR document 2018-22884), which is considerably larger the median value of disaster aid, approximately 4000 dollars. Less than two percent of all homeowners that received
} 
Since the calculation of relative severity uses the data on IH aid for homeowners, it implicitly measures the relative severity for households, $\Omega_{2}^{h} / \Omega_{1}^{h}$. The data on IH aid has the advantage that it provides a direct measure of the number of homeowners that received aid, allowing me to compare aid per homeowner-recipient across storm types. There is no corresponding measure of the number of firms or structures that received PA aid, making it difficult to directly compute relative severity for final-good firms. Instead, I assume that the relative severity is the same for households and final-good firms: $\Omega_{2} / \Omega_{1} \equiv \Omega_{2}^{h} / \Omega_{1}^{h}=\Omega_{2}^{y} / \Omega_{1}^{y}$.

The procedure to compute the empirical value of relative severity, $\Omega_{2} / \Omega_{1}$, is as follows. I divide the storms in the data into cyclones and non-cyclones. I normalize the severity from a non-cyclone storm in the low-risk region to unity. (I postpone the calibration of the actual levels of severity to later in the text.) I compute the severity for the remaining three categories. The first two rows of Table 3 report the severity in each category. I discuss how to compute each box in turn.

Table 3: Normalized Severity by Storm Type and Risk Region

\begin{tabular}{l|c|c|}
\multicolumn{1}{c}{} & \multicolumn{1}{c}{ Low risk } & \multicolumn{1}{c}{ High risk } \\
\cline { 2 - 3 } Non-cyclone & 1 & 2.03 \\
\cline { 2 - 3 } Cyclone & 1.44 & 2.09 \\
\cline { 2 - 3 } Weighted average & $\mathbf{1 . 0 3}$ & $\mathbf{2 . 0 5}$ \\
\cline { 2 - 3 } & &
\end{tabular}

Note: The first two rows report the average severity of non-cyclone and cyclone storms in the low-risk region (column 1) and in the high-risk region (column 2), conditional on setting the severity of a non-cyclone storm in the low-risk region to unity. The third row reports the average severity of a storm in the low-risk region (column 1) and in the high-risk region (column 2), again conditional on setting the severity of a non-cyclone storm in the low-risk region to unity.

To calculate the severity of a cyclone in the low-risk region, I analyze the subsample of low-risk counties that experienced both cyclones and non-cyclones. I compute average IH aid per homeowner-recipient for cyclones divided by the corresponding average for non-cyclones within each of these counties. Taking the average of this ratio across all low-risk counties in the subsample yields a value of 1.44, implying that cyclones that strike low-risk counties are 1.44 times as severe as non-cyclones. Hence, the severity of a cyclone in the low-risk region is $1 \times 1.44=1.44$ (second row, first column of Table 3 ).

To determine the severity of a cyclone in the high-risk region, I use NOAA data on cyclone storm tracks to calculate the maximum sustained wind speed for every county-cyclone pair. The cube of the average maximum sustained wind speed for county-cyclones in the high-risk

IH aid received the maximum grant. Even for large storms, relatively few homeowners received the maximum grant. For example, less than five percent of homeowners that received aid following Hurricanes Katrina or Sandy received the maximum grant. 
region divided by the corresponding value in the low-risk region equals 1.45 , implying that the a cyclone that strikes a high-risk county is 45 percent more severe than one that strikes a low-risk county. Thus, the severity of a cyclone in the high-risk region is $1.45 \times 1.44=2.09$ (second row, second column of Table 3).

I compute the severity of a non-cyclone in the high-risk region based on the severity of a cyclone in the high-risk region and the within-county differences in $\mathrm{IH}$ aid per homeownerrecipient for cyclones compared to non-cyclones in the high-risk region. Using the same process as in the low-risk region, I find that cyclones are approximately 3 percent more severe than non-cyclones in the high-risk region. This result implies that the severity of a non-cyclone in the high-risk region is 2.09/1.03 $=2.03$ (first row, right column of Table 3).

Finally, the severity of the average storm in each region (third row of Table 3), equals the weighted average of the severity values for the cyclones and non-cyclones, with the weights given by the region-specific fractions of cyclones and non-cyclones. Approximately 8 percent of storms in the low-risk region are cyclones and 30 percent of storms in the high-risk region are cyclones, yielding the weighted averages of 1.03 and 2.05 in the low- and high-risk regions, respectively. Thus, the average storm in the high-risk region is $2.05 / 1.03=1.98$ times as severe as in the low-risk region, resulting in the relative severity target, $\Omega_{2} / \Omega_{1}=1.98$.

Calibration of $\theta$. The difference between the relative aid and the relative severity is indicative of the effectiveness of adaptation and thus pins down $\theta$. The above discussion implies that storms in high-risk counties are on average 1.98 times as severe as those in low-risk counties, but they only receive 16 percent more aid per affected household. The value of $\theta$ that allows the model to match this variation (jointly with the other parameters and moments) is 3.78 (see Table 2).

\subsection{Federal policy}

I choose the fractions of damage covered by disaster aid, $\psi^{h o}, \psi^{h r}, \psi^{k y}$, and $\psi^{k r}$, to match four targets: (1)-(3) federal disaster aid to homeowners, renters, and final-good firms as fractions of total federal disaster aid and (4) total federal disaster aid as a fraction of total storm damage. To measure total federal disaster aid, I adjust the level of FEMA aid to account for other sources of federal assistance. CBO (2019) reports federal disaster aid from sources other than FEMA for a subset of storms from 2004-2016. Using this data, I calculate that on average, FEMA provides 73 percent of federal disaster aid to households (homeowners and renters), 76 percent of aid to final-good firms, and 52 percent of aid to rental-housing firms. The remaining aid is supplied by other agencies, such as the Department of Housing and Urban Development and the Department of Transportation. I inflate IH aid to homeowners and to renters by $1 / 0.73$, PA aid to final-good firms by $1 / 0.76$, and PA aid to rental-housing firms by $1 / 0.52$ to compute 
federal disaster aid for each group.

The calculated targets imply that 17 percent of federal disaster aid is provided to homeowners, 3 percent is provided to renters, and 79 percent is provided to final-good firms. (The remaining 1 percent is provided to rental-housing firms.) I calculate the ratio of total federal disaster aid to total storm damage for the storms with NOAA damage estimates. Averaging across storms yields a calibration target of 0.17 , implying that federal aid covers 17 percent of the damage from a storm.

I calibrate the adaptation subsidy using data on federal funding for adaptation investment. The two major sources of federal adaptation funding are the Hazard Mitigation Assistance program, administered by FEMA, and the US Army Corps of Engineers. I include expenditures from these two programs that fund capital to reduce damage from storms. I choose the size of the subsidy, $\eta$, to target average annual subsidy expenditures relative to output, equal to 1.0e-4. Subsidy parameter $\eta=0.09$ matches this target, implying that the federal government finances approximately 8 percent of adaptation investment.

\subsection{Storm probability and severity}

I set the probability parameters $\gamma_{1}$ and $\gamma_{2}$ equal to the average probability of a storm in the low- and high-risk regions, 0.002 and 0.022 respectively (calculated in Section 3.1). I choose the levels of storm severity for housing capital, $\Omega_{1}^{h}$ and $\Omega_{2}^{h}$, and final-good capital, $\Omega_{1}^{y}$ and $\Omega_{2}^{y}$, in each region to match four targets: (1) the ratio of federal disaster aid to output, (2) the fraction of total storm damage that occurs in the residential sector, and (3)-(4) the requirements that relative severities for final-good and rental-housing capital equal the estimate from Section 3.1: $\Omega_{2}^{y} / \Omega_{1}^{y}=\Omega_{2}^{h} / \Omega_{1}^{h}=\Omega_{2} / \Omega_{1}=1.98$.

CBO (2019) estimates that storms cause $\$ 34$ billion in damage to the residential sector, $\$ 9$ billion in damage to the commercial sector, and $\$ 12$ billion in damage to the public sector. However, the industries included in the commercial sector in the CBO study only account for approximately one quarter of private, non-residential fixed assets. Scaling up the commercial sector damages to account for the remaining three-quarters of private non-residential fixed assets implies that damage to the residential sector is 43 percent of total storm damage.

Referring to the first four rows of Table 2, the calibrated value of the storm severity for housing capital is larger than for final-good capital in each region, implying that, all else constant, a storm destroys a larger fraction of housing than final-good capital. This difference could be driven by the different locations of industrial and residential neighborhoods within a county. For example, residential neighborhoods could be more likely to locate in areas that are pretty but also with higher potential for storm damage, such as along the coast.

The relatively small values of storm probability and the relatively large values of storm 
severity in the calibrated model imply that the storm shocks are similar to "rare disasters" (Barro, 2006) or "catastrophes" (Pindyck and Wang, 2013) for an individual household or firm. However, while a storm could constitute a rare disaster for a household or firm, they are not rare or disastrous for the aggregate economy. For example, tornadoes occur almost every year in the Midwest and each tornado creates damage that is far less than one percent of US GDP. For the US economy as a whole, these storms are part of the regular weather patterns, as opposed to very rare and destructive macro events (like the Great Depression or a pandemic), studied in the literature on rare disasters and catastrophes.

\subsection{Insurance}

Parameter $\lambda$ is the unit cost of disbursing an insurance claim. Using data from the Insurance Information Institute, I calculate that the average annual value of insured losses divided by total damages for thunderstorms, floods, and cyclones from 2014-2018 (the time period over which the relevant data are available) equals 0.569 . This target applies to all storm damage. However, homeowners are the only agents in the model that can purchase insurance for their capital; renters do not own any risky capital and firms are risk neutral, implying that they would only purchase insurance in the model if it is priced below the actuarially fair value. Assuming that the empirical ratio of insured losses to damage for the aggregate economy is the same as the empirical ratio for just homeowners, I choose $\lambda$ so that the ratio of insured losses to homeowners divided by total damage to homeowners equals 0.569 . Consistent with this target, $\mathrm{CBO}$ (2019) finds that approximately 50 percent of storm damage to the residential sector is covered by insurance.

\subsection{Final-good production}

I set productive capital's income share in the production of the final good, $\alpha$, equal to 0.26 (Kiyotaki et al., 2011; Nakajima, forthcoming). This value is lower than the typical value of capital share in a single-asset model (between 0.3 and 0.4 ) because final-good production excludes the capital-intensive housing sector. I set the depreciation rates on final-good capital, $\delta^{y}$, housing capital, $\delta^{h}$, and adaptation capital, $\delta^{a}$, equal to the average depreciation rates for non-residential fixed assets, residential fixed assets, and structures (NIPA Tables 1.1 and 1.3), respectively. I use the depreciation rate for structures for adaptation capital since most adaptation capital is part of a building or structure (e.g., stilts, seawalls, etc.). I normalize total factor productivity in the production of the final good, $A^{y}$, to unity. I choose total factor productivity in the production of housing services, $A^{h}$, to equal the ratio of housing services divided by residential capital (NIPA Tables 2.3.5 and 1.1). 
Table 4: Targeted Moments

\begin{tabular}{lcc}
\hline \hline Moment & Model value & Empirical value \\
\hline Relative aid & 1.16 & 1.16 \\
Relative severity & 1.98 & 1.98 \\
(Disaster aid)/GDP & $5.8 \mathrm{e}-04$ & $5.8 \mathrm{e}-04$ \\
(Adaptation subsidy)/GDP & $1.0 \mathrm{e}-04$ & $1.0 \mathrm{e}-04$ \\
(Aid to homeowners)/(total disaster aid) & 0.17 & 0.17 \\
(Aid to renters)/(total disaster aid) & 0.03 & 0.03 \\
(Aid to final-good firms)/(total disaster aid) & 0.79 & 0.79 \\
(Disaster aid)/(storm damage) & 0.17 & 0.17 \\
(Damaged housing capital)/(damaged capital) & 0.43 & 0.43 \\
(Insurance claims)/(owner-occupied housing damage) & 0.57 & 0.57 \\
(Residential assets)/(non-residential assets) & 0.88 & 0.88 \\
(Owner-occupied housing)/(total housing) & 0.78 & 0.78 \\
(Avg. income homeowners)/(avg. income renters) & 1.5 & 1.5 \\
Homeowner fraction & 0.67 & 0.67 \\
(Net wealth)/GDP & 3.1 & 3.1 \\
\hline
\end{tabular}

Note: This table reports the values of the targeted moments in the model and the data. The main text and Appendix B provide a detailed description of the construction each target in the model and in the data.

\subsection{Mutual fund}

I set the exogenous interest rate on international bonds, $r^{\star}$, equal to 4 percent.

\subsection{Preferences and housing}

The coefficient of relative risk aversion equals 2 . I choose the exponent on non-durable consumption in the composite of non-durable consumption and housing services, $\zeta$, to match the ratio of private residential assets to non-residential assets, 0.88 (NIPA Table 1.1). I determine the discount rate, $\beta$, to match the average ratio of US net wealth to output, 3.1, where net wealth equals the sum of fixed assets, consumer durables and net foreign assets (NIPA Tables 1.1, 1.1.5, BEA International Data Table 1.1.). I pin down the preference-discount for rental housing, $\bar{\phi}^{r}$, the minimum owner-occupied house size, $\underline{h}^{p}$, and the fraction of households with a preference for homeownership, $\chi$, to match the fraction of the population living in owneroccupied housing, 0.67 , the fraction of residential assets that are owner-occupied, 0.78 (NIPA Table 5.1), and the ratio of mean homeowner income relative to mean renter income, 1.5 (CPS Table PINC-01). Finally, I set the preference discount for owner-occupied housing, $\bar{\phi}^{o}$, equal to any positive value less than one. As long as $\bar{\phi}^{o} \in(0,1)$, all households with $\phi_{i}^{o}=\bar{\phi}_{o}$ will choose to rent, implying that the exact value of $\bar{\phi}^{o}$ has no impact on the model's results. 


\subsection{Labor productivity process}

The persistent component of labor productivity process, $v_{i t}$, follows an AR(1) process of the form:

$$
v_{i, t}=\rho v_{i, t-1}+\varepsilon_{i t} \text {, with } \varepsilon_{i, t} \sim N\left(0, \sigma_{\varepsilon}^{2}\right)
$$

where parameter $\rho$ denotes the persistence and $\varepsilon_{i t}$ is a white noise process with variance $\sigma_{\varepsilon}^{2}$. I take the values for $\rho, \sigma_{\varepsilon}^{2}$, and the variance of household-specific fixed effect, $\sigma_{\xi}^{2}$, from Kaplan (2012). I use the Rouwenhorst method to approximate the AR(1) process in equation (18) with a five-state Markov chain. Kopecky and Suen (2010) show that this method is well-suited for discretizing a highly persistent process with a small number of states. Appendix B reports the Markov transition matrix, $\pi$, and the invariant distribution, $\Pi$.

Table 4 reports the empirical and model values of the moments. The model matches the empirical targets quite closely.

\section{External validation}

I take three approaches to validate the calibration: (1) I compare the elasticity of damage with respect to the probability of a storm in the model with empirical estimates from the literature, (2) I compare the elasticity of disaster aid with respect to the probability of a storm in the model with empirical estimates from the disaggregated data on FEMA aid, and (3) I analyze the model's performance on several moments that I do not target in the calibration. Appendix $\mathrm{C}$ provides additional details on the data sources and formally defines the aid- and damage-probability elasticities in the model.

I compare the empirical and model estimates of the elasticity of damage with respect to the probability of a storm. On the empirical side, Bakkensen and Mendelsohn (2016) use annual country-level data on tropical cyclones to estimate the elasticity of property damage with respect to a country's long-run frequency of high-intensity cyclones. Their estimated damage-probability elasticity equals $-0.19 .{ }^{18}$ Their regression estimates measure the effect of a marginal change in the probability of a storm, holding constant the severity of the storm and other country-level aggregates. To compute the analog of these estimates in the model, I resolve the model with slightly higher storm probabilities in each region. Comparing the baseline

\footnotetext{
${ }^{18}$ Using similar data, Hsiang and Narita (2012) estimate the partial elasticity of property damage with respect to the country's long-run cyclone exposure. Evaluating the partial elasticity at the US value of cyclone exposure yields an elasticity between -0.16 and -0.2 , depending on the specification. Hsiang and Narita (2012) measure cyclone exposure as the average annual maximum sustained wind speed. However, it is not clear whether this measure corresponds to the probability or the severity of a storm, or both, making it difficult to compare with the damage-probability elasticity in the model.
} 
and higher-probability specifications in each region captures the effect of a marginal change in storm probability holding storm severity constant, analogous to the empirical regression. I normalize damage in each model region by the region's GDP to control for differences in GDP between the baseline and higher-probability specifications. The resulting damage-probability elasticity in the model, equal to the average of the damage-probability elasticity from each region, is -0.167 , similar to the empirical estimate of -0.19 .

For the second validation exercise, I use county-level data on FEMA aid to estimate the elasticity of disaster aid with respect to the probability of a storm. I compare the resulting empirical estimate with the aid-probability elasticity implied by the model. The data for this validation exercise are the same as the data used in the calibration, however the source of the variation is different. The calibration is based on regional averages, while the regression estimate exploits county-level variation. The goal of the exercise is to understand whether the model value of the aid-probability elasticity, informed by mean differences across regions, is consistent with the empirical value of the aid-probability elasticity, informed by differences on the finest observable level, counties.

I estimate the aid-probability elasticity by running the following regression for each cyclone $i$ in county $j$ in state $k$ :

$$
\log \left(\frac{\text { FEMA Aid }}{\text { Affected households }}\right)_{i j k}=\beta_{0}+\beta_{1} \log \left(\operatorname{prob}_{j k}\right)+\alpha \mathbf{X}_{i j k}+\delta_{i}+\theta_{k}+\varepsilon_{i j k},
$$

where the dependent variable is the log of total FEMA aid for cyclone $i$ in county $j$ divided by the number of households affected by the storm. I determine the number of households affected by the storm based on the number of households in the county and the fraction of eligible households that apply for $\mathrm{IH}$ aid, as described in Section 3.1. Variable prob $_{j k}$ is the probability that a household experiences a storm in county $j$, calculated according to Section 3.1. Variable $\mathbf{X}$ denotes a vector of control variables, which includes the maximum wind speed, county GDP and population, and the fraction of households with flood insurance coverage. Variables $\delta_{i}$ and $\theta_{k}$ denote storm and state fixed effects, respectively. I focus exclusively on cyclones because they are the only storm for which I have a direct measure of severity: the maximum sustained wind speed. Table 5 reports the coefficient estimates with standard errors, clustered at the county level, in parentheses. The coefficient of interest, $\beta_{1}$, measures the elasticity of FEMA aid per affected household with respect to the probability of a storm. The estimated elasticity is -0.17 , implying that a one percent increase in the probability of a storm leads to a 0.17 percent decrease in FEMA aid per affected household.

As with the damage-probability elasticity, to compute the aid-probability elasticity in the model, I re-solve the model with slightly higher values of the storm probability in each region. 
The dependent variable in the regression (equation (19)), FEMA aid per affected household, corresponds to disaster aid in the model divided by number of affected households. Again, to control for differences in GDP across regions, I normalize disaster aid per affected household by GDP in each model region. The resulting aid-probability elasticity in the model, equal to the average of the aid-probability elasticity from each region, is -0.187 , similar to the empirical estimate of -0.17 .

Table 5: Regression Estimates: Elasticity of Aid With Respect to the Probability of a Storm

\begin{tabular}{lc}
\hline \hline Coefficient & Estimate \\
\hline Probability: $\beta_{1}$ & -0.17 \\
& $(0.041)$ \\
Maximum sustained wind speed: $\alpha_{0}$ & 0.017 \\
& $(0.0018)$ \\
GDP: $\alpha_{1}$ & $8.07 e-12$ \\
& $(1.22 e-12)$ \\
Population: $\alpha_{2}$ & $-1.04 e-6$ \\
& $(1.1 e-7)$ \\
Fraction of HHs with flood insurance: $\alpha_{3}$ & -0.59 \\
& $(0.42)$ \\
Constant: $\beta_{0}$ & 7.43 \\
\hline R-square & $(0.36)$ \\
Number of observations & 0.59 \\
\hline
\end{tabular}

Note: This table reports the coefficient estimates from the regression in equation (19). Standard errors, clustered at the county-level, are in parentheses.

The coefficient estimates on the control variables in Table 5 all have the expected signs, providing additional verification of some of the calibration assumptions. Increases in the maximum sustained wind speed increase FEMA aid per affected household, implying that storm severity and wind speed are positively correlated, as assumed in the calibration. Increases in GDP also increase FEMA aid per affected household, consistent with the notion that GDP proxies for the amount that could be destroyed. Working in the other direction, population is negatively correlated with FEMA aid per affected household. With GDP held constant, an increase in population does not directly increase damage, but it does increase the number of affected households, causing FEMA aid per affected household to fall. Lastly, although not statistically significant, the fraction of households with flood insurance coverage is negatively correlated with FEMA aid per affected household. This result is in line with the US policy 
that FEMA aid cannot duplicate insurance payments, as assumed in both the model and the calibration.

In the final validation exercise, I evaluate the model's performance on several moments that I do not target in the calibration. First, I compare the ratio of GDP between the lowand high-risk regions in the model with the corresponding ratio in the data. In the model, the only fundamental differences between the regions are the probability and the severity of storms. Since the high-risk region experiences more frequent and more severe storms, the model predicts that GDP per capita in the high-risk region is 0.5 percent smaller than in the lowrisk region. This prediction holds empirically as well, although the magnitude of the difference is slightly larger; in the data, GDP per capita is 2.3 percent lower in the high-risk region.

Second, I evaluate the model's fit with regards to the income and wealth distributions. The model matches coarse measures of the income and wealth distributions relatively well. For example, the model predicts that 77 percent of income and 92 percent of wealth is held by the top 40 percent, compared to 75 percent and 97 percent respectively in the data. Appendix C further disaggregates these statistics and reports the shares of income and wealth held by each quintile of the distribution in the model and the data. At this finer level of aggregation, the model continues to match the income distribution relatively well, but, as is common in this class of models, it struggles to match the high concentrations of wealth at the top of the wealth distribution. ${ }^{19}$ The model's quantitative results reveal that adaptive capacity is relatively constant across the wealth quintiles, suggesting that missing the top of the wealth distribution is not likely critical for quantifying adaptation incentives.

\section{Results}

I use the calibrated model to quantify the level and distribution of adaptation capital in the current US economy. I run three counterfactual experiments. In the first experiment, I quantify the moral hazard effects of disaster aid and the ability of the subsidy to correct the moral hazard. In the second experiment, I analyze the potential for adaptation to reduce the damage and welfare cost of climate change. The third experiment highlights the importance of modeling the idiosyncratic risk component of climate damage for understanding adaptation incentives and the welfare costs of climate change.

\subsection{Quantifying adaptation}

Table 6 reports the values of adaptation capital, storm damage, insurance claims, and federal disaster spending, measured as percents of the relevant variables, in the low- and high-risk

\footnotetext{
${ }^{19}$ Quadrini and Ríos-Ruel (1997) document that heterogeneous-agent versions of standard neoclassical growth models with uninsurable earnings shocks often have trouble matching the tails of the income and wealth distributions.
} 
regions as well as in the aggregate economy. Total capital equals all capital in the economy, including adaptive and productive owner-occupied housing capital, rental housing capital, and final-good capital. Similarly, adaptation capital equals the sum of adaptation capital used to protect owner-occupied housing, rental housing, and the final good.

Table 6: Macro-Aggregates: Baseline

\begin{tabular}{|c|c|c|c|}
\hline & $\begin{array}{l}\text { Low-risk } \\
\text { region }\end{array}$ & $\begin{array}{l}\text { High-risk } \\
\text { region }\end{array}$ & Aggregate \\
\hline $\begin{array}{l}\text { Adaptation capital } \\
\text { (percent of total capital) }\end{array}$ & 0.59 & 1.76 & 1.17 \\
\hline $\begin{array}{l}\text { Damaged capital } \\
\text { (percent of total capital) }\end{array}$ & 0.01 & 0.18 & 0.09 \\
\hline $\begin{array}{l}\text { Damage } \\
\text { (percent of output) }\end{array}$ & 0.07 & 0.79 & 0.42 \\
\hline $\begin{array}{l}\text { Insurance claims } \\
\text { (percent of damaged owner-occupied housing capital) }\end{array}$ & 52.6 & 61.3 & 56.9 \\
\hline $\begin{array}{l}\text { Disaster aid + subsidy } \\
\text { (percent of model tax payments) }\end{array}$ & 23.1 & 205.1 & 100.0 \\
\hline
\end{tabular}

Note: This table reports the values of adaptation capital, storm damage, insurance claims, and federal disaster spending, measured as percents of the relevant variables, in the low- and high-risk regions and in the aggregate economy. Total capital equals all capital in the economy, including residential and non-residential capital. Adaptation capital equals the sum of all residential and non-residential adaptation capital. Total damage includes the destroyed capital plus the values of the forgone output and the forgone housing services.

Beginning with the first row of Table 6, adaptation capital is larger in the high-risk region (where it equals 1.76 percent of the total capital stock) than in the low-risk region (where it equals 0.59 percent of the capital stock). The expected benefit from investing in adaptation capital is primarily determined by the probability and the severity of a storm (see equations (13) - (16)). Storms are more frequent and more severe in the high-risk region, creating stronger incentives to invest in adaptation. In the aggregate US economy, adaptation capital equals 1.17 percent of the total capital stock. The replacement value of the US capital stock in 2018 is approximately $\$ 68.4$ trillion (NPIA Table 1.1), implying that the replacement value of adaptation capital is approximately $\$ 800$ billion.

Relative to the total capital stock, the level of adaptation capital in the economy appears small. However, the denominator of the total capital stock can understate its importance. In the aggregate economy, storms destroy 0.09 percent of the capital stock each year (second row of Table 6). Thus, adaptation capital is over ten times the amount of capital destroyed by storms (1.17 percent of the capital stock compared to 0.09 percent).

The total damage from storms (third row of Table 6) includes the destroyed housing and final-good capital as well as the values of the forgone output and the forgone owner-occupied 
and rental housing services. Damage (measured as a percent of output) is considerably larger in the high-risk region than in the low-risk region, even though the households and firms in the high-risk region invest in more adaptation capital. In the aggregate economy, the results imply that storms cause damage equal to 0.42 percent of US output each year.

The fourth row of Table 6 reports the percent of damaged owner-occupied housing capital covered by insurance claims. Insurance claims are 56.9 percent of damage in the aggregate economy, the calibration target. Households in the high-risk region insure a larger fraction of their damage than households in the low-risk region (61.3 percent compared to 52.6 percent). Storms are more severe in the high-risk region, implying that the marginal utility cost of a storm is larger for households in the high-risk region, leading them to purchase more insurance.

Federal disaster policy leads to substantial transfers from the low- to high-risk region. The last row of Table 6 reports receipts of disaster aid and the adaptation subsidy, as a percentage of the region's tax payments. Households in the low-risk region only receive 23.1 percent of their tax payments in disaster aid and subsidies. In contrast, households in the high-risk region receive 205.1 percent.

Table 7: Adaptive Capacity

\begin{tabular}{lccc}
\hline \hline & $\begin{array}{c}\text { Low-risk } \\
\text { region }\end{array}$ & $\begin{array}{c}\text { High-risk } \\
\text { region }\end{array}$ & Aggregate \\
\hline Homeowners: $h^{a} / h^{p}$ & $1.5 \mathrm{e}-02$ & $3.7 \mathrm{e}-02$ & $2.6 \mathrm{e}-02$ \\
Rental-housing firms: $k^{r a} / k^{r p}$ & $4.3 \mathrm{e}-04$ & $1.1 \mathrm{e}-02$ & $5.7 \mathrm{e}-03$ \\
Final-good firms: $k^{y a} / k^{y p}$ & $2.2 \mathrm{e}-04$ & $6.1 \mathrm{e}-03$ & $3.2 \mathrm{e}-03$ \\
\hline
\end{tabular}

Note: This table reports average adaptive capacity among homeowners, rental-housing firms, and final-good firms, in the low-risk region (column 1), the high-risk region (column 2), and the aggregate economy (column $3)$.

While Table 6 reports the aggregate levels of adaptation capital, there is considerable variation in adaptation capital across homeowners, rental-housing firms, and final-good firms. Table 7 reports the average value of adaptive capacity for each of these groups in the low- and highrisk regions and in the aggregate economy. Adaptive capacity is substantially higher among homeowners (first row of Table 7) than among firms (second and third rows of Table 7). Unlike firms, homeowners are risk averse. Thus, they value adaptation capital not only because it reduces storm damage, but also because it reduces the variance in the realized levels of housing services and cash at hand. Adaptive capacity is larger for rental-housing firms than for finalgood firms because housing capital is more prone to storm damage than non-housing capital, $\Omega_{n}^{h}>\Omega_{n}^{y}$. 
Recall that homeowners can decrease the utility cost of a storm by investing in adaptation capital, which reduces the storm damage, and by purchasing insurance, which reduces the welfare cost of storm risk. How much a homeowner relies on each option partially depends on her wealth. To understand how wealth heterogeneity impacts adaptation and insurance decisions, I divide all households (including homeowners and renters) into wealth quintiles based on the total value of their housing and financial wealth at the start of the period, before the realization of the storm shock. Quintile one corresponds to the poorest households and quintile five corresponds to the richest.

Table 8: Homeowner Adaptive Capacity and Insurance By Wealth Quintile

\begin{tabular}{lccccc}
\hline \hline & \multicolumn{5}{c}{ Quintile } \\
\cline { 2 - 6 } & 1 & 2 & 3 & 4 & 5 \\
\hline $\begin{array}{l}\text { Insurance claims } \\
\text { (percent of damaged housing capital) }\end{array}$ & 80.9 & 67.1 & 55.0 & 49.8 & 46.1 \\
$\begin{array}{l}\text { Adaptive capacity: all homeowners } \\
\text { Adaptive capacity: } h^{p}=\underline{h}^{p}\end{array}$ & 0.024 & 0.023 & 0.025 & 0.027 & 0.028 \\
\hline
\end{tabular}

Note: For each wealth quintile, this table reports average insurance claims as a percent of damaged housing capital (first row), average adaptive capacity among all homeowners (second row), and average adaptive capacity among homeowners for whom the minimum house size constraint binds (third row). Quintile one denotes the lowest wealth households and quintile five denotes the highest wealth households.

The first row of Table 8 reports insurance claims as a percent of damaged housing capital averaged across homeowners in each wealth quintile. Insurance claims decrease substantially with wealth, equal to 80.9 percent in the first quintile, but only 46.1 percent in the fifth quintile. The intuition stems from the fact that poorer households are in a steeper region of their utility functions. As a result, storms generate a larger increase in marginal utility for poor households, raising the expected benefits from insurance relative to their richer counterparts.

The second row of Table 8 reports adaptive capacity $\left(a^{h} \equiv h^{a} / h^{p}\right)$ averaged across homeowners in each wealth quintile. Adaptive capacity is relatively constant across the different wealth quintiles as a result of two offsetting forces. Working in one direction, housing services are a normal good. A higher level of adaptive capacity enables the homeowner to consume more housing services when she is hit by a storm, implying that adaptive capacity increases with wealth. The insurance mechanism described above works in the opposite direction. The larger marginal utility cost of a storm for poorer homeowners creates stronger incentives for adaptation, implying that adaptive capacity decreases with wealth.

Finally, the third row of Table 8 reports adaptive capacity among the subgroup of homeowners for whom the minimum house size constraint binds. In every quintile, adaptive capacity 
for this subgroup is smaller than for the average homeowner in the quintile, with the largest proportional differences in the lower wealth quintiles.The intuition is that these homeowners are just barely able to afford to own a house. To meet the minimum house size constraint, they shift resources away from adaptation capital to productive capital, leaving them more exposed to damage from storms.

In sum, the variation in adaptive capacity among renters and homeowners has interesting implications for the distribution of housing capital destroyed by a storm. Rental-housing firms have substantially lower adaptive capacity than homeowners, implying that renters experience the largest percentage decrease in housing services from a storm. Among homeowners, the homeowners for whom the minimum house size constraint binds have the lowest adaptive capacity, and thus the largest percentage loss in housing services following a storm.

\subsection{Federal disaster policy}

Federal aid for disaster relief decreases the damage households and firms experience from a storm, reducing their incentives to invest in adaptation capital. Federal subsidies for adaptation mitigate this moral hazard by increasing households' and firms' incentives to invest in adaptation capital. To quantify these effects of federal policy, I solve for an "aid-only" and for a "no-policy" counterfactual stationary equilibrium. In the aid-only equilibrium, I set the adaptation subsidy equal to zero $(\eta=0)$, and in the no-policy equilibrium, I set both the disaster aid and the adaptation subsidy equal to zero $(\psi=\eta=0)$. Table 9 reports adaptation capital, damage and insurance claims, measured again as percents of the relevant variable, in both counterfactual equilibria and in the baseline.

Beginning from the counterfactual equilibrium with no federal policy, the provision of disaster aid alone reduces adaptation capital by 5 percent, from 1.14 percent of the capital stock in the no-policy equilibrium to 1.09 percent of the capital stock in the aid-only equilibrium (first row of Table 9). The decrease in adaptation implies that the provision of disaster aid increases storm damage from 0.42 percent of output in the no-policy equilibrium to 0.43 percent of output in the aid-only equilibrium. To put these moral hazard effects in perspective, storm-related disaster aid from FEMA averages $\$ 7.7$ billion per year over the 2004-2018 period. Scaling the model results by US GDP each year from 2004-2018 implies that the damage from storms is on average $\$ 3.2$ billion higher per year as a result of the moral hazard from the disaster aid. This increase in damage from moral hazard is approximately 40 percent of FEMA aid each year, suggesting large moral hazard consequences from disaster aid.

The federal subsidy for adaptation is designed to mitigate the moral hazard effects of disaster aid by reducing the relative price of adaptation investment. Indeed, the addition of the subsidy increases adaptation capital from 1.09 percent of the productive capital stock in the 
aid-only equilibrium to 1.17 percent of the capital stock in the baseline (first row of Table 9). Furthermore, the value of adaptation capital in the baseline exceeds its value in the no-policy equilibrium (1.17 percent of the capital stock compared to 1.14 percent). Thus, the adaptation subsidy more than offsets the moral hazard effects of disaster aid, implying that the net effect of federal disaster policy is to increase adaptation capital in the US economy.

Table 9: Effects of Federal Policy on Adaptation, Storm Damage, and Insurance

\begin{tabular}{lccc}
\hline \hline & $\begin{array}{c}\text { No policy } \\
(\psi=\eta=0)\end{array}$ & $\begin{array}{c}\text { Disaster aid only } \\
(\psi>0, \eta=0)\end{array}$ & $\begin{array}{c}\text { Baseline } \\
(\psi>0, \eta>0)\end{array}$ \\
\hline $\begin{array}{l}\text { Adaptation capital } \\
\text { (percent of total capital) } \\
\begin{array}{l}\text { Damage } \\
\text { (percent of output) }\end{array}\end{array}$ & 1.14 & 1.09 & 1.17 \\
$\begin{array}{l}\text { Insurance claims } \\
\text { (percent of damaged owner- }\end{array}$ & 6.42 & 0.43 & 0.42 \\
occupied housing capital) & 67.5 & 57.6 & 56.9 \\
\hline
\end{tabular}

Note: This table reports adaptation capital, damage, and insurances claims, measured as percents of the relevant variable, in the counterfactual equilibrium with no disaster policy (column 1), in the counterfactual equilibrium with no adaptation subsidy (column 2) and in the baseline economy with both components of federal disaster policy (column 3).

The third row of Table 9 reports insurance claims, measured as a percent of damaged owneroccupied housing capital. Insurance claims in the aid-only equilibrium are slightly larger than in the baseline (57.6 percent compared to 56.9 percent) because the removal of the subsidy increases the price of adaptive capacity relative to insurance, causing homeowners to substitute some insurance for adaptation. The removal of disaster aid leads to a much larger increase in insurance claims; insurance claims equal 67.5 percent of damage in the no-policy equilibrium compared to 57.6 percent of damage in the aid-only equilibrium. Eliminating disaster aid increases the household's exposure to risk by increasing the variance in the realized value of cash at hand. The household's optimal response to the increase in risk is to purchase additional insurance.

I next quantify how federal disaster policy affects welfare in the low- and high-risk regions and in the aggregate economy. I measure the welfare effects using the consumption equivalent variation $(\mathrm{CEV})$. The $\mathrm{CEV}$ is the percent increase in non-durable consumption, $c$, that a household would need in the counterfactual equilibrium with no federal disaster policy so that it is indifferent between the no-policy equilibrium and either the aid-only equilibrium or the baseline equilibrium. A positive value of the aid-only CEV indicates that disaster aid without the adaptation subsidy makes households better off. Similarly, a positive value of the baseline 
CEV indicates that the combination of disaster aid and adaptation subsidies makes households better off.

Table 10: Welfare Effects of Federal Disaster Policy: CEV (percent)

\begin{tabular}{lccc}
\hline \hline & $\begin{array}{c}\text { Low-risk } \\
\text { region }\end{array}$ & $\begin{array}{c}\text { High-risk } \\
\text { region }\end{array}$ & Aggregate \\
\hline Aid only $(\psi>0, \eta=0)$ & -0.09 & 0.07 & -0.008 \\
Baseline $(\psi>0, \eta>0)$ & -0.11 & 0.09 & -0.005 \\
\hline
\end{tabular}

Note: This table reports the consumption equivalent variation measured from the counterfactual equilibrium with no federal disaster policy, for the aid-only (first row) and baseline (second row) equilibria. Negative values indicate that the disaster policy makes households worse off.

Table 10 reports the CEV in each region and in the aggregate economy. The welfare effects of federal disaster policy for the aggregate economy are essentially zero (second row, third column of Table 10). ${ }^{20}$ However, the model does not take a stand on why government intervention through disaster aid and adaptation subsidies is necessary. There are no large inefficiencies in the model that such an intervention is designed to correct, and hence it seems reasonable that the welfare effects in the model are near zero. Federal disaster policy has non-zero and opposite welfare implications in each region; the CEV is positive in the high-risk region, implying welfare gains, and negative in the low-risk region, implying welfare losses. These opposite welfare effects are entirely driven by the transfers from the low- to the high-risk region that result from federal disaster policy (see last row of Table 6).

\subsection{Climate change}

Scientific models predict that climate change will affect the intensity and frequency of severe storms in the US (USGCRP, 2017). To simulate the effects of climate change in the model, I solve for new stationary equilibria with larger storm severities (the $\Omega$ parameters), or larger storm probabilities (the $\gamma$ parameters), or both. I choose the magnitudes of the changes in storm severity and probability to align with the scientific projections of the effects of climate change on storm intensity and frequency, respectively. The projections, and the uncertainty surrounding them, vary considerably by the type of storm (USGCRP, 2017). Given this variation, I use three different methods to incorporate climate change into the model, based on the projected changes in (1) cyclones, (2) extreme-precipitation events, and (3) severe floods.

\footnotetext{
${ }^{20}$ While very close to zero, the CEVs for the aggregate economy are negative, implying that federal disaster policy creates small welfare costs. The magnitude of the baseline CEV is smaller than the magnitude of the aid-only CEV because the adaptation subsidy corrects the moral hazard caused by the disaster aid, reducing the welfare cost. However, the subsidy over-corrects for the moral hazard (see Table 9), generating the small welfare cost of federal disaster policy in the baseline.
} 
Using each method, I determine the increases in storm severity and probability that would occur in year 2100 under two different emissions scenarios: a moderate-emissions scenario, corresponding to representative concentration pathway (RCP) 4.5 and a high-emissions scenario, corresponding to RCP 8.5. To put these scenarios in perspective, RCP 4.5 would imply approximately a doubling of atmospheric $\mathrm{CO}_{2}$ by the end of the century and RCP 8.5 would lead to a quadrupling of atmospheric $\mathrm{CO}_{2}$.

The first method of modeling climate change measures the changes in the storm distribution based on the projected effects of climate change on cyclones. Cyclones have the advantage that they are the most widely studied storm. There is considerable agreement across scientific models that climate change will lead to an increase in cyclone intensity (Knutson et al., 2019). In particular, Villarini and Vecchi (2013) use the output from 17 Global Climate Models (GCMs) produced under phase 5 of the Coupled Model Inter-comparison Project (CIMP5) to simulate the increase in the power dissipation index (PDI) for different emissions scenarios. Their projections imply that the PDI will increase by 50 percent under RCP 4.5 and by 100 percent under RCP 8.5. The predicted increases in the PDI are driven by increases in the cube of the cyclone's maximum sustained wind speed and in the amount of time that the cyclone is at its maximum wind speed, both of which map to higher storm severity in the model. ${ }^{21}$ Furthermore, using the same GCMs, Villarini and Vecchi (2012) find no impact on cyclone frequency in the North Atlantic Basin. ${ }^{22}$ Viewing the climate change projections for cyclones as representative of the climate change projections for all storms, I model the impact of climate change as a 50 and 100 percent increase in the storm severity parameters under RCP 4.5 and 8.5 respectively, with no change in the storm probability under either emissions scenario.

The second method of modeling climate change incorporates the climate change projections for extreme-precipitation events more broadly, since not all severe storms are cyclones. Specifically, I aggregate localized estimates of the projected changes in extreme precipitation under RCP 4.5 and 8.5 from the fourth National Climate Assessment, into projections for the low- and high-risk regions in the model. ${ }^{23}$ I find that the probability of an extreme precipitation event (defined as over 2 inches of precipitation in one day) increases by 77 percent in the low-risk region and by 57 percent in the high-risk region under RCP 4.5, and increases by

\footnotetext{
${ }^{21}$ Storm severity in the model corresponds in the data to the average storm severity experienced by all households in a region that are hit by a storm. Storm severity could increase because the maximum sustained wind speed increases and/or because the storm remains at its maximum sustained wind speed for longer, implying that more households experience the highest wind speeds.

${ }^{22}$ The scientific evidence is mixed on the impact of climate change on the frequency of North Atlantic cyclones (Knutson et al., 2019). To maintain consistency with the storm severity projections from Villarini and Vecchi (2013), I use their results for storm frequency as well. Both the extreme-precipitation and the flood-methods incorporate changes in storm probability.

${ }^{23}$ The data underlying the scenarios for the National Climate Assessment are based on statistically downscaled CMIP5 models and are available for download from: https://scenarios.globalchange.gov/loca-viewer/
} 
144 percent in the low-risk region and by 103 percent in the high-risk region under RCP 8.5. Additionally, the maximum precipitation in a single day increases by 9 and 15 percent in both regions under RCPs 4.5 and 8.5 , respectively.

Table 11: Parameter Values for Climate Change Experiments

\begin{tabular}{lcccccc}
\hline \hline & \multicolumn{3}{c}{ Storm probability } & \multicolumn{5}{c}{ Storm Severity } \\
\cline { 2 - 7 } & $\gamma_{1}$ & $\gamma_{2}$ & $\Omega_{1}^{h}$ & $\Omega_{1}^{y}$ & $\Omega_{2}^{h}$ & $\Omega_{2}^{y}$ \\
\hline $\begin{array}{l}\text { Baseline } \\
\text { Cyclone method }\end{array}$ & 0.002 & 0.02 & 0.15 & 0.11 & 0.30 & 0.21 \\
$\quad$ RCP 4.5 & & & & & & \\
$\quad$ RCP 8.5 & 0.002 & 0.02 & 0.23 & 0.16 & 0.45 & 0.32 \\
Extreme-precipitation method & 0.002 & 0.02 & 0.30 & 0.21 & 0.60 & 0.42 \\
$\quad$ & & & & & & \\
$\quad$ RCP 4.5 & 0.004 & 0.03 & 0.17 & 0.12 & 0.33 & 0.23 \\
RCP 8.5 & 0.005 & 0.04 & 0.17 & 0.12 & 0.34 & 0.24 \\
$\quad$ RCP 4.5 & & & & & & \\
$\quad$ RCP 8.5 & 0.003 & 0.03 & 0.15 & 0.11 & 0.30 & 0.21 \\
\hline
\end{tabular}

Note: This table reports the probability and severity parameter values in the baseline and in each climate change equilibrium.

I map the changes in the frequency of extreme-precipitation events and in the one-daymaximum precipitation to proportional changes in the model's storm probability and severity parameters, respectively. Both of these mappings involve considerable uncertainty. For example, it is unclear how to translate inches of rainfall into the storm's severity (e.g., its damage potential). While both FEMA and the USACE produce detailed flood-depth-damage curves, mapping inches of rainfall into feet of flood water requires knowledge of the areal extent of the rainfall and of the characteristics of the drainage basins for nearby rivers at the time of the storm. I use the extreme-precipitation method in spite of the uncertainties, because it provides a broader measure of the effects of climate change on storms then the climate change projections for cyclones. To address the uncertainties related to the damage from extremeprecipitation events, the third method focuses explicitly on the projected changes in one of the primary sources of extreme-precipitation damage: flooding.

To implement the flood method, I use scientific projections of the effects of climate change on inland flooding. Wobus et al. (2017) combine precipitation projections from an ensemble of 29 CMIP5 GCMs with hydrological models to forecast the effect of climate change on the probability of and damage from severe floods in the US (defined as 100-year floods), holding 
adaptation and the distribution of the population constant at their historical values. They find that the probability of a severe flood increases by 50 percent under RCP 4.5 and by 150 percent under RCP 8.5. Furthermore, they find that the changes in total flood damage under both emissions scenarios broadly mimic the changes in flood probability, implying that the damage per flood is unaffected by climate change. Therefore, I model the effects of climate change as a 50 and 150 percent increase in the storm probability parameters under RCP 4.5 and 8.5 respectively, with no change in the storm severity parameters under either emissions scenario. Table 11 reports the storm probability and severity parameters for each method of modeling climate change. ${ }^{24}$

\subsubsection{Response of adaptation to climate change}

Table 12 reports the average value of adaptation capital, measured as a percent of the total capital stock, in each climate change equilibrium. Climate change leads to a substantial increase in adaptation capital in both the low- and the high-risk region. For example, under the cyclone method for RCP 4.5, adaptation capital increases by 48 percent in the low-risk region (from 0.59 percent of the capital stock to 0.87 percent), and by 43 percent in the high-risk region (from 1.76 to 2.53 percent of the capital stock). The proportional increase in adaptation capital is larger in the low-risk region because of the diminishing returns to adaptive capacity in equation (2). Since the baseline level of adaptive capacity is lower in the low-risk region, its marginal product, in terms of the proportional reduction in damage, is higher.

Across all three methods of modeling climate change, the increase in adaptive capacity is larger under RCP 8.5 than under RCP 4.5. Recall that climate change increases the incentives to invest in adaptation capital because it increases the severity or probability of storms (see equations (13) - (16)). As climate change progresses, the magnitudes of the increases in the severity and probability parameters grow (see Table 11), creating stronger incentives to invest in adaptation.

Climate change leads to the biggest increases in adaptation capital under the cyclone method for each emissions scenario. To understand why, compare adaptation capital under the cyclone and flood methods for RCP 4.5. Both the cyclone and flood methods lead to a 50 percent increase in the expected severity of the storm shock, defined as the probability of the storm multiplied by the severity, $\gamma_{n} \Omega_{n}$. The methods differ because the storm severity is higher under the cyclone method and the storm probability is higher under the flood method. Due to the concavity of the utility function, homeowners increase adaptive capacity more in response to an increase in severity, $\Omega_{n}^{h}$, than in response to an increase in probability, $\gamma_{n}$. This is be-

\footnotetext{
${ }^{24}$ The only parameters that change between the baseline and the climate change equilibria are the probability and the severity of storms; there is no change in TFP. Under minimal assumptions, the model is consistent with balanced growth, implying that changes in TFP have no effect on the welfare cost of climate change.
} 
cause, all else constant, the increase in severity moves a homeowner that experiences a storm to a steeper portion of the utility function, while the increase in probability does not. The cyclone method has the largest increases in storm severity, generating the strongest incentives for adaptation.

Table 12: Adaptation Capital as a Percent of the Total Capital Stock

\begin{tabular}{lccc}
\hline \hline & $\begin{array}{c}\text { Low-risk } \\
\text { region }\end{array}$ & $\begin{array}{c}\text { High-risk } \\
\text { region }\end{array}$ & Aggregate \\
\hline Baseline & 0.59 & 1.76 & 1.17 \\
Cyclone method & & & \\
$\quad$ RCP 4.5 & 0.87 & 2.53 & 1.69 \\
$\quad$ RCP 8.5 & 1.14 & 3.25 & 2.18 \\
Extreme-precipitation method & & & \\
$\quad$ RCP 4.5 & 0.67 & 2.31 & 1.48 \\
$\quad$ RCP 8.5 & 0.73 & 2.74 & 1.72 \\
Flood method & & & \\
RCP 4.5 & 0.61 & 2.09 & 1.34 \\
RCP 8.5 & 0.64 & 2.72 & 1.66 \\
\hline
\end{tabular}

Note: This table reports adaptation capital as a percent of the total capital stock in the low-risk region (column 1), in the high-risk region (column 2), and in the aggregate economy (column 3). The first row reports these values in the baseline equilibrium and the remaining rows report the values in each climate change equilibrium.

In addition to the aggregate impacts, climate change also affects the distribution of adaptive capacity across different sub-groups of the population. Table 13 reports the increase in average adaptive capacity from its baseline value among renters and homeowners in each climate change equilibrium. The increases in storm severity under the cyclone and extremeprecipitation methods cause average adaptive capacity among homeowners to increase more than average adaptive capacity among rental-housing firms (first four rows of Table 13). In contrast, the large increases in probability under the flood method cause average adaptive capacity among rental-housing firms to increase more than average adaptive capacity among homeowners (last two rows of Table 13). The intuition for the differences between homeowners and renters again stems from the concavity of the utility function. As discussed above, for a given change in the expected severity of the storm shock, $\gamma_{n} \Omega_{n}^{h}$, homeowners increase adaptive capacity more in response to an increase in severity, $\Omega_{n}^{h}$, than in response to an increase in probability, $\gamma_{n}$. In contrast, the risk-neutral rental-housing firms increase adaptive capacity by the same amount, regardless of whether the increase in $\gamma_{n} \Omega_{n}^{h}$ is caused by an increase in severity or probability. 
Table 13: Increase in Adaptive Capacity From the Baseline

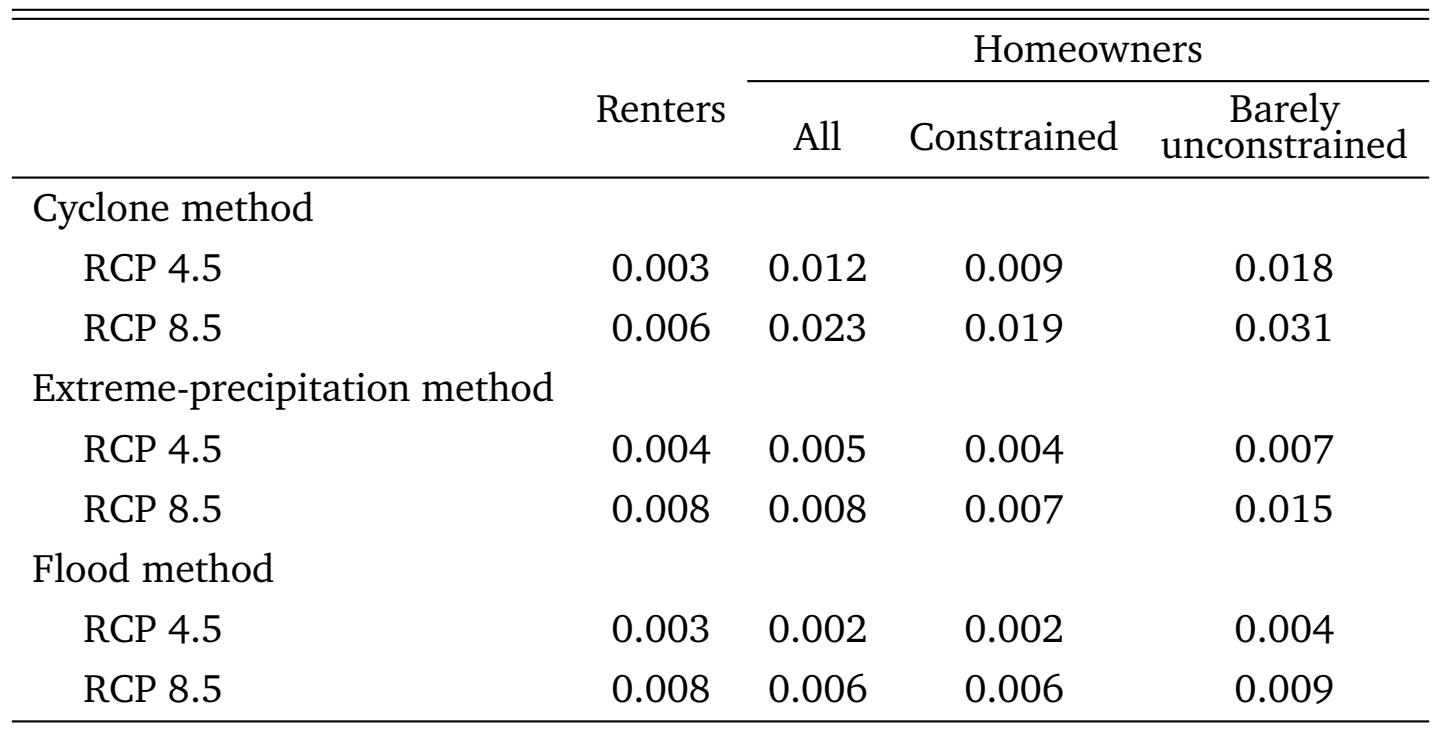

Note: This table reports the increase in average adaptive capacity by homeownership status from its corresponding average value in the baseline under each climate change equilibrium.

Relative to the average homeowner, climate change makes the subgroup of homeowners for whom the minimum house size constraint binds even more vulnerable to the damage from storms. The third column of Table 13 reports the increase in average adaptive capacity among these constrained homeowners. For comparison, the fourth column of Table 13 reports the increase in average adaptive capacity among barely unconstrained homeowners, defined as homeowners with a house that is barely larger (up to five percent) than the minimum house size. In every climate change equilibrium, the increase in average adaptive capacity is smaller among the constrained homeowners than among the barely unconstrained homeowners.

In sum, variation in adaptive capacity across homeowners and renters in the baseline leads to an unequal distribution of destroyed housing capital. This variation persists with climate change, and in some cases is even exacerbated. Renters continue to suffer the largest percentage decreases in housing services from a storm. Among homeowners, climate change magnifies the difference in adaptive capacity between constrained and unconstrained homeowners, resulting in a more unequal distribution of the percentage loss in housing services following a storm.

\subsubsection{Effects of adaptation on the damage and welfare cost of climate change}

To quantify the effects of adaptation on the damage and welfare cost of climate change, I compute a set of no-adaptation climate change equilibria, in which adaptation cannot respond to the increases in storm severity and probability. Specifically, I fix adaptive capacity for finalgood and rental-housing firms at their baseline values in each region. I fix adaptive capacity 
for homeowners at its average value in the baseline in each region. ${ }^{25}$ Comparing outcomes under the no-adaptation climate change equilibria with the corresponding outcomes under the climate change equilibria with adaptation discussed in Section 5.3.1 isolates the effects of adaptation.

Figure 2: Effects of Adaptation on the damage from climate change under RCPs 4.5 and 8.5
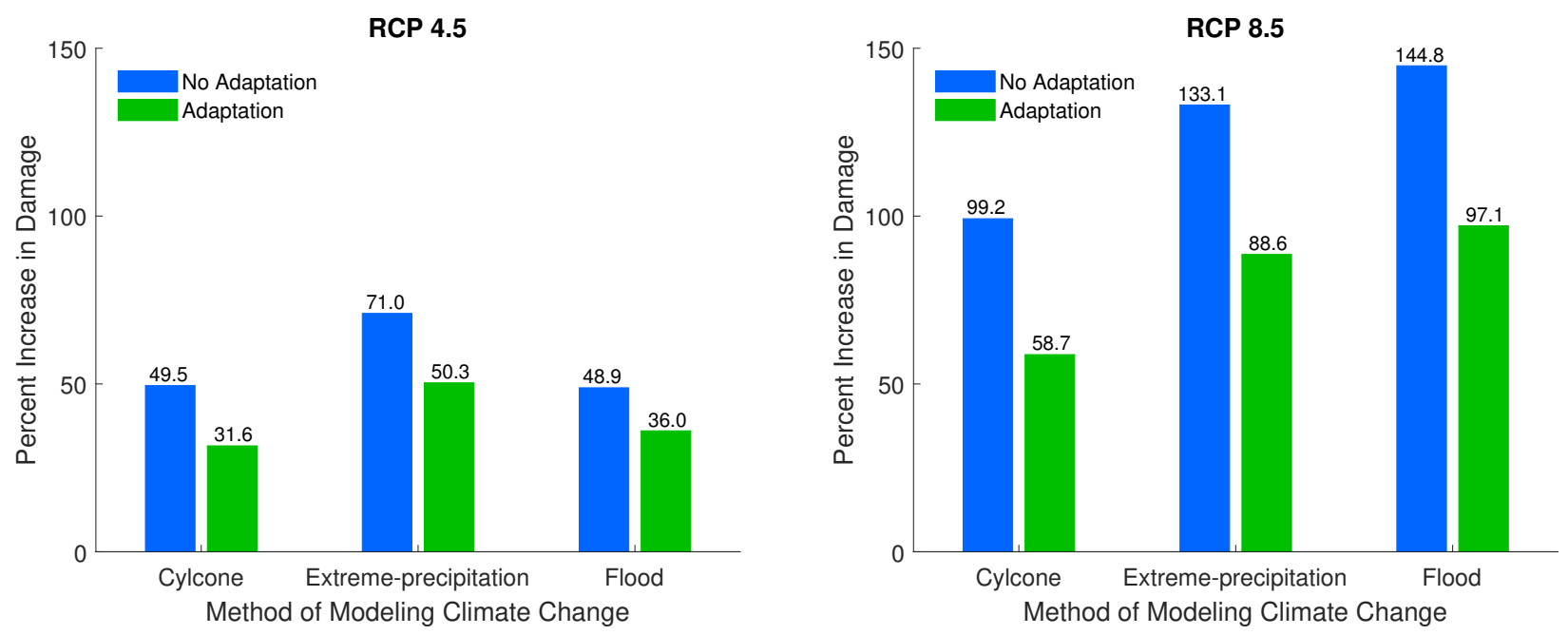

Note: The blue bars report the percent increase in damage from the baseline in the climate change equilibria when households and firms cannot increase adaptive capacity in response to the climate change. The green bars plot the percent increase in damage in each climate change equilibria when households and firms can increase adaptive capacity in response to the climate change.

The ability to adapt substantially reduces the damage from climate change. The left and right panels of Figure 2 plot the effects of adaptation on the increase in storm damage under RCPs 4.5 and 8.5, respectively. For each method of modeling climate change on the $\mathrm{x}$ axis, the blue and green bars plot the percent increase in damage from the baseline in the no-adaptation and adaptation climate-change equilibria, respectively. In the no-adaptation equilibria, the percent increase in damage approximately equals the percent increase in the expected severity of the storm shock, $\gamma \Omega$; since households and firms cannot adapt in response to the climate change, they cannot reduce the increase in damage from more frequent and more severe storms. ${ }^{26}$

\footnotetext{
${ }^{25}$ To avoid conflating changes in the distribution of adaptive capacity across homeowners with the effects of adaptation, I measure the impact of climate change in the no-adaptation equilibria from a modified baseline equilibrium in which all homeowners have the average adaptive capacity in the region. Since homeowner adaptive capacity is relatively constant across the wealth distribution (see Table 8), the modified baseline equilibrium is very similar to the baseline. For example, the difference in expected lifetime welfare for a household born in the baseline versus the modified baseline is approximately 0.01 percent. In the discussion in the text, I refer to both equilibria as the baseline.

${ }^{26}$ The proportional increase in damage is slightly less than the proportional increase in the expected severity of the storm shock because climate change decreases the expected marginal product of productive capital, reducing incentives for productive capital investment. All else constant, less productive capital reduces the realized damage
} 
When households and firms can adapt to climate change, the proportional increase in damage is considerably less than the proportional increase in the expected severity of the storm shock. For example, referring to the cyclone method under RCP 4.5 (left panel of Figure 2), the ability to adapt implies that a 50 percent increase in the expected severity of the storm shock only increases damage by 31.6 percent, instead of by 49.5 percent. Averaging across all climate change modeling methods and emissions scenarios, adaptation reduces the increase in damage from climate change by approximately one third.

Table 14: Welfare Effects of Climate Change With and Without Adaptation

\begin{tabular}{lcc}
\hline \hline & With adaptation & Without adaptation \\
\hline Cyclone method & & \\
RCP 4.5 & -0.52 & -0.57 \\
RCP 8.5 & -0.97 & -1.06 \\
Extreme-precipitation method & & \\
RCP 4.5 & -0.46 & -0.54 \\
RCP 8.5 & -0.88 & -0.96 \\
Flood method & & \\
RCP 4.5 & -0.28 & -0.34 \\
RCP 8.5 & -0.90 & -1.02 \\
\hline
\end{tabular}

Note: This table reports the consumption equivalent variation measured from the baseline equilibrium for the climate change equilibria in which adaptation can respond (column 1) and for the climate change equilibria in which adaptation cannot respond (column 2). Negative values indicate that climate change makes households worse off.

In addition to reducing damage, the ability to adapt also reduces the welfare costs of climate change. To measure the welfare effects of climate change, I use the consumption equivalent variation (CEV). The CEV measures the expected percent increase in non-durable consumption that the household would need in every period in the baseline, such that it is indifferent between the baseline and the climate change equilibria. Table 14 reports the CEV in the adaptation and no-adaptation equilibria for each climate change modeling method and emissions scenario. All values of the CEV are negative, indicating that climate change makes households worse off. I define the welfare cost of climate change to equal the negative of the CEV. Under all three methods of modeling climate change, the welfare cost of climate change is larger for the high emissions scenario (RCP 8.5). For example, referring to the cyclone method, the welfare cost of climate change under RCP 8.5 is 0.97 , almost double the welfare cost under RCP 4.5 of 0.52 .

because there is less capital for the storm to destroy. 
Comparing the CEVs across the adaptation and no-adaptation climate change equilibria, implies that adaptation reduces the welfare cost of climate change. Again referring to the cyclone method under RCP 4.5, adaptation reduces the welfare cost of climate change from 0.57 without adaptation to 0.52 with adaptation. Averaging across all climate change modeling methods and emissions scenarios, adaptation reduces the welfare costs of climate change by approximately 11 percent.

Overall, the effects of adaptation on the welfare costs of climate change in Table 14 are smaller than the effects on damage in Figure 2. Households and firms must use resources to invest in adaptation capital, which reduces the effects of adaptation on the welfare costs relative to the effects on damage. Additionally, households have ways besides adaptation to decrease the welfare costs of climate change, such as accumulating financial assets and insurance. When households cannot adapt, they rely more on the savings and insurance channels, further reducing the effect of adaptation on the welfare cost.

\subsection{Idiosyncratic storm risk}

Some types of climate damage, such as the damage caused by storms, is the realization of idiosyncratic shocks. In any given period, some agents are hit and directly experience damage while others are not hit, and thus do not directly experience damage. Yet, the standard approach in the environmental literature is to abstract from idiosyncratic risk and instead model climate change using a damage function that directly affects utility, output, or both. These damage functions assume that all agents within a region experience the average damage in the region every period.

To evaluate the importance of modeling the idiosyncratic risk component of climate damage, I specify a version of the model in which I eliminate idiosyncratic storm risk. I assume instead that every agent experiences the expected severity of the storm shock in every period, as would be implied by a climate damage function. Specifically, each homeowner and rentalhousing firm in region $n$ experiences a storm shock with severity $\bar{\Omega}_{n}^{h} \equiv \gamma_{n} \Omega_{n}^{h}$ in every period. Similarly, each final-good firm in region $n$ experiences a storm shock with severity $\bar{\Omega}_{n}^{y} \equiv \gamma_{n} \Omega_{n}^{y}$ in every period. Hence, if there is no adaptation, then storm damage causes all homeowners and rental-housing firms in region $n$ lose fraction $\bar{\Omega}_{n}^{h}$ of productive housing capital and all final-good firms in region $n$ lose fraction $\bar{\Omega}_{n}^{y}$ of productive final-good capital every period. I

refer to this specification as the damage-function specification because the terms $\bar{\Omega}_{n}^{h}$ and $\bar{\Omega}_{n}^{y}$ are similar to the climate damage functions used in the literature. 
Table 15: Welfare Effects of Climate Change:

Idiosyncratic-Storm-Risk vs. Damage-Function Specifications

\begin{tabular}{lcc}
\hline \hline & Idiosyncratic Storm Risk & Damage Function \\
\hline Cyclone method & & \\
$\quad$ RCP 4.5 & -0.52 & -0.39 \\
RCP 8.5 & -0.97 & -0.74 \\
Extreme-precipitation method & & \\
$\quad$ RCP 4.5 & -0.46 & -0.55 \\
RCP 8.5 & -0.88 & -0.91 \\
Flood method & & \\
$\quad$ RCP 4.5 & -0.28 & -0.39 \\
RCP 8.5 & -0.90 & -1.06 \\
\hline
\end{tabular}

Note: This table reports the consumption equivalent variation measured from the baseline equilibrium for each climate change equilibria under the idiosyncratic-storm-risk (column 1) and damage-function (column 2) specifications of the model.

Focusing first on the effects of idiosyncratic storm risk on adaptation incentives, I find that average adaptive capacity among homeowners in the baseline equilibrium under the damagefunction specification equals 0.005 , less than one quarter of its value from the idiosyncraticstorm-risk specification (reported in Table 7). As discussed in the context of Table 7, homeowners are risk averse, and thus they value adaptive capacity both because it reduces the realized damage from a storm and because it reduces the variance in the realized levels of housing services and cash at hand. This second motive is absent in the damage-function specification of the model, reducing homeowners' incentives to invest in adaptation. Adaptive capacity among rental-housing and final-good firms in the baseline equilibrium under the damage-function specification is exactly the same as under the idiosyncratic-storm-risk specification. Firms are risk neutral, and thus idiosyncratic storm risk has no direct impact on their decisions.

The damage-function specification also impacts the predicted welfare effects of climate change. Table 15 reports the welfare effects of climate change, measured using the CEV, under the idiosyncratic-storm-risk (first column) and damage-function (second column) specifications. Again, I define the welfare costs of climate change to equal the negative of the CEV. The damage-function specification decreases the predicted welfare costs of climate change under the cyclone method and increases them under the extreme-precipitation and flood methods.

The idiosyncratic-storm-risk and damage-function specifications generate different predictions for the welfare costs of climate change because of the concavity of the utility function. For example, as discussed in the context of Table 14, this concavity implies that the expected welfare cost from a 50 percent increase in storm severity (cyclone method, RCP 4.5) is greater than 
the expected welfare cost from a 50 percent increase in storm probability (flood method, RCP 4.5), even though both changes result in a 50 percent increase in expected severity, $\bar{\Omega}_{n}=\gamma_{n} \Omega_{n}$, all else constant. The 50 percent increase in storm severity generates a higher expected welfare cost because, all else constant, it moves households to a steeper portion of the utility function in the event of a storm. In contrast, the 50 percent increase in storm probability does not change the household's position on the utility function in the event of a storm, resulting in a lower expected welfare cost.

The welfare cost of climate change in the damage-function specification is in between these two extremes from the idiosyncratic-storm-risk specification. Referring to Table 15, the welfare cost from a 50 percent increase in $\bar{\Omega}_{n}$ (cyclone or flood method, RCP 4.5) is 0.39 , greater than the welfare cost from a 50 percent increase in storm probability (flood method, RCP 4.5), 0.28, and less than the welfare cost from a 50 percent increase in storm severity (cyclone method, RCP 4.5), 0.52. In general, the damage-function specification underestimates the welfare costs when climate change is modeled primarily as an increase in storm severity, as it is under the cyclone method, and overestimates the welfare costs when climate change is primarily modeled as an increase in storm probability, as it is under the extreme-precipitation and flood methods.

\section{Conclusion}

The welfare costs of climate change will partially be determined by households' and firms' abilities to adapt to the new weather patterns. Understanding the incentives for adaptation and its effects on damage is thus important for the design of climate policy and weather-related disaster policies more generally. This paper takes one step forward in this research agenda and quantifies the interactions between adaptation capital, federal disaster policy, and the increases in storm severity and probability brought about by climate change.

To obtain quantitative results, I calibrate the key parameters in the heterogeneous agent macro model from the empirical data on US storms, disaster aid, and cyclone wind speed. The calibration strategy exploits variation in the frequency with which US households experience severe storms and the disaster aid provided in response to the storms. The intuition borrows from an empirical literature that treats adaptation as a latent variable. The calibrated model

yields estimates of the size of this latent variable. Specifically, the results reveal that adaptation capital is slightly over one percent of the US capital stock.

I examine the interactions between adaptation, federal disaster policy, climate change, and idiosyncratic storm risk. I find that while disaster aid reduces adaptation in the US economy, the subsidy for adaptation more than offsets this moral hazard effect. Furthermore, the increases in storm severity and probability as a result of climate change generate a substantial increase in adaptation, reducing both the damage and the welfare cost of the climate change. Lastly, the 
model demonstrates the importance of including the idiosyncratic risk component of climate damage. Abstracting from idiosyncratic storm risk using a damage-function specification can have substantial implications for both adaptation incentives and the welfare cost of climate change.

The paper studies adaptation in the context of existing federal disaster policy. Adaptation could also have interesting implications for optimal disaster policy. Optimal policy might include disaster aid and adaptation subsides, as well as other types of government intervention to reduce the welfare costs of climate-change-related disasters. For example, non-disaster-specific government programs, such as unemployment insurance, can indirectly provide disaster assistance (Deryugina, 2017). Additionally, market and coordination failures can necessitate the public provision of capital (both adaptive and productive), which creates its own set of interesting moral hazard and public finance issues, see for example Barrage (2020). Understanding the optimal amount and type of government intervention in the context of storms and other climate-change-related disasters is an interesting area for future work.

In sum, the analysis highlights the quantitative importance of adaptation in response to climate change for the case of severe storms in the US. The effects of adaptation on the damage from storms and the associated welfare cost suggests that exploring different avenues for adaptation in response to different types of climate change is potentially important. Moreover, climate change is a global problem and adaptation incentives and technologies can differ across countries with different climates and income levels (Bakkensen and Mendelsohn, 2016). Modeling and quantifying different adaptation responses and understanding how these effects vary across countries is a promising avenue for future work.

\section{References}

Acemoglu, D., P. Aghion, L. Bursztyn, And D. HÉmous (2012): “The Environment and Directed Technical Change," American Economic Review, 102, 131-166.

Agrawala, S., F. Bosello, C. Carraro, K. D. Bruin, E. D. Cian, R. Dellink, and E. Lanzi (2011): "Plan or React? Analysis of Adaptation Costs and Benefits Using Integrated Assessment Models," Climate Change Economics, 2, 175-208.

AIYAGARI, S. R. (1994): "Uninsured Idiosyncratic Risk and Aggregate Saving," Quarterly Journal of Economics, 109, 659-684.

AnNAN, F. AND W. Schlenker (2015): "Federal Crop Insurance and the Disincentive to Adapt to Extreme Heat," American Economic Review: Papers and Proceedings, 105, 262-266.

Bakkensen, L. And L. Barrage (2017): "Flood Risk Belief Price Heterogenity and Coastal Home Price Dynamics: Going Under Water?” NBER working paper 23854. 
(2018): "Climate Shocks, Cyclones, and Economic Growth: Bridging the Micro-Macro Gap," .

BAKkensen, L. AND R. Mendelsohn (2016): "Risk and Adaptation: Evidence From Global Hurricane Damage and Fatalities," Journal of the Association of Environmental and Resource Economists, 3, 555-587.

Barrage, L. (2015): Climate Change Adaptation vs. Mitigation: A Fiscal Perspective, Wiley and Sons, chap. Climate Change Adaptation vs. Mitigation: A Fiscal Perspective.

- (2019): "Optimal Dynamic Carbon Taxes in a Climate-Economy Model with Distortionary Fiscal Policy," The Review of Economic Studies, 1-39.

- (2020): “The Fiscal Costs of Climate Change," AEA Papers and Proceedings, 107-112.

Barreca, A., K. Clay, O. Deschenes, M. Greenstone, and J. Shapiro (2016): "Adapting to Climate Change: The Remarkable Decline in the US Temperature-Mortality Relationship over the 20th Century," Journal of Political Economy, 124, 105-159.

BARro, R. (2006): "Rare Disasters and Asset Markets in the Twentieth Century," The Quarterly Journal of Economics, 121, 823-866.

Bosello, F., C. Carraro, And E. D. Cian (2010): "Climate Policy and the Optimal Balance Between Mitigation, Adaptation, and Unavoided Damage," FEEM working paper, 1-32.

- (2011): "Adapting to Climate Change. Costs, Benefits, and Modeling Approaches," International Review of Environmental and Resource Economics, 5, 245-284.

Brechet, T., N. Hritonenko, And Y. YArsenko (2013): "Adaptation and Mitigation in Longterm Climate Policy," Environmental Resource Economics.

Burke, M. AND K. EMERICK (2016): "Adaptation to Climate Change: Evidence from US Agriculture," American Economic Journal: Economic Policy, 8, 106-140.

CBO (2019): Expected Costs of Damage from Hurricane Winds and Storm-Related Flooding, congressional Budget Office Publication number 55019.

Cohen, C. And E. Werker (2008): “The Political Economy of "Natural" Disasters," Journal of Conflict Resolution, 52, 795-819.

DaVlasheridze, M., K. Fisher-VAnden, And H. A. Klaiber (2014): “The Effects of Adaptation Measures on Hurricane Induced Property Losses: Which FEMA Investments Have the Highest Returns?" Journal of Environmental Economics and Management.

DeBruin, K. C., R. B. Dellink, And R. S. J. Tol (2009): "AD-DiCE: An Implementation of Adaptation in the DICE Model," Climate Change, 95, 63-81.

Dell, M., B. Jones, AND B. Olken (2012): “Temperature Shocks and Economic Growth: Evidence From the Last Half Century," American Economic Journal: Macroeconomics, 4, 66-95. 
Deryugina, T. (2017): "The Fiscal Cost of Hurricanes: Disaster Aid Versus Social Insurance," American Economic Journal: Policy.

Desmet, K., R. E. Kopp, S. A. Kulp, D. K. Nagy, M. Oppenheimer, E. Rossi-Hansberg, and B. H. STRAUSs (forthcoming): "Evaluating the Economic Cost of Coastal Flooding," American Economic Journal: Macroeconomics.

EmAnuel, K. (2005): "Increasing Destructiveness of Tropical Cyclones Over the Past 30 Years," Nature, 464, 686-688.

FAVILUKIS, J. (2013): "Inequality, Stock Market Participation, and the Equity Premium," Journal of Financial Economics, 107, 740-759.

Felgenhauer, T. And K. C. D. Bruin (2009): “The Optimal Paths of Climate Change Mitigation and Adaptation Under Certainty and Uncertainty," The International Journal of Global Warming, 66-88.

Felgenhauer, T. AND M. Webster (2014): "Modeling Adaptation as a Flow and Stock Decision With Mitigation," Climate Change, 122, 665-679.

FEMA (2003): A Citizen's Guide to Disaster Assistance, https://training.fema.gov/emiweb/downloads/is7complete.pdf.

— (2019a): Hazard Mitigation Grant Program, https://www.fema.gov/hazard-mitigationgrant-program.

Individual Assistance Program and Policy
$\begin{aligned} & \text { Guide, } \\ & \text { 1abf12182d2d5e622d16accb37c4d163//APPG.pdf. }\end{aligned}$

(2020): The Disaster Declaration Process, https://www.fema.gov/disaster-declarationprocess.

Fisher, J. D. M. AND M. Gervais (2011): "Why Has Home Ownership Fallen Among the Young?" International Economic Review, 52, 883-912.

Gallagher, J. (2014): "Learning About an Infrequent Event: Evidence From Flood Insurance Take-up in the United States," American Economic Journal: Applied Economics, 6, 206-233.

Garrett, T. And R. Sobel (2007): “The Political Economy of FEMA Disaster Payments,” Economic Inquiry, 41, 496-509.

Gervais, M. (2002): "Housing Taxation and Capital Accumulation," Journal of Monetary Economics, 49, 1461-1489.

Golosov, M., J. Hassler, P. Krusell, And A. Tsyvinski (2014): "Optimal Taxes on Fossil Fuel in General Equilibrium," Econometrica, 82, 41-88.

Gourio, F. AND C. FRIES (2020): "Adaptation and the Cost of Rising Temperature for the US Economy," Unpublished Working Paper, Federal Reserve Bank of Chicago. 
HAssler, J. AND P. KRUSEll (2018): "Environmental Macroeconomics: the Case of Climate Change," Handbook of Environmental Economics, 4, 333-394.

HAssler, J., P. KRUsell, AND A. S. JR. (2016): "Environmental Macroeconomics," Handbook of Macroeconomics, 1893-2008.

Heutel, G. AND C. Fischer (2013): "Environmental Macroeconomics: Environmental Policy, Business Cycles and Directed Technical Change," Annual Review of Resource Economics, 5, 197-210.

Heutel, G., N. Miller, AND D. Molitor (2017): "Adaptation and the Mortality Effects of Temperature Across U.S. Climate Regions," NBER working paper 23271.

HSIANG, S. AND D. NARITA (2012): "Adaptation to Cyclone Risk: Evidence From the Global Cross-Section," Climate Change Economics, 3.

Hsiang, S. M. (2016): “Climate Econometrics,” Annual Review of Resource Economics, 8, 43-75.

IPCC (2000): Special report on emissions scenarios, Cambridge University Press.

(2014): Climate Change 2014: Synthesis Report. Contribution of Working Groups I, II, and III to the Fifth Assessment Report of the Intergovernmental Panel on Climate Change.

Kane, S. And J. Shogren (2000): "Linking Adaptation and Mitigation in Climate Change Policy," Climate Change, 45, 75-102.

KAPlAN, G. (2012): "Inequality and the life cycle," Quantitative Economics, 3, 471-525.

Keefer, P., E. Neumayer, And T. Plumper (2011): "Earthquake Propensity and the Politics of Mortality Prevention," World Development, 39, 1530-1541.

Kiyotaki, N., A. Michaelides, And K. Nikolov (2011): "Winners and Losers in Housing Markets," Journal of Money Credit and Banking, 43, 255-296.

Knutson, T., S. J. Camargo, J. C. L. Chan, K. Emanuel, C.-H. Ho, J. Kossin, M. Mohapatra, M. SATOH, M. Sugi, K. WAlsh, And L. Wu (2019): "Tropical Cyclones and Climate Damage Assessment," American Meteorological Society, 303-322.

KOPECKY, K. A. AND R. M. SUEN (2010): "Finite state Markov-chain approximations to highly persistent processes," Review of Economic Dynamics, 13, 701-714.

Krusell, P. And A. A. Smith (2017): "Climate Change Around the World," Slides from The Macro and Micro Economics of Climate Change LAEF Conference.

KuHn, M. AND J.-V. RIOS-Rull (2016): "2013 Update on the U.S. Earnings, Income, and Wealth Distributional Facts: A View From Macroeconomics," Federal Reserve Bank of Minneapolis Quarterly Review, 37, 1-73.

LEWIS, T. AND D. NiCKERson (1989): "Self-Insurance Against Natural Disasters," Journal of Environmental Economics and Management, 16, 20-223. 
NAKAJIMA, M. (forthcoming): "Capital Income Taxation with Housing," Journal of Economic Dynamics and Control.

NOAA (2020): "National Centers for Environmental Information (NCEI) U.S. Billion-Dollar Weather and Climate Disasters," https://www.ncdc.noaa.gov/billions/.

Nordhaus, W. D. (1992): "An optimal transition path for slowing climate change," Science, 258, 1315-1319.

(2010): "The Economics of Hurricanes and Implications of Global Warming," Climate Change Economics, 1, 1-20.

(2017): "Revisiting the social cost of carbon," Proceedings of the National Academy of Sciences, 114, 1518-1523.

NRC (2015): Affordability of National Flood Insurance Premiums, National Academies Press.

Pindyck, R. AND N. WANG (2013): "The Economic and Policy Consequences of Catastrophes," American Economic Journal: Economic Policy, 5, 306-339.

QuAdRini, V. AND J.-V. Ríos-RuEL (1997): "Understanding the US Distribution of Wealth," Federal Reserve Bank of Minneapolis Quarterly Review, 21, 22-36.

ReEves, A. (2011): "Political Disaster: Unilateral Powers, Electoral Incentives, and Presidential Disaster Declarations," The Journal of Politics.

SAdowski, N. C. AND D. Sutter (2008): "Mitigation Motivated by Past Experience: Prior Hurricanes and Damages," Ocean and Coastal Management, 51, 303-313.

SCHLENKER, W. AND M. RoberTs (2009): "Nonlinear Temperature Effects Idicate Severe Damages to U.S. Crop Yields Under Climate Change," Proceedings of the National Academy of Sciences, 106, 15594-98.

Strobl, E. (2011): “The Economic Growth Impact of Hurricanes: Evidence from US Coastal Counties," The Review of Economics and Statistics, 93, 575-589.

ToL, R. S. (2007): “The Double Trade-off Between Adaptation and Mitigation for Sea Level Rise: an Application of FUND," Mitigation and Adaptation Strategies for Global Climate Change, 12, 741-753.

USACE (2020): Who Pays and where does the money come from? Corps and Sponsor Roles in Sharing and Financing Project Costs, https://www.mvr.usace.army.mil/Portals/48/docs/RE/Guide/WhoPays.pdf.

USGCRP (2017): Climate Science Special Report: Fourth National Climate Assessment, Volume I, US Global Change Research Program Washing, DC, USA.

(2018): Impacts, Risks, and Adaptation in the United States: Fourth National Climate Assessment, Volume II, US Global Change Research Program. 
Villarini, G. AND G. A. VeCchi (2012): "North Atlantic Power Dissipation Index (PDI) and Accumulated Cyclone Energy (ACE): Statistical Modeling and Sensitivity to Sea Surface Temperature Changes," Climate, 25, 625-637.

(2013): "Projected Increases in North Atlantic Tropical Cyclone Intensity From CMIP5 Models," Journal of Climate, 26, 3241-3240.

WiLson, D. J. (2017): “The Impact of Weather on Local Employment: Using Big Data on Small Places," Federal Reserve Bank of San Francisco Working Paper 2016-21.

Wobus, C., E. Gutmann, R. Jones, M. Rissing, N. Mizukami, M. Lorie, H. Mahoney, A. W. Wood, D. Mills, AND J. MARTinich (2017): "Climate change impacts on flood risk and asset damages with mapped 100-year floodplains of the contiguous United States," Natural Hazards and Earth System Sciences, 17, 2199-2211.

\section{Appendix}

\section{A. Model}

\section{A.1. Mutual Funds}

The representative mutual fund divides household deposits among equities and bonds. Let $o_{i, t+1}$ denote an equity share in firm $i$. Let $q_{i, t+1}$ denote the weight on equity $i$ in the mutual fund's equity portfolio:

$$
q_{i, t+1}=\frac{o_{i, t+1} V_{i, t}^{e}}{s_{t+1}-b_{t+1}}, \quad \text { where } \quad \int_{0}^{2 N} q_{i, t+1} d i=1
$$

The numerator in equation (A.1) is the mutual fund's expenditure on equity $i$ and the denominator is the mutual fund's total equity expenditure, equal to its value of household deposits, $s_{t+1}$, minus its international bond holdings, $b_{t+1}$. I use the notation $V_{i, t}^{e}$ to refer to the exdividend value of firm $i$ in period $t$, equal to $V^{y e}\left(k_{i t}^{y p}, k_{i t}^{y a}, e_{i t}^{y} ; n\right)$ if firm $i$ is a final-good firm in region $n$ or $V^{r e}\left(k_{i t}^{r p}, k_{i t}^{r a}, e_{i t}^{r} ; n\right)$ if firm $i$ is a rental-housing firm in region $n$. The integral, taken over the measure $2 N$ of firms in the economy, requires that the equity weights sum to unity.

Define function $Q_{t+1}:[0,2 N] \rightarrow[0,1]$ to equal the "cumulative-weight" function:

$$
Q_{t+1}(i)=\int_{0}^{i} q_{k, t+1} d k, \quad \text { for } \quad i \in[0,2 N]
$$

analogous to a cumulative distribution function in probability theory. It follows from equation (A.2) that $d Q_{t+1}(i)=q_{i, t+1}$. The mutual fund chooses next period's cumulative weight function, $Q_{t+1}$, and bonds, $b_{t+1}$, to maximize the expectation of any strictly increasing and concave 
function, $H$, of the value of its portfolio at the end of period $t+1$ :

$$
\max _{Q_{t+1}, b_{t+1}} E_{t}\left[H\left(\int_{0}^{2 N} R_{i, t+1}\left(s_{t+1}-b_{t+1}\right) d Q_{t+1}(i)+\left(1+r^{\star}\right) b_{t+1}\right)\right] .
$$

Consider first the mutual fund's choice of $Q_{t+1}$. I classify a cumulative-weight function as either continuous, $Q_{t+1}^{C}$, or discrete $Q_{t+1}^{D}$, where a discrete cumulative-weight function is any cumulative-weight function that is not everywhere continuous. Lemma 1 (below) proves that the realized return to the equity portion of the mutual fund's portfolio under any continuous cumulative-weight function equals $1+r_{t+1}$ with certainty. The intuition is that under a continuous cumulative-weight function, the mutual fund allocates an infinitesimally small share of household deposits minus bond holdings to each of the infinitely many equities in its portfolio. Since the return realizations are independent and all equities have the same expected return, the variance in the return on the equity portfolio is zero. In contrast, the variance in the return on the equity portfolio formed using a discrete cumulative-weight function is not zero. Under a discrete cumulative-weight function, the mutual fund allocates a positive point mass of household deposits to at least one equity, the variance of which is then inherited by the portfolio.

Lemma 2 (below) shows that an equity portfolio formed at the end of period $t$ under any continuous cumulative-weight function, $Q_{t+1}^{C}$, second-order stochastically dominates an equity portfolio formed under any discrete cumulative-weight function, $Q_{t+1}^{D}$. It follows that since the mutual fund is risk-averse, it will always choose a continuous cumulative-weight function, earning return $1+r_{t+1}$ with certainty. The choice of the particular cumulative-weight function, or any variation in that choice across mutual funds, has no impact on the model's equilibrium outcomes, since all continuous cumulative-weight functions generate portfolios that earn return $1+r_{t+1}$ with certainty. Hence, focusing on a symmetric equilibrium with a representative mutual fund is without loss of generality.

I next show that the return on the representative mutual fund's optimal equity portfolio, $1+r_{t+1}$, equals the return from investing in international bonds, $1+r^{\star}$. Substituting the continuous cumulative-weight function into the optimization problem in equation (A.3) and taking the first order condition with respect to $b_{t+1}$ yields:

$$
E_{t}\left[H^{\prime}(\cdot)\left(-\int_{0}^{2 N} R_{i, t+1} d Q_{t+1}^{C}(i)+1+r^{\star}\right)\right]=0 .
$$

Under the continuous cumulative-weight function, the variance of the period $t+1$ portfolio value equals zero, implying that the argument $H^{\prime}(\cdot)$ is known in period $t$. Moving $H^{\prime}(\cdot)$ out- 
side of the expectation and evaluating the integral reveals that the return on the equity portfolio equals the return to bonds: $r_{t+1}=r^{\star} \forall t$.

Lemma 1 The variance in the realized value (and hence in the return) of the mutual fund's equity portfolio formed under a continuous cumulative-weight function is zero, and the corresponding variance for an equity portfolio formed under a discrete cumulative-weight function is not zero.

Proof: Define $X_{t+1}^{C}$ and $X_{t+1}^{D}$ to equal the period $t+1$ values of the representative mutual fund's equity portfolio, formed at the end of period $t$ under continuous, $Q_{t+1}^{C}$, and discrete, $Q_{t+1}^{D}$, cumulative-weight functions respectively. From the perspective of the mutual fund choosing investments at the end of period $t, X_{t+1}^{C}$ and $X_{t+1}^{D}$ are random variables, whose distributions depend on the distribution of storm shocks across the measure $2 N$ of firms in the economy. Formally, define $X_{t+1}^{C}$ as:

$$
X_{t+1}^{C}=\int_{0}^{2 N} R_{i, t+1}\left(s_{t+1}-b_{t+1}\right) d Q_{t+1}^{C}(i)
$$

I show that the variance of $X_{t+1}^{C}$ equals zero, implying that the realized value of $X_{t+1}^{C}$ always equals its expectation, $E_{t}\left(X_{t+1}^{C}\right)$.

The expectation of $X_{t+1}^{C}$ equals:

$$
E_{t}\left(X_{t+1}^{C}\right)=E_{t}\left[\int_{0}^{2 N} R_{i, t+1}\left(s_{t+1}-b_{t+1}\right) d Q_{t+1}^{C}(d i)\right]=\left(1+r_{t+1}\right)\left(s_{t+1}-b_{t+1}\right) .
$$

The variance of $X_{t+1}^{C}$ is given by the formula, $\operatorname{Var}\left(X_{t+1}^{C}\right)=E_{t}\left[\left(X_{t+1}^{C}\right)^{2}\right]-E\left[X_{t+1}^{C}\right]^{2}$. From equation (A.6), the second term in the variance formula equals: $E\left[X_{t+1}^{C}\right]^{2}=\left(1+r_{t+1}\right)^{2}\left(s_{t+1}-\right.$ $\left.b_{t+1}\right)^{2}$. I show $E_{t}\left[\left(X_{t+1}^{C}\right)^{2}\right]=E\left[X_{t+1}^{C}\right]^{2}$, implying that the variance of $X_{t+1}^{C}$ equals zero: 


$$
\begin{aligned}
E_{t}\left[\left(X_{t+1}^{C}\right)^{2}\right] & =E_{t}\left[\int_{0}^{2 N} R_{i, t+1}\left(s_{t+1}-b_{t+1}\right) d Q_{t+1}^{C}(i) \int_{0}^{2 N} R_{j, t+1}\left(s_{t+1}-b_{t+1}\right) d Q_{t+1}^{C}(j)\right] \\
& =\left(s_{t+1}-b_{t+1}\right)^{2} E_{t}\left[\int_{0}^{2 N} \int_{0}^{2 N} R_{i, t+1} R_{j, t+1} d Q_{t+1}^{C}(j) d Q_{t+1}^{C}(i)\right] \\
& =\left(s_{t+1}-b_{t+1}\right)^{2} \int_{0}^{2 N} \int_{0}^{2 N} E_{t}\left(R_{i, t+1} R_{j, t+1}\right) d Q_{t+1}^{C}(j) d Q_{t+1}^{C}(i) \\
& =\left(s_{t+1}-b_{t+1}\right)^{2} \int_{0}^{2 N} \int_{0}^{2 N} \operatorname{Cov}\left(R_{i, t+1}, R_{j, t+1}\right)+E_{t}\left(R_{i, t+1}\right) E_{t}\left(R_{j, t+1}\right) d Q_{t+1}^{C}(j) d Q_{t+1}^{C}(i) \\
& =\left(s_{t+1}-b_{t+1}\right)^{2}\left(1+r_{t+1}\right)^{2}=E\left[X_{t+1}^{C}\right]^{2} .
\end{aligned}
$$

Note that $\operatorname{Cov}\left(R_{i, t+1}, R_{j, t+1}\right)=0$ in the second to last line of the above derivation because the storm shock realizations are independent across firms.

Similarly, I show that the variance of $X_{t+1}^{D}$ is not equal to zero. Let $X \subseteq[0,2 N]$ denote the finite subset of equities at which the cumulative-weight function, $Q_{t+1}^{D}$, is discontinuous, indicating that these equities received a discrete point mass of household deposits. Let $q_{i, t+1}^{d}$ denote the equity weight for each equity $i \in \mathcal{X}$. Define $\hat{Q}_{t+1}^{D}$ to be the continuous component of $Q_{t+1}^{D}$ such that $d \hat{Q}_{t+1}^{D}(i)=0$ if $i \in \mathcal{X}$ and $d \hat{Q}_{t+1}^{D}(i)=d Q_{t+1}^{D}(i)$ if $i \notin \mathcal{X}$. Using these definitions, write the random variable $X_{t+1}^{D}$ as:

$$
X_{t+1}^{D}=\sum_{i \in \mathcal{X}} q_{i, t+1}^{d} R_{i, t+1}\left(s_{t+1}-b_{t+1}\right)+\int_{0}^{2 N} R_{i, t+1}\left(s_{t+1}-b_{t+1}\right) d \hat{Q}_{t+1}^{D}(i) .
$$

Since $\hat{Q}_{t+1}$ is continuous, the same reasoning that showed that $\operatorname{Var}\left(X_{t+1}^{C}\right)=0$ also implies that $\operatorname{Var}\left(\int_{0}^{2 N} R_{i, t+1}\left(s_{t+1}-b_{t+1}\right) d \hat{Q}_{t+1}^{D}(i)\right)=0$. However, the variance of the first term in equation (A.7) is not equal to zero:

$$
\operatorname{Var}\left(\sum_{i \in \mathcal{X}} q_{i, t+1}^{d} R_{i, t+1}\left(s_{t+1}-b_{t+1}\right)\right)=\left(s_{t+1}-b_{t+1}\right)^{2} \sum_{i \in X}\left(q_{i, t+1}^{d}\right)^{2} \operatorname{Var}\left(R_{i, t+1}\right)>0
$$

Therefore, it follows that the variance of $X_{t+1}^{D}$ must be greater than zero.

Lemma 2 An equity portfolio formed using a continuous cumulative-weight function second-order stochastically dominates one formed using a discrete cumulative-weight function.

Proof: Let $X_{t+1}^{C}$ and $X_{t+1}^{D}$ be defined as in Lemma 1. To show that $X_{t+1}^{C}$ second-order stochas- 
tically dominates $X_{t+1}^{D}$, I must show that $X_{t+1}^{D}$ is a mean-preserving spread of $X_{t+1}^{C}$. Define $\Delta_{t+1}=X_{t+1}^{D}-X_{t+1}^{C}$. Then $X_{t+1}^{D}$ is a mean-preserving spread of $X_{t+1}^{C}$ if $E_{t}\left(\Delta_{t+1} \mid X_{t+1}^{C}\right)=0$. Since the variance of $X_{t+1}^{C}=0$, the conditional expectation of $\Delta_{t+1}$ equals the unconditional expectation: $E_{t}\left(\Delta_{t+1} \mid X_{t+1}^{C}\right)=E_{t}\left(\Delta_{t+1}\right)$. I show that the unconditional expectation equals zero:

$$
\begin{aligned}
E_{t}\left(\Delta_{t+1}\right) & =\left(s_{t+1}-b_{t+1}\right) E_{t}\left[\int_{0}^{2 N} R_{i, t+1} d Q_{t+1}^{C}(i)-\int_{0}^{2 N} R_{i, t+1} d Q_{t+1}^{D}(i)\right] \\
& =\left(s_{t+1}-b_{t+1}\right)\left[\int_{0}^{2 N} E_{t}\left(R_{i, t+1}\right) d Q_{t+1}^{C}(i)-\int_{0}^{2 N} E_{t}\left(R_{i, t+1}\right) d Q_{t+1}^{D}(i)\right] \\
& =\left(s_{t+1}-b_{t+1}\right)\left(1+r_{t+1}\right)\left[\int_{0}^{2 N} d Q_{t+1}^{C}(i)-\int_{0}^{2 N} d Q_{t+1}^{D}(i)\right]=0 .
\end{aligned}
$$

\section{A.2. Incentives for adaptation}

The first order condition for adaptation capital for household $i$ in region $n$ yields the consumption-Euler equation:

$$
\begin{aligned}
& \frac{\partial U\left(c_{i t}, \tilde{h}_{i t}^{s}\right)}{\partial c_{t}}= \\
& \quad\left(1-\gamma_{n}\right) \beta \sum_{v_{i, t+1}} \pi\left(v_{i, t+1} \mid v_{i t}\right)\left[\left(\frac{\partial U\left(\cdot \mid v_{i, t+1}, 0\right)}{\partial c_{i, t+1}}\right) R_{i, t+1}^{m}(0)+\left(\frac{\partial U\left(\cdot \mid v_{i, t+1}, 0\right)}{\partial \tilde{h}_{i, t+1}^{s}}\right) R_{i, t+1}^{h}(0)\right] \\
& \quad+\gamma_{n} \beta \sum_{v_{i, t+1}} \pi\left(v_{i, t+1} \mid v_{i t}\right)\left[\left(\frac{\partial U\left(\cdot \mid v_{i, t+1}, 1\right)}{\partial c_{i, t+1}}\right) R_{i, t+1}^{m}(1)+\left(\frac{\partial U\left(\cdot \mid v_{i, t+1}, 1\right)}{\partial \tilde{h}_{i, t+1}^{s}}\right) R_{i, t+1}^{h}(1)\right] .
\end{aligned}
$$

$U\left(\cdot \mid v_{i, t+1}, e_{i, t+1}^{h}\right)$ denotes the value of next period's utility when shocks $v_{i, t+1}$ and $e_{i, t+1}^{h}$ materialize. $R_{i, t+1}^{m}$ and $R_{i, t+1}^{h}$ denote the returns to adaptation capital and from increased cash at hand and housing services respectively, defined in equations (13) and (14) in the main text. To simplify the notation, I take the first order condition assuming an interior solution in which $\psi^{h o} h_{i t}^{d}<h_{i t}^{d}-x_{i t}$. In equilibrium, it is never optimal to choose a level of insurance that violates this inequality.

The first order conditions for adaptation capital for a final-good firm $i$ and a rental-housing firm $i$ in region $n$ equal:

$$
1+r_{t+1}=\left(1-\gamma_{n}\right) R_{i, t+1}^{y}(0)+\gamma_{n} R_{i, t+1}^{y}(1) \quad \text { and } \quad 1+r_{t+1}=\left(1-\gamma_{n}\right) R_{i, t+1}^{r}(0)+\gamma_{n} R_{i, t+1}^{r}(1) \text {, }
$$

where $R_{i, t+1}^{y}$ and $R_{i, t+1}^{r}$ denote the returns to adaptation for a final-good and rental-housing firm respectively, defined in equations (15) and (16) in the main text. 
I show that the household's expected return to adaptation capital from increased cash at hand, $\gamma_{n} R_{i, t+1}^{m}(1)+\left(1-\gamma_{n}\right) R_{i, t+1}^{m}(0)$, is less than the expected return on financial assets, $1+$ $r_{t+1}$. The household's first order condition for financial assets yields the consumption-Euler equation:

$$
\begin{aligned}
& \frac{\partial U\left(c_{i t}, \tilde{h}_{i t}^{s}\right)}{\partial c_{t}}=\left(1-\gamma_{n}\right) \beta \sum_{v_{i, t+1}} \pi\left(v_{i, t+1} \mid v_{i t}\right)\left[\left(\frac{\partial U\left(\cdot \mid v_{i, t+1}, 0\right)}{\partial c_{i, t+1}}\right)\left(1+r_{t+1}\right)\right] \\
& \quad+\gamma_{n} \beta \sum_{v_{i, t+1}} \pi\left(v_{i, t+1} \mid v_{i t}\right)\left[\left(\frac{\partial U\left(\cdot \mid v_{i, t+1}, 1\right)}{\partial c_{i, t+1}}\right)\left(1+r_{t+1}\right)\right] .
\end{aligned}
$$

Letting $E\left(U_{c_{i t+1}}\right)$ denote the expected marginal utility of consumption:

$E\left(U_{c_{i t+1}}\right) \equiv\left(1-\gamma_{n}\right) \sum_{v_{i, t+1}} \pi\left(v_{i, t+1} \mid v_{i t}\right)\left(\frac{\partial U\left(\cdot \mid v_{i, t+1}, 0\right)}{\partial c_{i, t+1}}\right)+\gamma_{n} \sum_{v_{i, t+1}} \pi\left(v_{i, t+1} \mid v_{i t}\right)\left(\frac{\partial U\left(\cdot \mid v_{i, t+1}, 1\right)}{\partial c_{i, t+1}}\right)$,

one can rewrite equation (A.10) as:

$$
\frac{\partial U\left(c_{i t}, \tilde{h}_{i t}^{s}\right)}{\partial c_{t}}=\beta\left(1+r_{t+1}\right) E\left(U_{c_{i t+1}}\right) .
$$

Equating the consumption-Euler equation for financial assets (equation (A.11)) with the consumptionEuler equation for adaptation capital (equation (A.9)) implies that:

$$
\begin{aligned}
1+r_{t+1} & =\frac{\left(1-\gamma_{n}\right) \sum_{v_{i, t+1}} \pi\left(v_{i, t+1} \mid v_{i t}\right)\left(\frac{\partial U\left(\cdot \mid v_{i, t+1}, 0\right)}{\partial c_{i, t+1}}\right) R_{i, t+1}^{m}(0)}{E\left(U_{c_{i t+1}}\right)} \\
& +\frac{\gamma_{n} \sum_{v_{i, t+1}} \pi\left(v_{i, t+1} \mid v_{i t}\right)\left[\left(\frac{\partial U\left(\cdot \mid v_{i, t+1}, 1\right)}{\partial c_{i, t+1}}\right) R_{i, t+1}^{m}(1)+\left(\frac{\partial U\left(\cdot \mid v_{i, t+1}, 1\right)}{\partial \tilde{h}_{i, t+1}^{s}}\right) R_{i, t+1}^{h}(1)\right]}{E\left(U_{c_{i t+1}}\right)} .
\end{aligned}
$$

Exploiting the assumption that the marginal utility of housing services is positive, applying the equality that $R_{i, t+1}^{m}(0)=1-\delta^{a}$, and factoring out the $1-\delta^{a}$ yields the inequality:

$$
1+r_{t+1}>1-\delta^{a}+\frac{\gamma_{n} \sum_{v_{i, t+1}} \pi\left(v_{i, t+1} \mid v_{i t}\right)\left(\frac{\partial U\left(\cdot \mid v_{i, t+1}, 1\right)}{\partial c_{i, t+1}}\right)\left(R_{i, t+1}^{m}(1)-\left(1-\delta^{a}\right)\right)}{E\left(U_{c_{i t+1}}\right)} .
$$

In the empirically relevant region of the parameter space, the disaster aid and insurance payments do not fully compensate the household for the destroyed housing capital. Hence, the marginal utility of consumption is higher in a storm and the ratio of the marginal utility of 
consumption in a storm to the expected marginal utility of consumption exceeds unity. Thus we have:

$$
\begin{gathered}
1+r_{t+1}>1-\delta^{a}+\left(\frac{\sum_{v_{i, t+1}} \pi\left(v_{i, t+1} \mid v_{i t}\right)\left(\frac{\partial U\left(\cdot \mid v_{i, t+1}, 1\right)}{\partial c_{i, t+1}}\right)}{E\left(U_{c_{i t+1}}\right)}\right) \gamma_{n}\left(R_{i, t+1}^{m}(1)-1-\delta^{a}\right) \\
>1-\delta^{a}+\gamma_{n}\left(R_{i, t+1}^{m}(1)-\left(1-\delta^{a}\right)\right)=\left(1-\gamma_{n}\right) R_{i, t+1}^{m}(0)+\gamma_{n} R_{i, t+1}^{m}(1) .
\end{gathered}
$$

It follows that the return to financial assets, $1+r_{t+1}$, exceeds the household's expected return to adaptation capital from increased cash at hand, $\left(1-\gamma_{n}\right) R_{i, t+1}^{m}(0)+\gamma_{n} R_{i, t+1}^{m}(1)$.

\section{B. Calibration}

\section{B.1. Data}

Data on Presidential Disaster Declarations, Housing Assistance to homeowners and renters (through FEMA's Individuals and Households Program), Public Assistance, National Flood Insurance Program policies, and the Hazard Mitigation Grant Program are available from FEMA.gov (https://www.fema.gov/data-sets). Data on each cyclone's location, maximum sustained wind speed, and wind radii at six hour time steps are available from NOAA's best track dataset and extended best track dataset for Atlantic and Pacific cyclones. The NOAA best track dataset contains all information except the wind radii for the maximum sustained wind speed. The NOAA extended best track data includes the radii for the maximum sustained wind speed, as well as all the information in the NOAA best track data. ${ }^{27}$ Storm-level damage estimates for tropical cyclones are from NOAA's tropical cyclone reports and estimates of damage for large non-cyclone storms (those with more than one billion dollars in estimated damage) are from the Billion-Dollar Weather and Climate Disasters database assembled by NOAA's National Center of Environmental Information (NOAA, 2020). Combined, the NOAA damage data cover approximately 44 percent of the PDDs in my sample. Data on USACE adaptation expenditures are from the USACE civil works budget reports. ${ }^{28}$ Data on county population and GDP are from the BEA regional accounts. County-level data on household size and the number of homeowners and renters are from Census ACS Tables DP04 and B25008, respectively.

Following a severe storm, each affected state can request a PDD from the federal government. The PDD authorizes the federal government to provide aid through FEMA. The PDD data include a description of the event, the date, and the affected counties within the state. I include all PDDs that involve heavy rain, flooding, and/or strong winds. I drop observations for

\footnotetext{
${ }^{27}$ The NOAA best track data can be downloaded from: www.nhc.noaa.gov/data/. The NOAA extended best track data set can be downloaded from: rammb.cira.colostate.edu/research/tropical_cyclones/tc_extended_best_track_dataset/.

${ }^{28}$ USACE budget reports can be downloaded from: www.usace.army.mil/Missions/Civil-Works/Budget/.
} 
counties coded as American Indian reservations because the reservations do not directly map to US counties. I also drop PDDs that are emergency declarations (equal to approximately 2 percent of the total number of PDDs). Emergency declarations are a type of PDD that can be made before the storm actually occurs, and are often used to prepare for the coming storm instead of to mitigate the damage following the storm (FEMA, 2020).

A PDD authorizes the federal government to provide disaster aid through FEMA. FEMA aid includes both direct assistance to households through the Individuals and Households (IH) program and assistance to local governments and communities through the Public Assistance (PA) program. Data on the IH program begins in 2004. For each county-PDD with an authorized $\mathrm{IH}$ program, the data include $\mathrm{IH}$ aid to renters, $\mathrm{IH}$ aid to homeowners, the category of aid, the number of maximum grants, the numbers of renters and homeowners who registered for aid, and the numbers of renters and homeowners who were approved for aid. I include all $\mathrm{IH}$ aid designed to relieve the financial and utility losses associated with damaged housing capital. This aid is categorized as either rental assistance (which provides homeowners and renters funds for temporary housing) or repair and replace assistance (which provides homeowners funds to repair the damaged housing capital). I exclude IH aid categorized as other needs assistance, because this aid is not directly tied to damaged housing capital and is instead used for other disaster-related expenses such as child care and funeral costs (FEMA, 2019b).

Table B.1: Expenditures on FEMA aid for Disaster Relief From a PDD (billions of 2018 dollars)

\begin{tabular}{lcccc}
\hline \hline & Mean & Standard deviation & Min & Max \\
\hline IH aid for renters & 0.0072 & 0.099 & 0.0 & 2.53 \\
IH aid for homeowners & 0.026 & 0.24 & 0.0 & 5.91 \\
PA aid & 0.13 & 1.17 & 0.0 & 24.8 \\
Total FEMA aid & 0.17 & 1.48 & $2.03 e-4$ & 33.2 \\
\hline
\end{tabular}

Note: This table reports the mean (column 1), standard deviation (column 2), minimum (column 3), and maximum column (4), of different types of FEMA aid from a Presidential Disaster Declaration. IH aid denotes aid provided through FEMA's Individuals and Households program and PA aid denotes aid provided through FEMA's Public Assistance program.

Data on Public Assistance begin in 1998. For each county-PDD with an authorized Public Assistance program, the data include the amount of Public Assistance, the application title, and the applicant name and address. In some of the observations, the data code a portion of the Public Assistance grants for a PDD as statewide, instead of assigning the grant to a particular county. If the relevant county is obvious from the application title, the applicant name, or the location of the applicant, I assign the Public Assistance grant to that county. If the relevant county is not obvious, I divide the statewide Public Assistance grant among the counties that 
received FEMA aid for the particular PDD in proportion to the county's cube of the maximum sustained wind speed if the PDD is for a cyclone, or in proportion to the amount of FEMA aid each county received for the PDD, if the PDD is not for a cyclone.

In total, the data set includes 11,188 county-PDD observations with non-zero FEMA aid, coming from 695 unique PDDs. Table B. 1 reports summary statistics on FEMA aid expenditures per PDD. There is considerable variation in aid expenditures per PDD. The storms that cause the PDDs vary significantly in their size, duration, and severity. At the extremes, the PDD with the maximum FEMA aid expenditures is for Hurricane Katrina in Louisiana in 2005 and the PDD with the minimum FEMA aid expenditures is for severe storms and tornadoes in Colorado in May 2008.

\section{B.2. Calibration of the effectiveness of adaptation, $\theta$}

I show that the total FEMA aid from a storm is positively correlated with the total damage from a storm. I estimate the following regression on the subset of storms for which I have damage estimates:

$$
(\text { FEMA aid })_{i}=\beta_{0}+\beta_{1} \text { damage }_{i}+\varepsilon_{i}
$$

The dependent variable is the total FEMA aid for storm $i$ and the independent variable is the total damage from storm $i$. Table B.2 reports the estimated values of the coefficients with robust standard errors in parentheses. The coefficient on damage, $\beta_{1}$ is positive and statistically significant, implying that FEMA aid is positively correlated with storm damage.

Table B.2: Correlation between total FEMA aid and storm damage

\begin{tabular}{lc}
\hline \hline Coefficient & Estimate \\
\hline Damage: $\beta_{1}$ & 0.15 \\
& $(0.04)$ \\
Constant: $\beta_{0}$ & $-4.9 e 8$ \\
& $(3.1 e 8)$ \\
\hline R-square & 0.77 \\
Number of observations & 50 \\
\hline
\end{tabular}

Note: This table reports the regression estimates from equation (B.1) with robust standard errors in parentheses.

I show that the fraction of damage covered by FEMA aid is uncorrelated with the total storm damage. I estimate the following regression on the subset of storms for which I have damage 
estimates:

$$
\left(\frac{\text { FEMA aid }}{\text { damage }}\right)_{i}=\alpha_{0}+\alpha_{1} \text { damage }_{i}+\varepsilon_{i} \text {. }
$$

The dependent variable is the total FEMA aid for storm $i$ divided by the damage from storm $i$. The independent variable is the total damage from storm $i$. Table B. 3 reports the estimated values of the coefficients with robust standard errors in parentheses. The coefficient on damage, $\alpha_{1}$, is statistically insignificant, implying that there is no statistically significant correlation between the fraction of damage covered by FEMA aid and the total damage from the storm.

Table B.3: Correlation between the fraction of storm damage covered by FEMA aid and total storm damage

\begin{tabular}{lc}
\hline \hline Coefficient & Estimate \\
\hline Damage: $\alpha_{1}$ & $5.8 e-15$ \\
& $(3.8 e-13)$ \\
Constant: $\alpha_{0}$ & 0.12 \\
& $(0.016)$ \\
\hline R-square & 0.0 \\
Number of observations & 50 \\
\hline
\end{tabular}

Note: This table reports the regression estimates from equation (B.2) with robust standard errors in parentheses.

Low- and high-risk regions. The fraction of uninsured homeowners or renters for a countyPDD equals the fraction of homeowners or renters in the county without the relevant insurance policy. I assume that the relevant insurance policy is flood insurance if the PDD involves flooding and homeowners or renters insurance if the PDD does not involve flooding. I use two criteria to determine whether a PDD involves flooding, depending on the year of the event. For PDDs between 2006-2016, FEMA specifically reports total IH aid for flood damage. I classify PDDs between 2006 and 2016 as flood events if there exists IH aid for flood damage. All cyclones received aid for flood damage and thus are classified as flood events. I classify PDDs outside of the 2006-2016 period as flood events if the PDD is for a cyclone or if the title of the PDD contains the word "flood". Using this second criterion to classify PDDs over the entire time period (2004-2018) does not substantially change the results.

Next, I compute the fractions of homeowners and renters with flood insurance policies in each county. Using the publicly available data on the start and end dates and policy characteristics of all National Flood Insurance Program policies that begin in 2009 or later, I calculate the number of flood insurance policies in force for homeowners and renters in every county 
in every month from 2010-2018. I assume that a residential flood-insurance policy holder is a homeowner if the policy includes coverage for the actual structure (as opposed to just for the contents) and a renter otherwise. For years prior to 2010, I use the average fraction of homeowners or renters in the county with flood insurance policies from 2010 - 2018. Regarding homeowners and renters insurance, the Insurance Information Institute reports that 95 percent of homeowners have homeowners insurance and 37 percent of renters have renters insurance. I assume that these percentages are the same for all counties.

In sum, if the PDD does not involve flooding, then I assume that 5 percent of homeowners and 63 percent of renters are eligible for aid. If a PDD does involve flooding, then I assume that one minus the county-specific fraction of homeowners with flood insurance are eligible for aid, and similarly for renters.

For each county-PDD, I measure the fraction of households affected by the storm as the number of IH applicants divided by number of eligible households. However, some PDD-county pairs only receive PA grants, there is no IH program and hence there are no applicants for IH aid. For these observations, I assume that the fraction of households affected by the storm equals the average fraction of households affected by a storm among similar county-PDDs with IH programs. For cyclone events, I take this average over county-PDD pairs with similar maximum sustained wind speeds and for non-cyclone events I take the average over countyPDD pairs with similar amounts of PA aid.

I allocate all PA aid that is not specifically targeted towards housing to final-good firms. I use the applicant name and the application title to determine whether the PA grant is for housing. Specifically, I code the grant as a housing grant if the applicant name or application title contains one of the following phrases: housing, apartment, residence, nursing home, assisted living, retirement home, retirement village, or retirement community.

Relative severity. For each cyclone-county pair, I calculate the wind speed that the county experienced during each time step of the storm. For every six hour time step in the storm track, I check if the county intersects each of the four wind bands (maximum wind, 64 knots, 50 knots, and 34 knots). I take the maximum over all the time steps to calculate the maximum wind speed the county experienced from the cyclone. If a county does not fall within any of the wind bands, I assign it a wind speed equal to zero. I re-code the storm in that county as a noncyclone storm instead of a cyclone storm since I do not have information on the wind-speed of the storm at the point it hit the county. 


\section{B.3. Adaptation subsidy}

I calculate the total federal expenditures for adaptation in each year. I count a USACE expenditure as adaptation if it is categorized as construction or maintenance and the project type code (also labeled business line depending on the year) relates to flooding. The 2015 budget and the 2004-2009 budgets do not separately report maintenance from operation and maintenance. I multiply operation and maintenance expenditures in these years by the average of maintenance expenditures as a fraction of total operation and maintenance expenditures in the other years. I count an expenditure by FEMA's Hazard Mitigation Assistance program as adaptation if it is for capital investment to reduce damage from storms, such as retrofitting structures to withstand high winds or flood-proofing buildings.

\section{B.4. Labor income process}

I use the Rouwenhorst method to calculate the Markov transition matrix for the persistent shock:

$$
\pi=\left(\begin{array}{lllll}
0.9413 & 0.0573 & 0.0013 & 0.0000 & 0.0000 \\
0.0143 & 0.9420 & 0.0430 & 0.0007 & 0.0000 \\
0.0002 & 0.0287 & 0.9422 & 0.0287 & 0.0002 \\
0.0000 & 0.0007 & 0.0430 & 0.9420 & 0.0143 \\
0.0000 & 0.0000 & 0.0013 & 0.0573 & 0.9413
\end{array}\right)
$$

The corresponding invariant distribution equals: $\Pi=(0.0625,0.2500,0.3750,0.2500,0.0625)$.

\section{External validation}

Data on the share of aggregate income received by each quintile of the income distribution are from Table H-2 of the US Census Bureau Current Population Survey (CPS). A household's income in the model equals its labor income plus its asset income. Data on the share of aggregate wealth held by each quintile of the wealth distribution are from the Survey of Consumer Finances, as reported in Kuhn and Rios-Rull (2016). A household's wealth in the model equals the sum of its productive housing capital, adaptive housing capital, and financial assets. Tables C. 1 and C. 2 report the model and empirical values of the shares of income and wealth for each quintile of the income and wealth distributions, respectively. The model matches the overall income and wealth distributions reasonably well, but, as discussed in the main text, it does not capture the high concentrations of wealth at the top of the distribution. 
Table C.1: Share of Income Recieved by Each Qunitile of the Income Distribution

\begin{tabular}{lccccc}
\hline \hline & \multicolumn{5}{c}{ Quintile } \\
\cline { 2 - 6 } & First & Second & Third & Fourth & Fifth \\
\hline Model & 3.4 & 6.6 & 12.7 & 24.3 & 53.0 \\
Data & 3.1 & 8.3 & 14.1 & 22.6 & 52.0 \\
\hline
\end{tabular}

Note: This table reports the share of income received by each quintile of the income distribution in the model (row 1 ) and in the CPS (row 2).

Table C.2: Share of Wealth Held by Each Qunitile of the Wealth Distribution

\begin{tabular}{lccccc}
\hline \hline & \multicolumn{5}{c}{ Quintile } \\
\cline { 2 - 6 } & First & Second & Third & Fourth & Fifth \\
\hline Model & 0.1 & 1.5 & 6.1 & 17.8 & 74.5 \\
Data & -0.7 & 0.6 & 3.2 & 9.8 & 87.0 \\
\hline
\end{tabular}

Note: This table reports the share wealth held by each quintile of the wealth distribution in the model (row 1 ) and in the SCF (row 2).

To compute the damage-probability elasticity in the model, I increase the storm probability by one percent in each region and re-solve the model. I normalize damage by GDP in each region to control for differences in GDP across model regions. Importantly, the dependent variable in Bakkensen and Mendelsohn (2016) measures damage from each storm. All else constant, an increase in storm probability in the data does not increase damage per storm. However, the model is specified at the annual level instead of the storm level. All else constant, an increase in the storm probability in the model does increase the annual damage from storms because more households and firms experience a storm. To ensure that the model elasticity is comparable to the empirical estimates, I define a storm in the model as any positive realization of the storm shock for a household or final-good firm. By the law of large numbers, there are $2 \gamma_{n}$ storms in region $n$ each period. The exact definition of a storm is not important; what matters is only that an increase in storm probability does not mechanically increase damage per storm, holding constant all adaptation, savings, insurance, investment, and hiring decisions.

The damage-probability elasticity in model region $n$ equals $\left[\left(\hat{B}_{n}-B_{n}\right) / B_{n}\right] /\left[\left(1.01 \gamma_{n}-\gamma_{n}\right) / \gamma_{n}\right]$, where $B_{n}$ and $\hat{B}_{n}$ (defined formally below) denote normalized damaged per storm in region $n$ in the baseline and higher-probability equilibria, respectively. The numerator is the percent change in normalized damage per storm and the denominator is the percent change in the probability of a storm. The damage-probability elasticity for the aggregate economy equals the average of the damage-probability elasticities from the low- and high-risk regions.

As with the damage-probability elasticity, to compute the aid-probability elasticity in the model, I increase the storm probability by one percent in each region and re-solve the model. 
The dependent variable in equation (19), FEMA aid per affected household, corresponds to disaster aid in the model divided by number of affected households. Again, I normalize disaster aid per affected household by GDP in each model region to control for differences in GDP across regions. The aid-probability elasticity in model region $n$ equals $\left[\left(\hat{G}_{n}-G_{n}\right) / G_{n}\right] /\left[\left(1.01 \gamma_{n}-\right.\right.$ $\left.\gamma_{n}\right) / \gamma_{n}$ ], where $G_{n}$ and $\hat{G}_{n}$ (defined formally below) denote normalized disaster aid per affected household in region $n$ in the baseline and higher-probability equilibria, respectively.

In the stationary equilibrium of the model, normalized damage per storm in region $\mathrm{n}, B_{n}$, and normalized aid per affected household, $G_{n}$, equal:

$$
\begin{aligned}
B_{n} & \equiv \frac{\int h^{d} d \mu_{g^{h \mid n}}^{h}+\int k^{y d} d \mu_{g^{y} \mid n}^{y}+\int k^{r d} d \mu_{g^{r} \mid n}^{r}}{2 \gamma_{n} G D P_{n}} \\
G_{n} & \equiv \frac{\Lambda_{n}+\psi^{k y} \int k^{y d} d \mu_{g^{y} \mid n}^{y}+\left(\psi^{h r}+\psi^{k r}\right) \int k^{r d}\left(g^{r}\right) d \mu_{g^{r} \mid n}^{r}}{\gamma_{n} G D P_{n}} .
\end{aligned}
$$

Quantities $\int h^{d} d \mu_{g \mid n}^{h}, \int k^{y d} d \mu_{g y \mid n}^{y}$, and $\int k^{r d} d \mu_{g^{r} \mid n}^{r}$ denote aggregate damage to homeowners, final-good, and rental-housing firms, in region $n$ respectively:

$$
\begin{aligned}
\int h^{d} d \mu_{g^{h \mid n}}^{h} & \equiv \int \gamma_{n} \Omega_{n}^{h} F\left(a^{h^{\prime}}\right) h^{p^{\prime}} d \mu_{g^{h \mid n}}^{h} \\
\int k^{y d} d \mu_{g^{y} \mid n}^{y} & \equiv \int \gamma_{n} \Omega_{n}^{y} F\left(a^{y^{\prime}}\right) k^{y p^{\prime}} d \mu_{g^{y} \mid n}^{y} \\
\int k^{r d} d \mu_{g^{r} \mid n}^{r} & \equiv \int \gamma_{n} \Omega_{n}^{h} F\left(a^{r^{\prime}}\right) k^{r p^{\prime}} d \mu_{g^{r} \mid n}^{r} .
\end{aligned}
$$

Variable $\Lambda_{n}$ denotes total aid to homeowners in region $n$ (defined in Section 2.4). GDP in each region $n$ equals:

$$
G D P_{n} \equiv \int \tilde{y} d \mu_{g^{y} \mid n}^{y}+p_{n}^{r}\left[\int \tilde{h}^{s r} d \mu_{g^{r} \mid n}^{r}+\int A^{h} \tilde{h}^{p} d \mu_{g^{h} \mid n}^{h}\right]
$$


where:

$$
\begin{aligned}
\int \tilde{y} d \mu_{g^{y} \mid n}^{y} & \equiv \int\left[1-\gamma_{n} \Omega_{n}^{y} F\left(a^{y^{\prime}}\right)\right]\left(k^{y p^{\prime}}\right)\left(\frac{A^{y}(1-\alpha)}{w_{n}}\right)^{\frac{1-\alpha}{\alpha}} d \mu_{g^{y} \mid n}^{y} \\
\int \tilde{h}^{s r} d \mu_{g^{r} \mid n}^{r} & \equiv \int\left[1-\gamma_{n} \Omega_{n}^{r} F\left(a^{r^{\prime}}\right)\right] A^{h}\left(k^{r p^{\prime}}\right) d \mu_{g^{r} \mid n}^{r} \\
\int \tilde{h}^{p} d \mu_{g^{h} \mid n}^{h} & \equiv \int\left[1-\gamma_{n} \Omega_{n}^{h} F\left(a^{h^{\prime}}\right)\right]\left(h^{p^{\prime}}\right) d \mu_{g^{h} \mid n}^{h}
\end{aligned}
$$

